\title{
REVIEW \\ How do they do Wnt they do?: regulation of transcription by the $\mathrm{Wnt} / \beta$-catenin pathway
}

\author{
H. C. Archbold, ' Y. X. Yang, ${ }^{2}$ L. Chen ${ }^{2}$ and K. M. Cadigan ${ }^{1,2}$ \\ I Program in Cell and Molecular Biology, University of Michigan, Ann Arbor, MI, USA \\ 2 Department of Molecular, Cellular and Developmental Biology, University of Michigan, Ann Arbor, MI, USA
}

Received 24 January 2011, revision requested 15 February 20II,

revision received 17 March 2011 , accepted 19 March 2011

Correspondence: K. M. Cadigan, Department of Molecular, Cellular and Developmental Biology, University of Michigan, Ann Arbor, MI 48।09-1048, USA.

E-mail: cadigan@umich.edu

\begin{abstract}
Wnt/ $\beta$-catenin signalling is known to play many roles in metazoan development and tissue homeostasis. Misregulation of the pathway has also been linked to many human diseases. In this review, specific aspects of the pathway's involvement in these processes are discussed, with an emphasis on how $\mathrm{Wnt} / \beta$-catenin signalling regulates gene expression in a cell and temporally specific manner. The T-cell factor (TCF) family of transcription factors, which mediate a large portion of $\mathrm{Wnt} / \beta$-catenin signalling, will be discussed in detail. Invertebrates contain a single TCF gene that contains two DNAbinding domains, the high mobility group (HMG) domain and the C-clamp, which increases the specificity of DNA binding. In vertebrates, the situation is more complex, with four TCF genes producing many isoforms that contain the HMG domain, but only some of which possess a C-clamp. Vertebrate TCFs have been reported to act in concert with many other transcription factors, which may explain how they obtain sufficient specificity for specific DNA sequences, as well as how they achieve a wide diversity of transcriptional outputs in different cells.
\end{abstract}

Keywords C-clamp, high mobility group domain, lymphoid enhancerbinding factor 1 , T-cell factor, Wnt, $\beta$-catenin.
Wnts are a family of secreted proteins that can exert profound influences on cell behaviour through activation of several signalling pathways. In this review, we focus on the best-understood Wnt signalling pathway, sometimes called 'canonical' Wnt signalling but hereafter referred to as $\mathrm{Wnt} / \beta$-catenin signalling. This particular Wnt pathway acts by increasing levels of nuclear $\beta$-catenin, which then serves as a co-regulator for transcription factors that can recruit $\beta$-catenin to specific regulatory elements (Cadigan 2008, Cadigan $\&$ Peifer 2009, MacDonald et al. 2009). This pathway is known to play many pivotal roles in animal development (Logan \& Nusse 2004, Grigoryan et al. 2008, Petersen \& Reddien 2009, Niehrs 2010) and adult tissue maintenance (Polakis 2007, Nusse et al. 2008, Haegebarth \& Clevers 2009, Wend et al. 2010). In addition, aberrant Wnt signalling has been linked to several human diseases, most notably (but not restricted to) several cancers (Clevers 2006, Polakis 2007). This review covers a few examples of $\mathrm{Wnt} / \beta$-catenin signalling in normal and pathological contexts, where some information is known about the transcriptional targets. The ability of this pathway to activate diverse transcriptional programs in different contexts is remarkable, and we discuss some of the mechanisms that contribute to this diversity of transcriptional output.

Most of our attention will focus on the T-cell factor/ lymphoid enhancer-binding factor 1 (TCF/LEF1) (TCF) family of high mobility group (HMG) domain proteins, which act with $\beta$-catenin to regulate numerous Wnt targets. But we also discuss other DNA-binding proteins that utilize $\beta$-catenin to regulate gene expression. It is unlikely that TCFs possess enough DNA-binding specificity to account for their ability to find specific Wnt 
response elements (WREs) among the huge excess of genomic DNA sequences. How TCFs interact with other transcription factors to increase DNA-binding specificity will be discussed. These interactions likely contribute to the differences in target gene expression that the $\mathrm{Wnt} / \beta$ catenin pathway achieves in different cellular contexts.

$\beta$-catenin is most commonly thought of as a transcriptional co-activator, and this is reflected in our current knowledge of direct targets of $\mathrm{Wnt} / \beta$-catenin regulation, which are predominately activated in response to Wnt signalling. But we also discuss reports that link $\beta$-catenin to direct transcriptional repression, a less common form of Wnt regulation, but one that might be currently underappreciated among Wnt researchers.

\section{Overview of $\mathbf{W n t} / \beta$-signalling}

The overall stability and nuclear localization of $\beta$-catenin is thought to play a central role in determining the level of Wnt/ $\beta$ catenin signalling. In the absence of Wnt stimulation, $\beta$-catenin is constitutively inhibited by a complex (termed the $\beta$-catenin destruction complex) containing glycogen synthase kinase 3 (GSK3) and casein kinase I (CKI), as well as the scaffolding proteins Axin and adenomatous polyposis coli (APC) protein (Cadigan \& Peifer 2009, Kennell \& Cadigan 2009). Phosphorylation of specific residues in the $\mathrm{N}$-terminus of $\beta$-catenin by CKI and GSK3 is followed by ubiquitination and proteosomal degradation (Cadigan \& Peifer 2009, MacDonald et al. 2009), (Fig. 1). In addition, Axin and APC are thought to sequester $\beta$-catenin in the cytosol, and/or to promote $\beta$-catenin efflux from the nucleus (Brocardo \& Henderson 2008).
Without Wnt signalling, the $\beta$-catenin destruction complex keeps the level of $\beta$-catenin low, restricting $\beta$-catenin to its essential role in supporting cadherinmediated cell adhesion (Stepniak et al. 2009).

When Wnt protein is recognized at the cell surface by members of the Frizzled $(\mathrm{Fz})$ family of proteins and low density lipoprotein receptor related protein 5 or 6 (LRP 5/6), a large complex termed the 'Wnt signalosome' is formed (Cadigan \& Peifer 2009, MacDonald et al. 2009). The signalosome interacts with the $\beta$-catenin destruction complex, inhibiting its activity. This results in the accumulation of $\beta$-catenin, some of which enters the nucleus (Fig. 1).

Once in the nucleus, $\beta$-catenin can bind to several DNA-binding proteins, the best understood of which are the TCFs. Some TCFs are thought to act as a transcriptional switch, repressing Wnt target gene expression in the absence of signalling and activating transcription upon forming a complex with $\beta$-catenin (Fig. 1). There is also a wealth of information on other transcriptional co-factors that contribute to TCF repression in the absence of Wnt signalling or are required for $\beta$-catenin-dependent activation of Wnt targets. These factors, several of which alter the state of Wnt target gene chromatin, will not be discussed in detail here, but can be explored in several recent reviews (Arce et al. 2006, Willert \& Jones 2006, Cadigan \& Peifer 2009, Mosimann et al. 2009).

\section{The TCF family: a historical perspective}

The TCF family of transcription factors was first discovered by researchers interested in lymphocyte gene

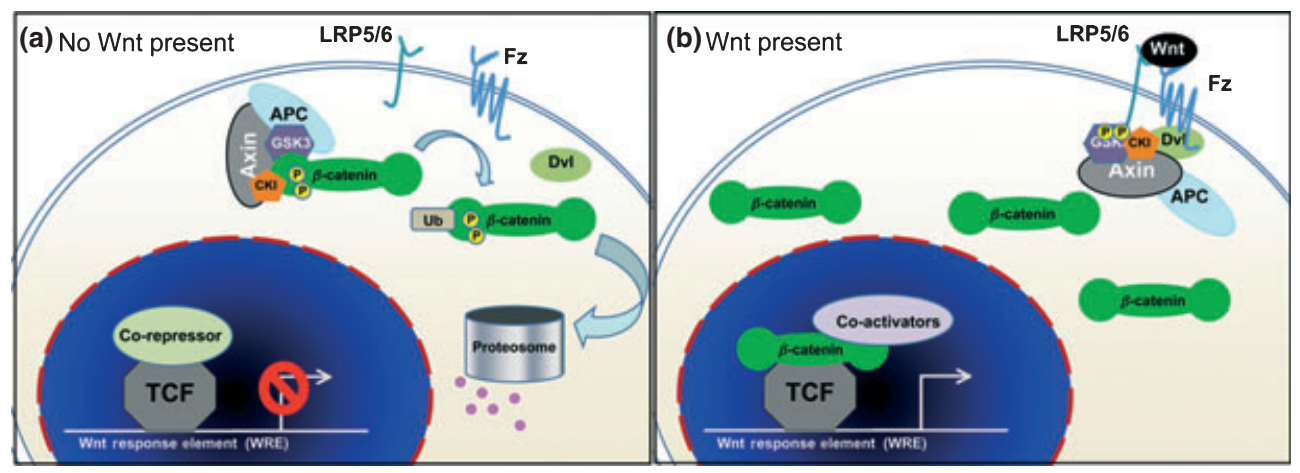

Figure I Basic outline of the Wnt/ $\beta$-catenin signalling pathway. (a) In the absence of the Wnt ligand, $\beta$-catenin is phosphorylated by a 'destruction' complex containing APC, Axin and the CKI and GSK3 kinases. These results in ubiquitylation and proteosomal degradation of $\beta$-catenin. In the nucleus, TCF can recruit co-repressors to Wnt targets, keeping their rate of transcription very low. (b) When Wnt ligand binds to the Fz and LRP5/6 co-receptors, the destruction complex moves to the plasma membrane through multiple protein-protein interactions with the receptor complex and Dvl. $\beta$-catenin is no longer phosphorylated/ degraded and newly synthesized/ $\beta$-catenin accumulates in the cytosol and the nucleus. Nuclear $\beta$-catenin binds to TCFs, displacing co-repressors and recruiting co-activators to increase expression of Wnt targets. See the text for more details. APC, adenomatous polyposis coli; CKI, casein kinase I; GSK3, glycogen synthase kinase 3; TCF, T-cell factor 1; Fz, Frizzled; LRP, lipoprotein receptor related protein; Dvl, Dishevelled. 
regulation. A protein originally called TCF1 $\alpha$ or lymphoid enhancer-binding factor 1 (LEF1) was highly expressed in pre-B and pre-T cells and bound a specific DNA sequence in an enhancer controlling the T-cell receptor $\alpha(\mathrm{TCR} \alpha)$ gene (Waterman \& Jones 1990, Waterman et al. 1991) (Travis et al. 1991). Another protein enriched in immature T cells called TCF1 bound to a similar sequence in a CD3a enhancer (van de Wetering et al. 1991). Both LEF1 and TCF1 were found to contain a single HMG domain, which was sufficient for DNA-specific binding (Giese et al. 1991, Oosterwegel et al. 1991, Waterman et al. 1991). HMG domains are found in animals, plants and fungi, and TCF1 and LEF1 belong to a subgroup within this family, most closely related to the HMG domains of SOX proteins (e.g. SRY) and fungal mating type proteins (e.g. STE11) (Laudet et al. 1993).

In addition to sequence specific DNA binding, the HMG domain of LEF1 has been shown to bend DNA up to $130^{\circ}$, (Giese et al. 1992) which was confirmed by solving the crystal structure of a LEF1-DNA-binding site complex (Love et al. 1995). This bending has been proposed to play an architectural role in coordinating the binding of several other factors to the TCR $\alpha$ enhancer (Carlsson et al. 1993, Giese \& Grosschedl 1993, Giese et al. 1995). This protein-enhancer complex is sometimes referred to as the ' $\mathrm{T}$ cell enhanceosome' (Balmelle et al. 2004). The high degree of conservation between the HMG domains of the TCF family (Fig. 2) suggests that all members have the ability to bend DNA, though this remains to be tested directly.

Although interest in LEF1 and TCF1 was initially focused on lymphocytes, the finding that mice lacking a functional LEF1 gene displayed defects to several organ systems indicated a much broader role in developmental biology (van Genderen et al. 1994). This connection was further solidified by the findings that LEF1 and TCF3 (another member of the family) could bind to

(a)

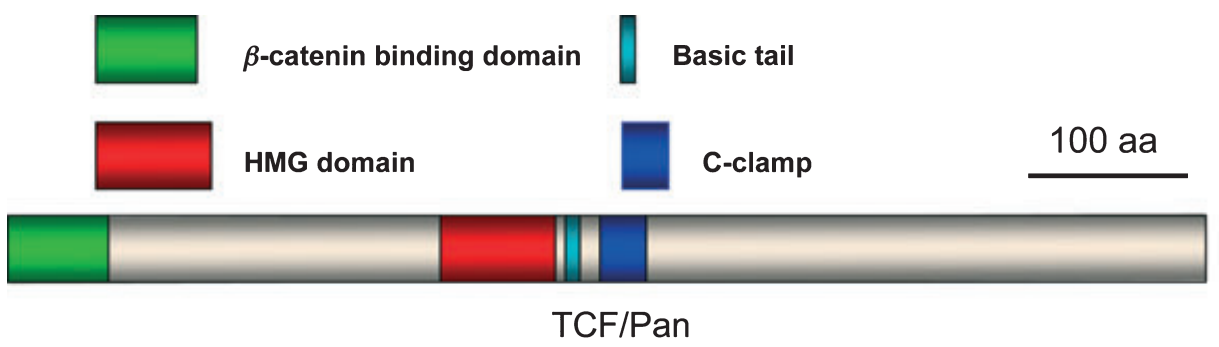

(b)

$\begin{array}{ll}\text { S. domuncula } & \text { TCF } \\ \text { A. queenslandica } & \text { TCF } \\ \text { M. leidyi } & \text { TCF } \\ \text { H. magnipapillata } & \text { TCF } \\ \text { C. elegans } & \text { POP-1 } \\ \text { D. melanogaster } & \text { PanA } \\ \text { H. sapiens } & \text { TCF 1E } \\ \text { H. sapiens } & \text { TCF4E } \\ \text { H. sapiens } & \text { LEF1 } \\ \text { H. sapiens } & \text { TCF3 }\end{array}$

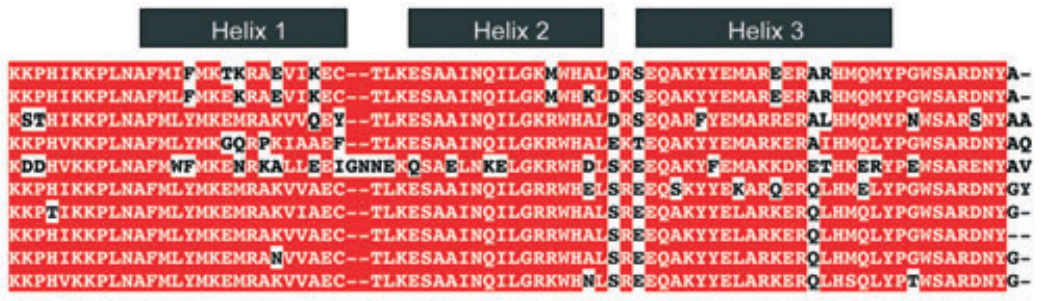

S. domuncula TCF

A. queenslandica TCF

M. leidyi

H. magnipapillata TCF

C. elegans POP-1

D. melanogaster PanA

H. Sapiens TCF1E

H. sapiens sapiens

H. Sapiens

LEF 1

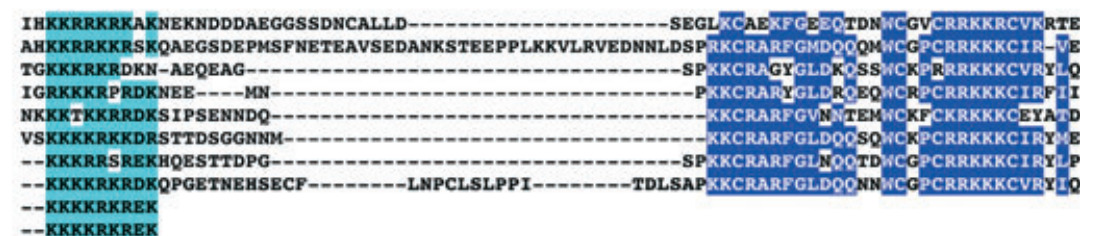

Figure 2 (a) Cartoon depicting the Drosophila TCF/Pan (the PanA isoform; 751 aa) showing the location of the $\beta$-catenin binding domain (green), the HMG domain (red), the basic tail (aqua) and the C-clamp (blue). (b) Alignment of the HMG domains, basic tails and C-clamps among metazoan TCFs. Non-conserved residues are not coloured in the alignment. The positions of the three $\alpha$-helices of the HMG domain, based on the structure of LEF1 (Love et al. 1995) are indicated at the top of the figure. The six invertebrate TCFs possess all three domains, while only the E box isoforms of vertebrate TCF1 and TCF4 possess C-clamps. The degree of conservation in the HMG domain is quite high, e.g. the TCF of Suberities domuncula and human TCF4E are $79.5 \%$ identical, $85.9 \%$ conserved. The C-clamp is less conserved (55.2\% identity; $58.6 \%$ for the $S$. domuncula-human TCF4E comparison). The number of non-conserved residues between the basic tail and C-clamps are highly variable. The GenBank accession number of each protein sequence is in parentheses: S. domuncula (CAH04889.1); Amphimedon queenslandica (ADO16566.1); Mnemiopsis leidyi (ADO34164.1); Hydra magnipapillata (XP_002159974.1); Caenorhabditis elegans (NP_491053.3); Drosophila melanogaster (isoform A; NP_726522); human TCF1E (EAW62279.1); TCF4E (CAB97213.1); LEF1 (NP_001124185) and TCF3 (NP_112573.1). TCF, T-cell factor 1; HMG, high mobility group; LEF1, lymphoid enhancer-binding factor 1. 
$\beta$-catenin (Behrens et al. 1996, Huber et al. 1996, Molenaar 1996). It was known that mutants in the fly homolog of $\beta$-catenin, armadillo (arm) caused defects very similar to wingless $(w g)$ mutants, a Wnt gene important in many aspects of fly development (Riggleman et al. 1989, Peifer et al. 1991, Noordermeer et al. 1994, Siegfried et al. 1994). In addition, misexpression of $\beta$-catenin in ventral blastomeres of Xenopus embryos induced a secondary body axis (Heasman et al. 1994), reminiscent of misexpression of several Wnt genes (McMahon \& Moon 1989, Smith \& Harland 1991, Sokol et al. 1991).

The N-terminus of TCFs are required for binding to $\beta$-catenin, and deletion of this portion of a TCF gene produces a protein that can dominantly inhibit Wnt signalling in several organisms (Behrens et al. 1996, Molenaar 1996, van de Wetering et al. 1997, Kratochwil et al. 2002). In addition, placing multiple copies of high affinity TCF binding sites upstream of a minimal promoter-reporter gene cassette results in reporter gene expression that is highly activated by $\mathrm{Wnt} / \beta$-catenin signalling (Molenaar 1996, Korinek et al. 1997, van de Wetering et al. 1997). These now classic observations contribute to the current working model of Wnt target gene activation depicted in (Fig. 1).

\section{Wnt/ $\beta$-catenin signalling in development}

Stimulation of the $\mathrm{Wnt} / \beta$-catenin pathway can result in a diverse array of cellular outcomes, depending on the context. For example, in Drosophila, the fly Wnt protein Wg acts through Arm to promote cell stem identity (Lin et al. 2008, Takashima et al. 2008, Sinenko et al. 2009). While Wg/Arm signalling stimulates proliferation in several tissues (Baker 2007, Herranz \& Milan 2008), the pathway can also repress the cell cycle (Duman-Scheel et al. 2004). The same is true for apoptosis, where Wg/ Arm signalling can activate (Cox et al. 2000, Lin et al. 2004) or repress (Cox et al. 2000, Giraldez \& Cohen 2003) programmed cell death. In some contexts, such as the developing wing, Wg acts as a morphogen, activating distinct targets in a concentration dependent manner (Zecca et al. 1996, Neumann \& Cohen 1997). Since most transcriptional targets of Wg/Arm signalling are regulated in a cell-type (Lee \& Frasch 2000, Knirr \& Frasch 2001) or temporally restricted manner (Heemskerk et al. 1991), it is not surprising the the pathway can effect different cells in dramatically different ways.

The following sections summarize some of the vast literature covering $\mathrm{Wnt} / \beta$-catenin signalling in development, spanning the entire metazoan clade. Understanding the molecular basis for the specificity of transcriptional outcome in these different systems requires a detailed understanding of how stabilized $\beta$-catenin regulates gene expression, and this review discusses the field's progress towards realizing this challenging goal.

\section{Wnt/ $\beta$-catenin signalling in establishing the primary body axes of metazoans}

Wnts and $\beta$-catenin are not found in choanoflagellates (King et al. 2008), but are present in all metazoans. Three Wnt genes are found in the demosponge Amphimedon queenslandica (Adamska et al. 2010) and four Wnt genes are present in the Mnemiopsis leidyi genome (Pang et al. 1999). The sea anemone, Nematostella vectensis has $14 \mathrm{Wnt}$ genes, including 12 of the 13 subgroups found in mammals (Kusserow et al. 2005). This suggests a radiation of the Wnt family after the cnidarian/bilaterian common ancestor diverged from sponges and ctenophores. For a more comprehensive list of Wnt gene number across metazoan evolution see (Lengfeld et al. 2009).

The expression patterns of Wnts in simple metazoans are highly suggestive of important roles in development. In Amphimedon larvae Wnt is expressed at the posterior end (Adamska et al. 2010). In Hydra, Wnt3 is expressed at the prospective oral pole of embryos and larvae, which will give rise to the head of the adult (Hobmayer et al. 2000, Plickert et al. 2006, Duffy et al. 2010). In Nematostella embryos, Wnts are expressed in overlapping patterns along the anterior/posterior $(\mathrm{A} / \mathrm{P})$ axis, suggesting that they provide positional information along the primary body axis (Kusserow et al. 2005). The expression of the four ctenophore Wnts in complementary dynamic patterns during embryogenesis also suggests important developmental roles in this organism (Pang et al. 1999).

In addition to the presence of Wnts, simple metazoans possess most of the downstream signalling components identified in bilaterians. For example, sponges, ctenophores and cnidarians all contain one gene encoding $\beta$-catenin, GSK3 and TCF, which are well conserved with those in other metazoans. Consistent with the existence of a functional $\mathrm{Wnt} / \beta$-catenin pathway, application of GSK3 inhibitors, well known to stabilize $\beta$-catenin and TCF transcriptional readouts in mammalian cell culture (Cohen \& Goedert 2004), produce dramatic phenotypes in these organisms. In sponges, GSK3 inhibition leads to ectopic formation of ostia (canal openings), which can disrupt feeding (Lapebie et al. 2009, Windsor \& Leys 2010). GSK3 inhibition in Hydra produces multiple head and tentacles along the body (Broun et al. 2005, Muller et al. 2007, Duffy et al. 2010). In the marine cnidarian Hydractina echinata, this multiple head phenotype is suppressed by RNAi depletion of TCF (Duffy et al. 2010). In Hydra, depletion of $\beta$-catenin results in loss of head structures, opposite to the phenotype obtained with GSK3 inhibition (Gee 
et al. 2010). These results indicate that the basic outlines of the pathway in these organisms are likely operating in a similar fashion to that outlined in Fig. 1.

The direct transcriptional targets of $\mathrm{Wnt} / \beta$-catenin signalling in these simple systems are currently not known but one candidate in cnidarians is the Brachyury gene, known to be a direct target of Wnt3a signalling in mouse embryos (Yamaguchi et al. 1999). In Hydractina, Brachyury is expressed at the oral pole (like Wnt3a) and is upregulated by GSK3 inhibition and downregulated by Wnt3a and TCF depletion (Duffy et al. 2010). In addition, this report provided evidence that Wnt3 and TCF are positively regulated by the pathway in Hydractina (Duffy et al. 2010). Regulation of TCFs by the $\mathrm{Wnt} / \beta$-catenin pathway is also found in mammalian systems (Hovanes et al. 2001). Autoregulation of Wnt gene expression by the pathway is also likely in Hydra, where in addition to Wnt3 (Hobmayer et al. 2000) six other Wnt genes are expressed at the oral end of the organism (Lengfeld et al. 2009). During head regeneration, expression of Wnt3 precedes the other Wnts, suggesting that they may be activated by Wnt3 signalling (Lengfeld et al. 2009).

In bilaterians, there is also abundant evidence that Wnt/ $\beta$-catenin signalling is critical for axial patterning. In Planaria, depletion of $\beta$-catenin results in additional head structures in posterior regions (Gurley et al. 2008, Iglesias et al. 2008, Petersen \& Reddien 2008). The pathway is also required for the formation of posterior structures in mouse embryos (Liu et al. 1999, Yamaguchi et al. 1999, Huelsken et al. 2000, Kelly et al. 2004) and $\mathrm{Wnt} / \beta$-catenin signalling plays a similar role in specifying cell identities along the $\mathrm{A} / \mathrm{P}$ axis of the CNS of Xenopus (Niehrs 2010). When one considers that the oral pole of cnidarians likely corresponds to the posterior end of the body plan (Meinhardt 2002, Guder et al. 2006, Niehrs 2010), it appears that the role of high levels of $\mathrm{Wnt} / \beta$-catenin signalling in promoting posterior identity may be very ancient and predate the split between cnidarians and bilaterians (Petersen \& Reddien 2009, Niehrs 2010) (Fig. 3).

Two notable exceptions to the global role for Wnt/ $\beta$-catenin signalling in establishing the $\mathrm{A} / \mathrm{P}$ body axis are Drosophila and Caenorhabditis elegans. In flies, $\mathrm{Wg} / \mathrm{Arm}$ signalling is involved in establishing $\mathrm{A} / \mathrm{P}$ identity in each segment (Sanson 2001), while the maternally provided transcription factor Bicoid is a major determinant of global A/P patterning (Porcher \& Dostatni 2010). This is likely the result of the high degree of specialization that has occurred in dipteran evolution (Riechmann \& Ephrussi 2001) and the role of $\mathrm{Wnt} / \beta$-catenin signalling in other insects is similar to other metazoans [reviewed in (Niehrs 2010)]. In C. elegans, asymmetric cell divisions (mostly along the $\mathrm{A} / \mathrm{P}$ axis) are controlled by the $\mathrm{Wnt} / \beta$-catenin/asymmetry pathway, in which two $\beta$-catenin proteins (WRM-1 and SYS-1) act through distinct mechanisms to regulate the TCF family member POP-1. WRM-1 promotes POP-1 nuclear efflux while SYS-1 acts in a similar manner as $\beta$-catenin/Arm (Mizumoto \& Sawa 2007). It is not clear how the five C. elegans Wnts can provide positional information to regulate all the asymmetric cell divisions controlled by POP-1, but there is evidence that transiently expressed Wnt (MOM-2) in posterior blastomeres can maintain A/P polarity in other cells through a Wnt-dependent relay mechanism (Bischoff \& Schnabel 2006). While the rapid generation time and stripped down genomes of Drosophila and C. elegans have made them powerful genetic systems for understanding the molecular basis of development (including Wnt/ $\beta$-catenin signalling) it appears that their overall developmental strategies for axial patterning have diverged from the general metazoan scheme.

\section{Wnt/ $\beta$-catenin signalling in establishing the A/P axis of vertebrates}

In addition to the $\mathrm{Wnt} / \beta$-catenin pathway forming a gradient of Wnt signalling along the $\mathrm{A} / \mathrm{P}$ axis, a gradient of BMP signalling along the dorsal/ventral (D/V) axis is found in a wide array of bilaterians. Niehrs (2010) has proposed a Cartesian coordinate system of Wnt and BMP signalling to control bilaterian body axes. In Xenopus embryogenesis, these perpendicular gradients are initiated by the Spemann organizer (De Robertis \& Kuroda 2004, Vonica \& Gumbiner 2007). Maternally provided Wnt5a and Wnt11 (Tao et al. 2005, Cha et al. 2008) and other Wnt signalling components (White \& Heasman 2008) are relocated to the future dorsal side of the embryo opposite to sperm entry. Wnt/ $\beta$-catenin signalling then activates the expression of two homeodomain transcription factors, Siamois and Twin, which establish organizer identity (Ishibashi et al. 2008). Analysis of the regions upstream of the twin and siamois transcription start sites (TSSs) demonstrated the existence of functionally important binding sites for TCFs (Brannon et al. 1997, Laurent et al. 1997, Fan et al. 1998), which is supported by more recent data with chromatin immunoprecipitation (ChIP) of TCF3 (Hikasa et al. 2010). Siamois, Twin and Wnt/ $\beta$-catenin signalling then act together to activate expression of a variety of BMP antagonists, which emanate from the organizer to set up a gradient of BMP4 signalling activity across the $\mathrm{D} / \mathrm{V}$ axis (De Robertis \& Kuroda 2004, Vonica \& Gumbiner 2007).

In addition to expressing BMP antagonists, the Spemann organizer also expresses antagonists of Wnt/ $\beta$-catenin signalling, such as Dickkopf1 (Dkk1), Cerberus and secreted frizzled related protein 2 (sFRP2). Dkk1 is thought to be directly activated by TCF and 


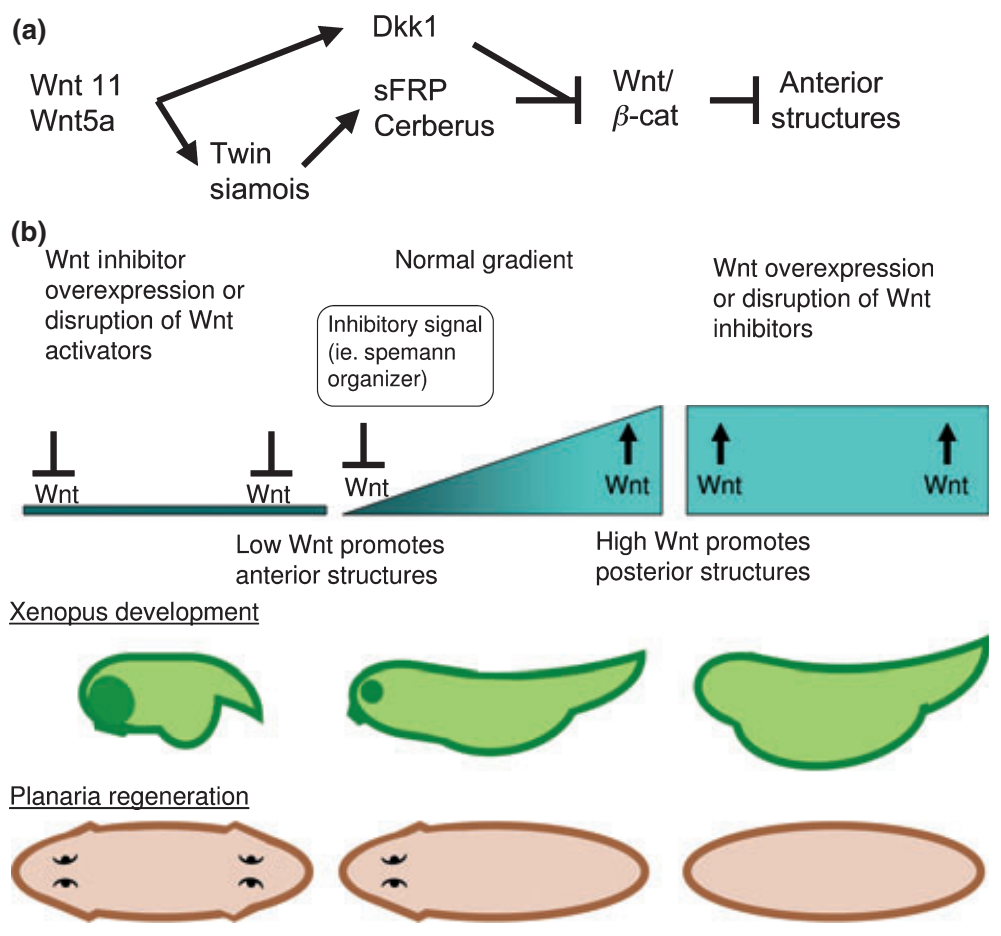

Figure $3 \mathrm{Wnt} / \beta$-catenin signalling in establishing the metazoan A/P axis. (a) Some of the circuitry involved in establishing the A/P axis in Xenopus. Maternal Wnt11 and Wnt5a act through $\beta$-catenin to directly activate the Spreman organizer genes siamois and twin (Brannon et al. 1997, Laurent et al. 1997, Fan et al. 1998, Tao et al. 2005, Cha et al. 2008). Wnt/ $\beta$-catenin signalling also activates expression of Dkk1 (Chamorro et al. 2005), and Siamois and Twin are thought to activate cerberus and sFRP expression (Engleka \& Kessler 2001, Yamamoto et al. 2003a). These three Wnt antagonist suppress pathway activation in dorsal/anterior structures, allowing anterior structures to form (Niehrs 2006). See the text for more details. (b) Cartoon of an amphibian tadpole or regenerating Planaria, illustrating the Inhibition of $\mathrm{Wnt} / \beta$-catenin signalling promotes an anterior identity, while expression of Wnt3a promotes a posterior identity (centre column). Expression of Wnt antagonists in Xenopus or reduction of $\beta$-catenin activity in Planaria causes an expansion of anterior structures at the expense of posterior structures (Niehrs 2006, Petersen \& Reddien 2009). Conversely, inappropriate activation of Wnt/ $\beta$-catenin signalling caused loss of anterior structures. See text for further explanation. A/P, anterior/posterior.

$\beta$-catenin (Chamorro et al. 2005), while Cerberus and sFRP2 are Siamois-dependent (Engleka \& Kessler 2001, Yamamoto et al. 2003a). These Wnt antagonists contribute to a Wnt/ $\beta$-catenin signalling gradient with the highest Wnt signalling in the posterior (De Robertis \& Kuroda 2004, Vonica \& Gumbiner 2007). Overexpression of Dkk1 (decreasing signalling levels) expands anterior structures and morpholino depletion of Dkk1 (increasing signalling levels) results in reduced anterior identity (Niehrs 2006). Consistent with this, disruption of the mouse Dkk1 gene results in embryos with a loss of head (Mukhopadhyay et al. 2001). In Hydra, Wnt/ $\beta$ catenin signalling inhibits $D k k$ expression, indicating the existence of an ancient Wnt-Dkk axial patterning circuit (Guder et al. 2006, Niehrs 2010).

\section{Neural crest: cross-regulation facilitates Wnt-dependent context specificity}

One outcome of the $\mathrm{Wnt} / \beta$-catenin signalling gradient in vertebrates is the induction of the neural crest (NC).
In Xenopus, low BMP4 signalling and other signals in the dorsal portion of the embryo are required for induction of the neural plate (Stern 2005). After the neural plate invaginates to form the neural tube, NC cells are specified near the dorsal-lateral portion of the neural tube (Barembaum \& Bronner-Fraser 2005). Wnt/ $\beta$-catenin signalling is required for this induction, and the Wnt3a expressed in the overlying epidermis appears to be the ligand (McGrew et al. 1997, Li et al. 2009). The gradient of Wnt signalling from the posterior of the embryo is required to prevent $\mathrm{NC}$ induction in the anterior neural fold (Li et al. 2009). After specification, NC cells migrate to different locations to differentiate into a diverse array of tissues, including facial cartilage, bones and smooth muscle cells of the heart (SaukaSpengler \& Bronner-Fraser 2006).

How $\mathrm{Wnt} / \beta$-catenin signalling induces the $\mathrm{NC}$ is being elucidated in detail. There are over a dozen transcription factors that have been shown to be required for specification of the NC cell fate (Barembaum \& Bronner-Fraser 2005, Sauka-Spengler \& 
Bronner-Fraser 2006). The expression of many of these genes has been shown to be Wnt-dependent, but they also cross-regulate each other, making it difficult to identify the direct targets of the $\mathrm{Wnt} / \beta$-catenin pathway. Recently, two reports have used a combination of approaches to provide evidence that Gbx2 and Meis3 are important direct Wnt targets in NC induction in Xenopus (Li et al. 2009, Elkouby et al. 2010). Hormone-inducible versions of TCF or $\beta$-catenin (fused to the glucocorticoid receptor) demonstrated activation in the absence of protein synthesis. An enrichment of $\beta$-catenin at the regulatory regions of these genes was demonstrated via ChIP. Finally, predicted TCF sites in the regulatory regions were mutated, leading to a loss of reporter gene expression (Li et al. 2009, Elkouby et al. 2010). These results argue that these genes are direct targets of the pathway.

Consistent with the above data, Gbx2 morphants display a loss of many NC markers (Li et al. 2009). Depletion of Meis3 has a similar phenotype, including a reduction in Gbx2 expression (Elkouby et al. 2010). Meis3 is clearly a major target of $\mathrm{Wnt} / \beta$-catenin signalling, because exogenous addition of the Meis3 gene can rescue the loss of NC seen in Wnt3a morphants (Elkouby et al. 2010). These studies suggest that $\mathrm{Wnt} / \beta$-catenin signalling initially induces both Meis3 and Gbx2, and Meis3 contributes to Gbx2 expression. In a similar manner, Slug 2 is directly activated by the $\mathrm{Wnt} / \beta$-catenin pathway (Vallin et al. 2001) but also requires Meis 3 and Gbx2 for expression (Li et al. 2009, Elkouby et al. 2010). In addition, Gbx2 is a transcription repressor, which inhibits the expression of anterior neural fold markers such as Six1, restricting NC induction to posterior regions (Fig. 4).

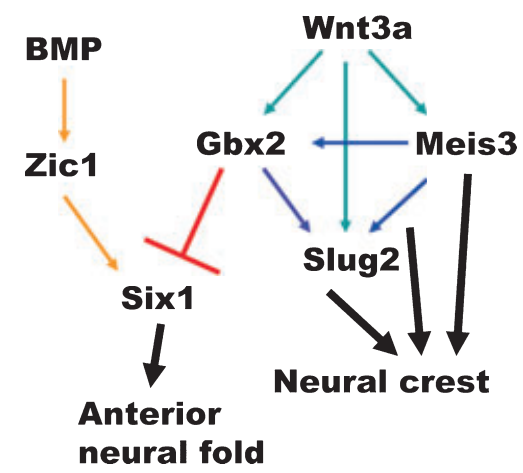

Figure $4 \mathrm{Wnt} / \beta$-catenin signalling induces neural crest. Wnt3a from the overlying epidermis induces expression of Meis 3 and Gbx2 are induced in the neural tube (Li et al. 2009, Elkouby et al. 2010). Meis3 also cross regulates Gbx2 (Elkouby et al. 2010) and Slug2 is activated by a combination of Wnt3a, Gbx2 and Meis3 (Vallin et al. 2001, Li et al. 2009, Elkouby et al. 2010). See text for further information.
The cross-regulation of Wnt targets Meis3 and Gbx2 is one illustration of the complex regulatory networks that are found in development. Such cross-regulation can also occur between the TCF- $\beta$-catenin complex and its targets. Wnt3a is essential for posterior axial growth in mice (Yamaguchi et al. 1999, Aulehla et al. 2003, Dunty et al. 2008). A similar loss of caudal structures is observed when combinations of the caudal homeobox genes $(C d x 1, C d x 2$ or $C d x 4)$ are mutated in mice or zebrafish (Shimizu et al. 2005, Davidson \& Zon 2006, Young et al. 2009). Cdx genes are activated by Wnt/ $\beta$-catenin signalling (Ikeya \& Takada 2001, Gaunt et al. 2003) and in some cases this regulation is direct (Lickert et al. 2000, Ikeya \& Takada 2001, Pilon et al. 2006). However, Wnt3a expression also requires $\mathrm{Cdx}$ activity, and loss of function $C d x 2$ and $C d x 4$ phenotypes can be rescued by an activated version of LEF1 (Young et al. 2009). A similar positive feedback loop between Wnt and Cdx has also been reported to be required for posterior development in Xenopus (Faas \& Isaacs 2009). Interestingly, Cdx1 autoregulation has been reported to require a physical interaction between LEF1 and Cdx1 (Beland et al. 2004), providing a clue as to how TCF family members and Cdx proteins act together. A similar relationship has been demonstrated between the Wnt target Brachyury and the Wnt/ $\beta$-catenin pathway in promoting posterior mesoderm development (Martin \& Kimelman 2008).

\section{Cardiogenesis: reiterative Wnt/ $\beta$-catenin signalling required}

Beyond helping establish the basic body plan, Wnt/ $\beta$-catenin signalling is important for a multitude of developmental decisions. These include limb formation, bone, hair and teeth development as well as formation of every major organ (see (Grigoryan et al. 2008) for a comprehensive review of $\beta$-catenin-dependent developmental processes in mice). In this review, we will focus on heart formation, which provides a good example of how the $\mathrm{Wnt} / \beta$-catenin pathway is used repeatedly to achieve different outcomes in different developmental contexts, even in the same tissue. Further information on the role of canonical and non-canonical Wnt signalling in heart development can be found in additional reviews (Cohen et al. 2008, Kwon et al. 2008, Gessert \& Kuhl 2010).

Although the tube-like insect heart is morphologically different from the multichambered vertebrate heart, they appear to share a common ancestry. One striking example supporting this view is provided by the tinman/ Nkx2.5 gene, which is required for heart formation in Drosophila and several vertebrate systems (Bodmer \& Venkatesh 1998, Evans 1999). In flies, Wg/Arm signalling is required for tinman expression and heart 
formation in general (Wu et al. 1995, Park et al. 1996). In contrast, the first studies in vertebrates found that $\mathrm{Wnt} / \beta$-catenin signalling is required to restrict specification of cardiac mesoderm (Marvin et al. 2001, Schneider \& Mercola 2001, Lickert et al. 2002).

This paradox between invertebrate and vertebrates has been resolved by the realization that the Wnt/ $\beta$-catenin pathway plays two opposing roles in early vertebrate cardiogenesis. Temporal control of Wnt expression revealed that before gastrulation, the pathway activates $N k x 2.5$ expression in zebrafish embryos (Ueno et al. 2007). After gastrulation, the previously described inhibitory role was evident. This biphasic relationship was also observed in mouse ES cells, which spontaneously differentiate into cardiomyocytes. Activation of $\mathrm{Wnt} / \beta$-catenin signalling in early cultures dramatically enhanced cardiomyoctes differentiation but pathway activation in later cultures reduced cardiogenesis (Ueno et al. 2007). These data suggest that the initial pro-cardiogenic effect of the $\mathrm{Wnt} / \beta$-catenin pathway in vertebrates is analogous to the positive effect that Wg/Arm signalling has on heart development in the fly.

What are some of the direct targets in the initial regulation of cardiogenesis by the pathway? In flies, the presence of functional TCF binding sites in the enhancers that drive the expression of the transcription factors Sloppy paired 1 (Slp1) and Even-skipped (Eve) in the cardiac precursors provides strong evidence that these genes are directly activated by Wg/Arm signalling (Halfon et al. 2000, Lee \& Frasch 2000, Knirr \& Frasch 2001, Han et al. 2002). In mouse ES cells, gene profiling revealed many potential targets, including Brachyury, Mesp1 and Sox17 (Liu et al. 2007, Ueno et al. 2007). In regard to repression of cardiogenesis, the homeodomain protein Hex is an important Wnt target that is repressed in the presumptive cardiac mesoderm (Foley \& Mercola 2005). In Xenopus, GATA6 expression is repressed by $\mathrm{Wnt} / \beta$-catenin signalling, and forced expression of GATA6 is sufficient to rescue many aspects of heart development that are disrupted by ectopic Wnt pathway activation (Afouda et al. 2008). The mechanism by which these genes are repressed by $\mathrm{Wnt} / \beta$-catenin signalling is not known.

After the initial specification of the presumptive heart field, a population of cardiomyocytes known as the secondary heart field (SHF) will give rise to the future right ventricle and inflow and outflow tracts of the heart (Dyer \& Kirby 2009). Conditional knockout of $\beta$-catenin causes a significant reduction in these structures ( $\mathrm{Ai}$ et al. 2007, Cohen et al. 2007, Klaus et al. 2007, Kwon et al. 2007, Tian et al. 2010). Removal of $\beta$-catenin before SHF specification resulted in a loss of Islet1 (a LIM homeodomain) expression, a marker of SHF cells (Cai et al. 2003). There is some evidence to indicate that the activation of Islet 1 transcription by $\mathrm{Wnt} / \beta$-catenin signalling is direct (Lin et al. 2007). Later removal of $\beta$-catenin in the developing SHF resulted in normal Islet1 expression, but the right ventricle and outflow tracts still failed to form (Ai et al. 2007, Kwon et al. 2007). These results indicate multiple roles for Wnt/ $\beta$-catenin signalling in SHF development, both in establishing the SHF and subsequent differentiation of heart tissue.

The complexity of target gene regulation by the Wnt/ $\beta$-catenin pathway in the development of the secondary heart filed is evidenced by the findings that $\mathrm{Wnt} / \beta$ catenin signalling represses Islet 1 expression in differentiating cardiomyocytes (Kwon et al. 2009). Likewise, GATA6, which is repressed by $\mathrm{Wnt} / \beta$-catenin signalling in early heart development in Xenopus (Afouda et al. 2008), is directly activated by $\mathrm{Wnt} / \beta$-catenin signalling in the posterior SHF (Tian et al. 2010). The factors that enable the same pathway to both activate and repress the same targets during the cardiomyocyte cell lineage are not known.

There are several additional events in heart development where $\mathrm{Wnt} / \beta$-catenin signalling is also required. Mutations lowering pathway activity in cardiac NC cells result in defects to the cardiac outflow tract (Hamblet et al. 2002, Kioussi et al. 2002). This phenotype is similar to that observed when the gene encoding the bicoid homeodomain protein PitX2 is mutated (Kioussi et al. 2002). PitX2 is directly activated by LEF1 and $\beta$ catenin and then PitX2 subsequently recruits $\beta$-catenin to the Cyclin D2 regulatory region, activating this cell cycle regulator and promoting proliferation of the cardiac NC cells (Kioussi et al. 2002). The Wnt/ $\beta$ catenin pathway also promotes endocardial cell proliferation, which contributes to heart valve formation (Gitler et al. 2003, Hurlstone et al. 2003, Liebner et al. 2004, Alfieri et al. 2010). Likewise, loss of $\beta$-catenin in the developing epicardium results in defects in coronary artery formation (Zamora et al. 2007).

Heart development highlights the multiple roles that the $\mathrm{Wnt} / \beta$-catenin pathway plays in regulating cell fate and organogenesis (Fig. 5). How can one signalling pathway be utilized so many times to regulate different genes in the cardiac cell lineage? Understanding how Wnt transcriptional output diversity is generated requires a more detailed understanding of how TCF family members and other transcription factors that mediate $\mathrm{Wnt} / \beta$-catenin-dependent gene regulation function on target gene chromatin.

\section{$W n t / \beta$-catenin signalling in stem cell biology and regeneration}

In addition to the myriad roles that the $\mathrm{Wnt} / \beta$-catenin pathway plays in normal development, it is also a key 


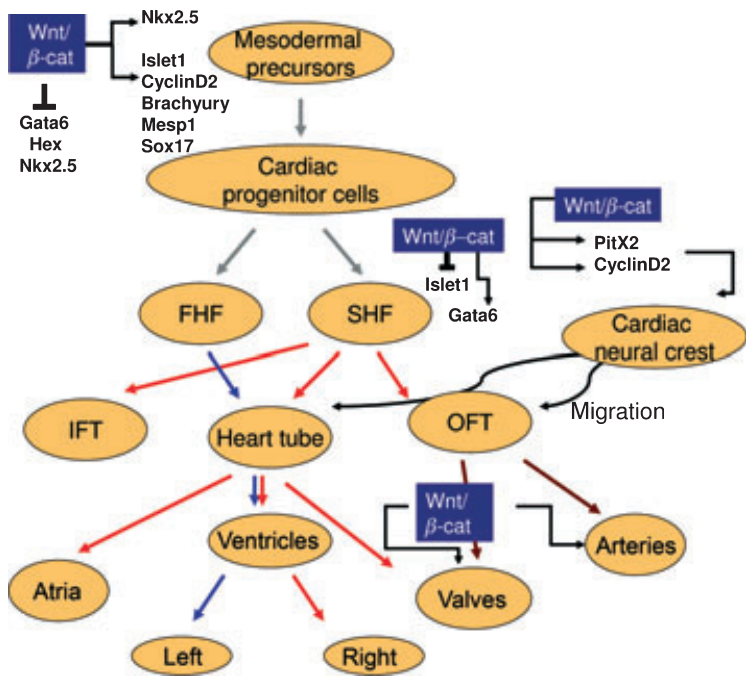

Figure $5 \mathrm{Wnt} / \beta$-catenin signalling (Wnt/ $\beta$-cat) has multiple roles in heart development. This schematic depicts a few of the roles the pathway plays in mammalian heart development, both as an activator and as a repressor of gene activity. Prior to gastrulation, $n k x 2.5$ is positively activated by $\mathrm{Wnt} / \beta$-cat signalling, while it is repressed after gastrulation, as are cardiogenic factors GATA6 and Hex (Foley \& Mercola 2005, Ueno et al. 2007, Afouda et al. 2008). Activation of a number of Wnt target genes early in development, such as Islet1 have been linked to the proliferation of cardiac progenitor cells (Lin et al. 2007). These Islet $1^{+}$cells contribute to the second heart field (SHF), inflow tract (IFT) and outflow tract (OFT). The $\mathrm{SHF}$ is required for proper formation of the atria and the right ventricle. In the posterior SHF, Wnt activates GATA6 (Tian et al. 2010), and represses Islet1 expression (Kwon et al. 2009). Wnt/ $\beta$-cat signalling is also instrumental in driving proliferation of cardiac neural crest cells (Kioussi et al. 2002), which migrate to the heart tube and OFT, and is important in valve and artery formation (Zamora et al. 2007) along with endocardial proliferation (Gitler et al. 2003, Hurlstone et al. 2003, Liebner et al. 2004, Alfieri et al. 2010). See text for more information. FHF, first heart field.

regulator of adult tissue homeostasis. The role of Wnt/ $\beta$-catenin signalling in stem cell maintenance has been well documented in the intestine (Pinto \& Clevers 2005, Barker \& Clevers 2010), hair follicles and in the skin (Blanpain et al. 2007, Blanpain \& Fuchs 2009, Haegebarth \& Clevers 2009). In the mouse small intestine, TCF4 and $\beta$-catenin are required for maintenance of the crypt stem cells (Pinto \& Clevers 2005). Microarray profiling has identified many transcriptional targets of the Wnt/ $\beta$-catenin pathway (van de Wetering et al. 2002, Van der Flier et al. 2007). One biologically important target is $c-m y c$, which is required for normal intestinal crypt development (Muncan et al. 2006). As will be discussed in the following section, $c-m y c$ appears to be a direct target of the pathway. Another gene that is activated by $\mathrm{Wnt} / \beta$-catenin signalling encodes the orphan receptor $\operatorname{Lgr} 5$, which has received a great deal of attention, since it marks a population of multipotent cells in the crypt that give rise to all the specialized cells of the intestinal epithelia (Barker \& Clevers 2010). Another biologically important Wnt target is the bHLH transcription factor Achaete scute-like 2 (Ascl2), which is required for the maintenance of the $\operatorname{Lgr} 5$-positive stem cells and can induce crypt hyperplasia upon forced expression (van der Flier et al. 2009). Both Lgr5 and Ascl2 were identified in a genome-wide survey of chromatin enriched for TCF4 binding (Hatzis et al. 2008), suggesting they may be direct targets of $\mathrm{Wnt} / \beta$ catenin signalling. In addition to intestinal stem cells, Lgr5 and the related protein Lgr6 also appear to mark stem cells populations in several other organs as well (Haegebarth \& Clevers 2009, Snippert et al. 2010).

$\mathrm{Wnt} / \beta$-catenin signalling has also been linked to the ability to replace damaged cells or to regenerate deleted tissues in a wide array of metazoans. In Hydra and Planaria, organisms renowned for their ability to regenerate large portions of their bodies after bisection, the pathway promotes posterior cell fates as described in the previous section. In Hydra, decapitation of the head results in rapid induction of Wnt 3 expression in the epithelial cells which is required for head regeneration (Hobmayer et al. 2000, Chera et al. 2009, Lengfeld et al. 2009). When Hydra is bisected in the midgastric region, a wave of apoptosis among the interstitial cells is coupled to release of Wnt3 from these dying cells, which results in subsequent activation of Wnt3 transcription in epithelial and head regeneration (Chera et al. 2009, Galliot \& Chera 2010).

The coupling of apoptosis to generation of a Wnt signal in regenerating Hydra is reminiscent of a similar phenomenon described in Drosophila imaginal discs, where apoptotic cells express Wg, which is thought to promote compensatory proliferation of neighbouring cells to maintain the size of the tissue (Fan \& Bergmann 2008, Martin et al. 2009). While Wg is dispensable for disc repair in response to irradiation (Perez-Garijo et al. 2009), a functional role for $\mathrm{Wg}$ has been reported in disc regeneration following expression of a pro-apoptotic signal, where Wg induced expression of myc and cyclin $E$ to promote proliferation (Smith-Bolton et al. 2009).

In vertebrates, $\mathrm{Wnt} / \beta$-catenin signalling has been shown to be required for tail fin regeneration in zebrafish (Stoick-Cooper et al. 2007). Wnt10a is induced after fin cutting, and blocking the pathway prevents induction of fibroblast growth factor 20 a $(f g f 20 a$ ) expression, which is required for regeneration of this tissue (Wills et al. 2008). Interestingly, fgf $20 a$ is directly activated by TCF$\beta$-catenin in cultured human cells (Chamorro et al. 2005), though it is not clear whether this is the case in regenerating zebrafish tails. The pathway is also thought 
to play a role in the initial step of limb regeneration in Xenopus (Yokoyama et al. 2007), though the molecular targets remain to be identified.

\section{Wnts gone wrong: misregulated signalling in disease}

Given the numerous functions of $\mathrm{Wnt} / \beta$-catenin signalling in development and stem cell biology, it is not surprising that misregulation of the pathway would be connected to a large number of diseases. Activation of $\mathrm{Wnt} / \beta$-catenin signalling has been linked to many different types of human cancer, including colorectal cancer (CRC) (Polakis 2000, 2007), hepatocellular carcinomas (Armengol et al. 2009), cancers of the adrenal gland (El Wakil \& Lalli 2011, Morris et al. 2010), Wilm's tumour (Tycko et al. 2007), breast cancer (Zardawi et al. 2009) and several hematological malignancies (Ge \& Wang 2010). In some cancers, for example, melanoma, down-regulation of the pathway leads to more aggressive malignancy (Lucero et al. 2010). Many of these cancers contain either lossof-function mutations in the APC gene, causing stabilization of $\beta$-catenin, or gain-of-function mutations in $\beta$-catenin, which interfere with phosphorylation of $\beta$-catenin by the destruction complex (Polakis 2000, 2007). Loss of Axin or Axin2 is also correlated with some forms of cancer (Laurent-Puig \& Zucman-Rossi 2006). In the next section, we focus on the role of $c-m y c$ activation by the $\mathrm{Wnt} / \beta$-catenin pathway, because of the biologically relevance of this regulation in cancer, and as an example of how difficult it can be to identify all the DNA regulatory sequences that mediate Wnt responsiveness (i.e. WRE) of a target gene.

\section{CRC: activation of c-myc expression by the $\mathrm{Wnt} / \beta$-catenin pathway}

The $c$-myc gene encodes a basic helix-loop-helix (bHLH) protein that promotes cell growth in many cell types (Soucek \& Evan 2010). Elevated expression of $c-m y c$ has been linked to numerous human cancers (Eilers \& Eisenman 2008). c-myc expression is activated by Wnt/ $\beta$-catenin signalling in CRC cells ( $\mathrm{He}$ et al. 1998, van de Wetering et al. 2002) and in the experimentally induced murine epithelial hyperplasia associated with temporally controlled deletion of APC (leading to $\beta$-catenin stabilization) (Sansom et al. 2004). Strikingly, simultaneous loss of APC and $c-m y c$ in this system completely suppressed the overgrowth phenotype caused by APC removal, even though $\beta$-catenin levels were still abnormally high (Sansom et al. 2007). Microarray analysis suggests that many of the changes in gene expression observed upon removal of APC are c-myc dependent (Sansom et al. 2007), indicating that $c-m y c$ is a major factor in mediating the effect of elevated $\mathrm{Wnt} / \beta$-catenin signalling in the intestinal epithelia.

When $c-m y c$ was first identified as a potential transcriptional target of the $\mathrm{Wnt} / \beta$-catenin pathway in CRC, examination of the region $5^{\prime}$ of the TSS revealed the presence of conserved TCF binding sites (He et al. 1998). This region of DNA could activate a minimal promoter/luciferase reporter upon $\mathrm{Wnt} / \beta$-catenin pathway activation and thus fits the definition of a WRE. Mutation of two TCF binding sites within this WRE abolished this activation (He et al. 1998). ChIP studies demonstrated that this region was bound by LEF1 and $\beta$-catenin in CRC cells (Sierra et al. 2006). More recently, another site enriched for $\beta$-catenin binding in CRC cells was identified downstream of the $c$-myc transcription unit (Yochum et al. 2008). This region also conferred Wnt responsiveness in a reporter gene assay and contained functionally important TCF sites (Yochum et al. 2008). Chromatin loops between these two WREs and the $c-m y c$ proximal promoter have been reported (Yochum et al. 2010).

While, the data described above suggest that the WREs identified $5^{\prime}$ and $3^{\prime}$ of the $c-m y c$ gene contribute to regulation by $\mathrm{Wnt} / \beta$-catenin signalling, the large intergenic regions surrounding this Wnt target raised the possibility of other WREs further removed from the TSS (Fig. 6). Indeed, when a genomic fragment containing the $5^{\prime}$ and $3^{\prime}$ WREs were tested in a transgenic mouse reporter assay, there was little transcriptional activity observed (Lavenu et al. 1994). An in silico search for WREs identified two regions approx. 26 and $36 \mathrm{~kb}$ upstream of the $c$-myc TSS (Hallikas et al. 2006). Both regions drove the expression of a reporter in transgenic mice in a subset of the $c-m y c$ pattern, though it is not clear whether these elements are regulated by Wnt/ $\beta$-catenin signalling (Hallikas et al. 2006).

Another potentially important WRE controlling $c-m y c$ has been identified through genome-wide association scans for polymorphisms that increase an individual's risk of developing CRC (Tomlinson et al. 2007, Zanke et al. 2007). A single nucleotide polymorphism (G/T; known as rs6983267) was linked with an increased occurrence of adenomas and CRC. While control populations had an approximate 50/50 distribution of the $\mathrm{G}$ and $\mathrm{T}$ allele, the $\mathrm{G}$ allele was found at approx. $56 \%$ in affected individuals (Tomlinson et al. 2007, Zanke et al. 2007). This polymorphism is located approx. $335 \mathrm{~kb}$ upstream of the $c$-myc TSS (Fig. 6).

The realization that this polymorphism occurs in a putative TCF binding site (GATGAAAGG vs. GATGAAAGT) suggested that this polymorphism resides within a WRE controlling c-myc expression. Consistent with this, TCF4 was highly enriched at this site compared to the other $1 \mathrm{Mb}$ of DNA surrounding the 


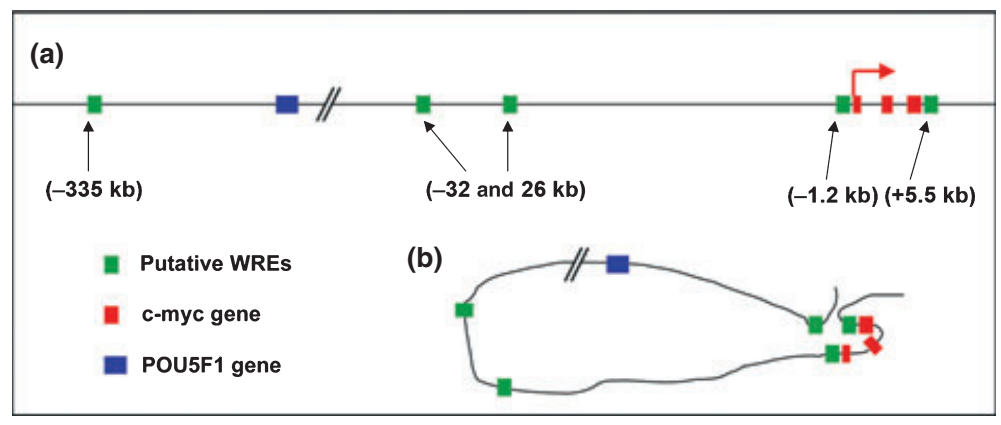

Figure 6 Complex regulation of the Wnt target gene $c-m y c$. (a) WREs are located both near and removed from the $c$-myc proximal promoter. The numbers in parentheses refer to the approximate position of the $5^{\prime}$ end of the WRE in relation to the c-myc TSS. The $5^{\prime}(-1.2 \mathrm{~kb})$ and $3^{\prime}(+5.5 \mathrm{~kb})$ WREs respond to $\mathrm{Wnt} / \beta$-catenin signalling in cell culture (He et al. 1998, Yochum et al. 2008). The far upstream $(-335 \mathrm{~kb})$ WRE is active in cell culture and transgenic mice (Tuupanen et al. 2009) and contains a polymorphism in a TCF binding sites that correlated with increased risk of CRC (Pomerantz et al. 2009, Tuupanen et al. 2009, Wright et al. 2010). The putative WREs at $-26 \mathrm{~kb}$ and $-32 \mathrm{~kb}$ are expressed in transgenic mice (Hallikas et al. 2006). (b) The presence of chromatin loops between the far upstream and the $3^{\prime}$ WRE have been documented in CRC cells with high levels of Wnt/ $\beta$-catenin signalling (Pomerantz et al. 2009, Wright et al. 2010, Yochum et al. 2010). These loops are stabilized by protein complexes (data not shown) containing TCF and $\beta$-catenin. Presumably, the large chromatin loop allows the upstream enhancer to bypass the POU5F1 gene, though this has not been experimentally confirmed. WRE, Wnt response elements; TSS, transcription start sites; TCF, T-cell factor; CRC, colorectal cancer.

c-myc locus (Tuupanen et al. 2009). This region had WRE activity in cell culture reporter assays (Pomerantz et al. 2009, Tuupanen et al. 2009, Sotelo et al. 2010, Wright et al. 2010). More impressively, this region drove expression of a reporter in transgenic mouse embryos in a pattern very similar to the majority of endogenous $c-m y c$ expression, which was abolished by mutation of the polymorphic TCF site and an adjacent site (Tuupanen et al. 2009). Consistent with the increased risk of CRC, the G allele WRE had a greater response to $\mathrm{Wnt} / \beta$-catenin pathway activation in cell culture reporter assays (Pomerantz et al. 2009, Tuupanen et al. 2009, Wright et al. 2010). When a CRC cell line with a G/T genotype was examined, TCF4 and $\beta$-catenin were enriched on the $\mathrm{G}$ allele chromatin, and this allele was more than two times more actively transcribed than the $\mathrm{T}$ allele (Wright et al. 2010). Taken together, these data support a model where increased recruitment of TCF 4 and $\beta$-catenin to the G allele WRE results in higher levels of $c-m y c$ transcription. A chromatin loop between this distal WRE and the c-myc proximal promoter has been demonstrated (Pomerantz et al. 2009, Wright et al. 2010), suggesting a mechanism by which this element can act over such a great distance (Fig. 6B).

The regulation of $c-m y c$ by the $\mathrm{Wnt} / \beta$-catenin pathway illustrates an inconvenient truth about studying gene regulation in higher eukaryotes. The existence of a WRE over $300 \mathrm{~kb}$ from the $c-m y c$ TSS should no longer cause surprise, given the existence of functional elements acting at an even greater distance in regulating sonic hedgehog (Jeong et al. 2006). In addition, there is a growing realization that the majority of developmen- tally regulated enhancers are more than $100 \mathrm{~kb}$ away from the nearest TSS (Visel et al. 2009). The ability to scan the large regions of genome surrounding Wnt targets of interest may often be necessary to identify some functionally important WREs.

\section{Wnts and oxidative stress: diabetes and Alzheimer's disease}

In addition to cancers, the $\mathrm{Wnt} / \beta$-catenin pathway has been linked to many other diseases, including several pathologies in the kidney (Pulkkinen et al. 2008, Hwang et al. 2009, Lancaster \& Gleeson 2010), bone (Krishnan et al. 2006) and cardiac repair (Saraswati et al. 2010). In this section, we briefly review the role of Wnt $/ \beta$-catenin signalling in metabolic disorders and neurodegenerative diseases. While the direct links between these disorders and $\mathrm{Wnt} / \beta$-catenin signalling are not as well established as in cancer, there are some candidate targets where misregulation of the pathway could underlie the pathology.

Emerging evidence has linked several players in Wnt/ $\beta$-catenin signalling to metabolic disorders and type 2 diabetes mellitus. Genome-wide association studies demonstrated a strong connection between diabetes type 2 risk and SNPs within the TCF7L2 (TCF4) gene, although the cellular basis of this association is still uncertain (Schinner et al. 2009). Mutations in the Wnt receptors LRP5 and 6 have also been implicated in obesity and type 1 diabetes and metabolic syndrome respectively (Jin 2008). Wnt/ $\beta$-catenin signalling appears to play roles both in the proliferation of pancreatic $\beta$-cells, and in the insulin release from islet 
cells. $\beta$-cell proliferation in cell culture and a transgenic mouse models appears to be the result of Wnt activation of targets like cyclin D1 (Liu \& Habener 2008, Schinner et al. 2008), as well as cyclin D2 and PitX2 (Rulifson et al. 2007). Consistent with this, knockdown of TCF4 decreases $\beta$-cell proliferation and promotes apoptosis (Liu \& Habener 2008, Shu et al. 2008).

In addition to promoting $\beta$-cell proliferation, the $\mathrm{Wnt} / \beta$-catenin pathway is also required for efficient insulin secretion (Fujino et al. 2003). The pathway may play a role in insulin sensing by activating glucokinase transcription (Schinner et al. 2008). It is interesting to note that antagonism of Wnt signalling by oxidative stress appears to play an important role in the pathology of insulin resistance and diabetes. The forkhead box DNA-binding protein FOXO, has been shown to compete with TCFs for $\beta$-catenin binding (Hoogeboom et al. 2008). Upregulation of FOXOs in response to oxidative stress may contribute to insulin resistance by the promotion of gluconeogenesis and/or the promotion of apoptosis and downregulation of TCF-mediated gene expression (Manolagas \& Almeida 2007).

The effects of oxidative stress may also be a factor in the neurodegeneration of Alzheimer's disease (AD), where Wnt signalling has been ascribed a neuroprotective role (Manolagas \& Almeida 2007). Extracellular accumulation of amyloid- $\beta$ (A- $\beta$ ) has been shown to bind $\mathrm{Fz}$ receptors and downregulate Wnt signalling, and it has been hypothesized that some of the cytotoxity caused by A- $\beta$ may be the result of chronic suppression of Wnt/ $\beta$-catenin signalling (Inestrosa $\&$ Toledo 2008). The protective effects of $\beta$-catenin overexpression, but not of transcriptionally inactive $\beta$-catenin, indicate that transcriptional activation of target genes plays a role in ameliorating A- $\beta$ toxicity (Chacon et al. 2008). One possibility is that oxidative stress may exacerbate cytotoxity in $\mathrm{AD}$ by increasing FOXO, which then competes with TCF for $\beta$-catenin, reducing the expression of anti-apoptotic factors.

Clearly, much remains to be elucidated concerning the role $\mathrm{Wnt} / \beta$-catenin signalling plays in neurodegeneration and other diseases. Information gained from the study of Wnt-mediated transcriptional regulation in model systems should facilitate the identification of the important targets in many pathological states where genetics suggests that aberrant Wnt signalling plays a causal role. Given the prominence of TCF family members in regulating numerous Wnt targets, the next few sections will review TCF function in detail.

\section{The TCF family: major regulators of $\mathrm{Wnt} / \beta$ - catenin transcription}

The TCF family of transcription factors is the best characterized DNA-binding regulators of $\mathrm{Wnt} / \beta$-catenin target gene expression. In addition to a $\beta$-catenin binding domain at the $\mathrm{N}$-terminus, a hallmark of this family is the presence of a highly conserved HMG domain, followed by a stretch of basic residues (Fig. 2). The TCF subfamily of HMG domains is found throughout metazoans, but not in the sister group choanoflagellates (King et al. 2008). The HMG domain contacts DNA largely through minor groove contacts and results in a large bending of the double helix (Love et al. 1995). High affinity binding sites for these HMGs have been determined for Drosophila TCF/Pangolin (TCF/Pan) and all four mammalian TCFs (Giese et al. 1991, van de Wetering et al. 1997, van Beest et al. 2000, Hallikas et al. 2006, Atcha et al. 2007). While, these studies show that a site of CCTTTGATS $(\mathrm{S}=\mathrm{G} / \mathrm{C})$ is bound with highest affinity in vitro, as will be described in the following section, many functional TCF binding sites in WREs fit this consensus, while others diverge markedly.

There is a single TCF gene in almost all invertebrate species that have been examined thus far (Figs 2 and 6), with TCF/Pan from flies and POP-1 from C. elegans being the most thoroughly characterized. In contrast, amphibians and mammals have four TCF genes. These are most commonly referred to as TCF1 (TCF7), LEF1 (LEF1), TCF3 (TCF7L1) and TCF4 (TCF7L2). The names in parentheses are from the Human Genome Organization (HUGO). In zebrafish, the TCF7L1 gene is duplicated (TCF7L1 $a$ and TCF7L1b), giving a total of five TCF genes in bony fish (Dorsky et al. 2003). As will be discussed below, there is evidence that some of the vertebrate TCFs are more specialized in their function compared to their invertebrate counterparts.

\section{The TCF transcriptional switch}

The current working model for regulation of WREs by TCFs proposes the existence of a transcriptional switch, where TCF and co-repressors inhibit the target gene expression in the absence of signalling, and then act with $\beta$-catenin and other co-activators to activate transcription of targets (Fig. 1). Evidence for this model was first obtained in the Drosophila embryo. TCF/pan mutants display mispatterning of the epidermis indicative of reduction of Wg signalling (Brunner et al. 1997, van de Wetering et al. 1997, Schweizer et al. 2003). This defect was not as severe as that of null alleles of $w g$. However, a wg; TCF/pan double mutant looked identical to TCF/pan mutants (Cavallo et al. 1998). In $w g$ mutants, there is no activation of targets and TCF repression is intact, resulting in a severe loss of Wg signalling phenotype. But in wg; TCF/pan double mutants, loss of repression of Wg targets allows some expression (i.e. derepression), resulting in a less severe phenotype (Cavallo et al. 1998). Genetic and physical interactions between TCFs and TLE family co-repres- 
sors (Cavallo et al. 1998, Roose et al. 1998) provided further support for the transcriptional model. The model has also been confirmed in fly cell culture using a combination of RNAi and ChIP of TCF/Pan in the absence and presence of Wg signalling (Fang et al. 2006).

In C. elegans, the POP-1 loss-of-function phenotypes indicate both positive and negative roles in regulating Wnt targets (Phillips \& Kimble 2009). In some contexts, for example, blocking mesoderm cell fate in the early embryo, repression of Wnt targets is the predominant effect observed (Rocheleau et al. 1997, Thorpe et al. 1997). But in other stages, for example, QL neuroblast migration and stem cell specification in the somatic gonad, loss of POP-1 has a similar phenotype as loss of other $\mathrm{Wnt} / \beta$-catenin components (Herman 2001, Lam et al. 2006). Clearly, POP-1 and TCF/Pan can both repress and activate Wnt targets.

In vertebrates, some TCF family members are more closely linked to either repression or activation. For example, headless ( $h d l$ ) mutants in zebrafish are loss of function TCF3a alleles and display a lack of head structures (Kim et al. 2000), similar to Dkk1 knockouts in mice (Mukhopadhyay et al. 2001). While hdl mutants could be efficiently rescued with a TCF3a transgene, adding the VP16 domain, a potent transcriptional activation domain to TCF3a, abolished rescue activity of the transgene (Kim et al. 2000). This suggests that most of TCF3a's transcriptional activity is repressive. Knockout of TCF3 in mice also resulted in phenotypes associated with an increase in $\mathrm{Wnt} / \beta$-catenin signalling (Merrill et al. 2004) and siRNA inhibiton of TCF3 in mouse ES cells largely results in increased expression of target genes (Cole et al. 2008). In contrast, LEF1 knockouts have phenotypes best explained by a loss of $\mathrm{Wnt} / \beta$-catenin signalling (van Genderen et al. 1994, Reya et al. 2000, Kratochwil et al. 2002).

In contrast to TCF3 and LEF1, TCF1 appears to be more versatile. Mouse embryos lacking both TCF1 and LEF1 have a loss of caudal somites that is reminiscent of Wnt3a mutants (Galceran et al. 1999). TCF1 and LEF1 also act redundantly to pattern the mesoderm in Xenopus embryos, and this activity is linked to transcriptional activation (Liu et al. 2005). However, TCF1 and TCF3 have also been shown to act redundantly in repressing Spemann organizer genes such as siamois in ventral blastomeres (Houston et al. 2002, Standley et al. 2006). Loss of the TCF1 gene in mice demonstrated that it was a tumour suppressor in the intestine and mammary gland (Roose et al. 1999).

The situation for TCF4 also indicates both positive and negative roles in regulating Wnt targets. TCF4 knockouts display a loss of stem cells in the intestinal crypts (Korinek et al. 1998), consistent with a loss of
Wnt/ $\beta$-catenin signalling. Consistent with this, TCF4 is required for activation of Spemann organizer genes in Xenopus (Standley et al. 2006). Conversely, loss of TCF4 can result in elevated activation of a Wnt/ $\beta$-catenin signalling in CRC cells, suggesting a possible role for TCF4 as a tumour suppressor (Tang et al. 2008). Further support for a bi-modal role for TCF4 comes from studies of TCF3; TCF4 double knockouts in the skin epithelia of mice (Nguyen et al. 2009). Loss of both TCFs in the skin epithelia resulted in a dramatic decline in epidermal survival, which was not observed when $\beta$-catenin was removed (Nguyen et al. 2009). Microarray profiling revealed that many genes were repressed by TCF3 and TCF4 in a redundant manner, which were either activated or not regulated by $\beta$-catenin (Nguyen et al. 2009). These data fit a model where the two TCFs are repressing gene expression in the absence of $\mathrm{Wnt} / \beta$-catenin signalling. Like TCF1, TCF4 can activate or repress Wnt targets, depending on the context.

The loss-of-function studies summarized above suggest a model where the transcriptional switch in vertebrate WREs is mediated by two distinct TCFs. For example, in two CRC cell lines, siRNA data fit a model, where TCF4 represses Wnt targets in the absence of signalling and TCF1 works with $\beta$-catenin to activate targets (Tang et al. 2008). Given that these results are not consistent with the phenotype of TCF1 and TCF4 knockouts in mice (Korinek et al. 1998, Roose et al. 1999), follow-up experiments with ChIP and reporter genes are required to confirm this model. In the presumptive Spemann organizer, TCF3 occupies the WRE upstream of the siamois TSS, and its binding to chromatin is reduced by $\mathrm{Wnt} / \beta$-catenin signalling (Hikasa et al. 2010). It will be interesting to determine the occupancy of TCF4 on the siamois WRE in response to pathway activation, since this TCF is required for siamois regulation (Standley et al. 2006).

\section{Functional analysis of TCF-DNA recognition in WREs}

The DNA sequence motif (CCTTTGATS) that mediates high affinity binding of TCFs in vitro (van de Wetering et al. 1997, van Beest et al. 2000, Hallikas et al. 2006) has been shown to be necessary and sufficient for activation of TCF- $\beta$-catenin-dependent transcription. This sequence motif has been found in many WREs, that is, regulatory sequences that can activate transcription of promoters in response to $\mathrm{Wnt} / \beta$-catenin signalling. Mutation of these motifs in these WREs abolished activation by the pathway (He et al. 1998, Yamaguchi et al. 1999, Barolo 2006, Chang et al. 2008a). In addition, multiple copies of this motif placed upstream of a minimal promoter confer $\mathrm{Wnt} / \beta$-catenin responsiveness in cell culture (Korinek et al. 1997, Lum et al. 
2003, DasGupta et al. 2005) and in transgenic mice and fish (DasGupta \& Fuchs 1999, Dorsky et al. 2002, Maretto et al. 2003, Nakaya et al. 2005). These studies, combined with the TCF loss-of-function studies described in the previous section have led to the view that TCFs are the major transcriptional regulators of $\mathrm{Wnt} / \beta$-catenin signalling in most contexts.

Testing the functionality of TCF binding sites in WREs has suggested that the switch model for TCF transcriptional regulation is WRE-specific. In several cases, mutation of the TCF binding sites clearly demonstrated both a repressive and a positive role. When a single TCF site is destroyed in the END-1 WRE, a reduction in activation by $\mathrm{Wnt} / \beta$-catenin signalling was observed, but the reporter was also expressed in cells where it was normally repressed by POP-1 (Shetty et al. 2005). Similar phenotypes were observed when TCF sites were mutated in the siamois WRE in Xenopus (Brannon et al. 1997, Fan et al. 1998) as well as an eve WRE in flies (Knirr \& Frasch 2001). In contrast, mutation of TCF sites in a WRE controlling expression of decapentapleigic $(d p p)$ in the fly visceral mesoderm resulted in a huge derepression of expression with no loss in maximal activation (Yang et al. 2000). It appears that for this WRE, Wg/Arm signalling activates expression by alleviating TCF/Pan repression. At the other extreme, mutation of TCF sites often results in loss of expression of the WRE reporter (Yamaguchi et al. 1999, Lee \& Frasch 2000, Chang et al. 2008b). For these WREs, there appears to be little role for TCF repression, and regulation by the pathway occurs through TCF- $\beta$-catenin mediated activation (see Fig. 7A and $\mathrm{B}$ for further explanation).

Like many transcription factors, the TCF consensus site is not inviolate. Many functional TCF binding sites in WREs have one or more substitutions from the consensus (Barolo 2006). Systematic analysis of TCF4DNA binding in vitro also demonstrated that single substitutions from the CCTTTGATS consensus reduced, but did not abolish, recognition by TCF4 (Hallikas et al. 2006). There is no strict correlation between functional significance and adherence to the TCF consensus site. For example, the TCF site that is polymorphic in the far upstream $c-m y c$ WRE has either

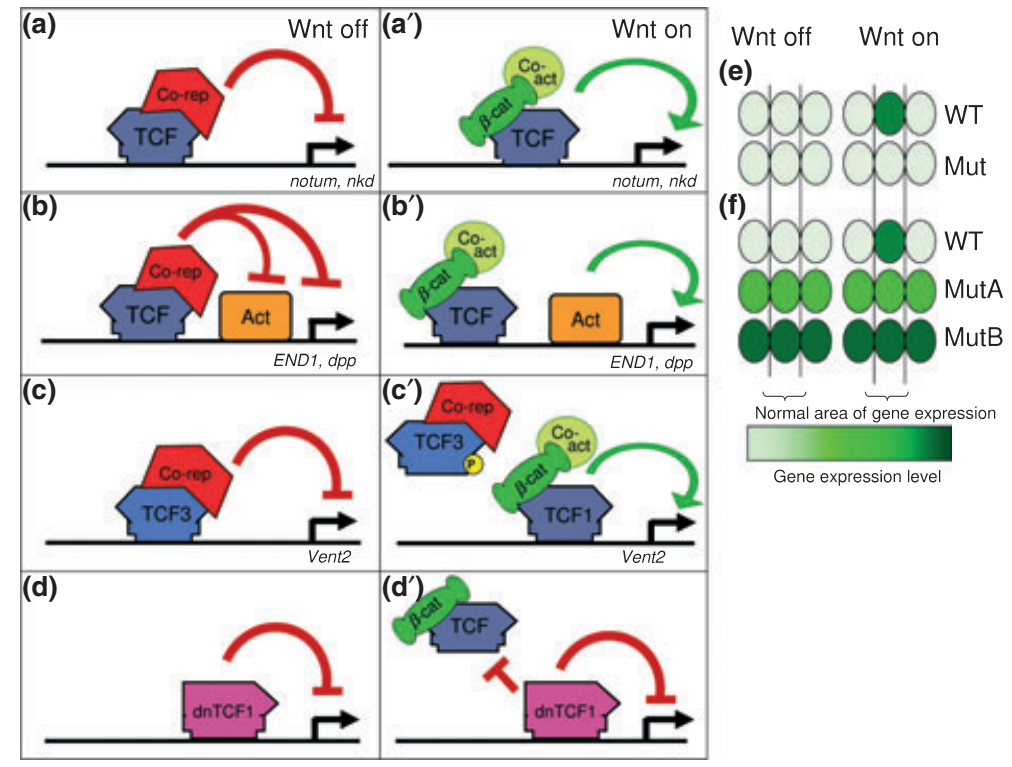

Figure 7 Variations on TCF transcriptional switches. (a \& b) In organisms with a single TCF gene, the protein interacts with co-repressors in the absence of signalling, while $\beta$-catenin binding to TCF displaces co-repressors and recruits co-activators. In WREs from the $n k d$ and notum genes, mutation of TCF binding sites results in a loss of activation (e) presumably due to the absence of other transcriptional activators (Chang et al. 2008b). In other WREs such as END1 the loss of a single TCF site reduces activation by Wnt/b-catenin signalling, but there is also significant derepression of expression in cells where the WRE is not normally active (f, middle row), presumably due to the presence of other transcriptional activators (Shetty et al. 2005). In some cases (e.g. the visceral mesodermal dpp WRE), mutation of the TCF sites results in full activation of expression in many cells (f, lower row), suggesting that the primary function of $\beta$-catenin is to relieve TCF repression (Yang et al. 2000). (c) In Xenopus, where multiple TCFs reside in the same cells, the transcriptional switch may be accomplished by HIPK2-mediated phosphorylation of the repressive TCF3, which reduces its binding to WRE chromatin, allowing TCF1 to bind and activate transcription (Hikasa \& Sokol 2011). (d) The activity of a WRE can also be blocked by dominant negative isoforms of TCF which lack the ability to bind $\beta$-catenin (Roose et al. 1999, Hovanes et al. 2001). See the text for additional examples of WRE regulation by TCFs. WRE, Wnt response elements; TCF, T-cell factor; HIPK2, homeodomain interacting protein kinase 2. 
one (CCTTTㅁAG) or two (TCTTTCATG) changes from the consensus, with the first site having increased affinity for TCF4 (Tuupanen et al. 2009, Wright et al. 2010). Likewise, binding sites that are highly functional in fly WREs from the naked cuticle (nkd) locus can have two (GCTTTGTTC) or three (GCTTTGACA) differences from the consensus (Chang et al. $2008 \mathrm{a}$ ). In addition to such high affinity sites in the eve and $s l p 1$ WREs, there were also more divergent sites (e.g. ACTTCACAG) that were footprinted by TCF/Pan in vitro and contributed to activation in transgenic fly reporter assays (Lee \& Frasch 2000, Knirr \& Frasch 2001). The heterogeneity of what constitutes a TCF binding site makes locating biologically relevant WREs by sequence analysis alone extremely difficult.

A simple analysis of randomly selected human intergenic DNA helps to illustrate how common predicted TCF binding sites are in the genome (Table 1). Perfect or near perfect sites (CCTTTGAWS) are rare (1 every approx. $22 \mathrm{~kb}$ ). But if one allows a modest level of degeneracy, for example, SCTTTGAWS or CTTTGWWS, the frequency increases to $1 / 10300$ or $1 / 2500$ respectively (Table 1 ). These sequences are well within the range of known functional TCF sites (see preceding paragraph and Chang et al. 2008a, Knirr \& Frasch 2001, Lee \& Frasch 2000). When the consensus is loosened to the level of the polymorphic TCF site found in the upstream c-myc WRE (GTTTGWWS; Pomerantz et al. 2009, Tuupanen et al. 2009, Wright et al. 2010), the frequency in random DNA is 1 in 645 bp (Table 1). This analysis suggests that there are millions of potential TCF binding sites in the human genome, and the challenge for researchers is to determine how TCF

Table I The frequency of TCF sites depends on how one defines a TCF site. An open source algorithm called Target Explorer (Sosinsky et al. 2003) was used to create a weighted matrix of high to lower quality TCF sites. This matrix was used to search several stretches of human intergenic DNA totalling $134 \mathrm{~kb}$ for potential TCF sites. While TCF sites matching the high affinity consensus site (CCTTTGAWS) are relatively rare, allowing increasing degrees of degeneracy causes a rapid increase in the number of potential sites. See text for further explanation

\begin{tabular}{ll}
\hline TCF site & $\begin{array}{l}\text { Frequency in random } \\
\text { intergenic DNA (bp) }\end{array}$ \\
\hline CCTTTGAWS & $\sim 1 / 22300$ \\
SCTTTGAWS & $\sim 1 / 10300$ \\
CTTTGWWS & $\sim 1 / 2500$ \\
$\begin{array}{l}\text { SCTTTGWW, SGTTTGWWS } \\
\text { or SCTTTCWWS }\end{array}$ & $\sim 1 / 1175$ \\
CTTTGWW, GTTTGWW & \\
or CTTTCWW & $\sim 1 / 645$ \\
\hline
\end{tabular}

TCF, T-cell factor. can identify functional sites among the sea of irrelevant ones.

\section{Bipartite binding of some TCFs through C-clamp-Helper site interaction}

Are TCF sites the only sequence information in WREs that facilitate TCF binding? A distinct sequence motif with a consensus of GCCGCCR ( $\mathrm{R}=\mathrm{A} / \mathrm{G})$ has been shown to be critical for the activation of six WREs in fly cells (Chang et al. 2008b). Unlike classic TCF sites, multiple copies of this element (termed the Helper site) are not sufficient for activation of a promoter/reporter cassette. However, these elements greatly enhance the ability of HMG domain binding sites to respond to pathway activation (Chang et al. 2008b). While the orientation and spacing of the Helper sites are not fixed in relation to HMG sites, they are predominantly within $6 \mathrm{bp}$ of each other. It appears that the presence of a Helper site nearby provides additional context to the TCF site to facilitate TCF/Pan activation of WREs (Chang et al. 2008b).

How do Helper sites facilitate TCF-mediated activation of WREs? The breakthrough came from the identification of an additional DNA-binding domain found in some isoforms of vertebrate TCFs, for example, TCF-1E and TCF-4E (Atcha et al. 2007). This domain, coined the C-clamp, contains four highly conserved Cysteine residues (Fig. 2). The presence of a C-clamp downstream of the HMG domain of TCF1 enabled the protein to recognize sequences containing the classic HMG binding site and an additional sequence of RCCG (Atcha et al. 2007). WREs from the LEF1 and $c d x 1$ genes are only activated by TCFs containing a C-clamp (Atcha et al. 2003, 2007, Hecht \& Stemmler 2003). These WREs contain RCCG motifs in close proximity to HMG binding sites (Atcha et al. 2007). The RCCG motif from vertebrates is similar to the first four nucleotides in the Helper site (GCCG). In flies, the major isoform of TCF/Pan contains a C-clamp, and this domain is required for activation of the WREs containing Helper sites (Chang et al. 2008b). Furthermore, recombinant TCF/Pan had a dramatic increase in affinity for HMG sites if a Helper site was present, and this enhanced binding was C-clamp dependent (Chang et al. 2008b). These results suggest a model where TCF/ Pan, TCF1E and TCF4E recognize DNA through a bipartite mechanism involving HMG domain-HMGsite and C-clamp-Helper site interactions.

In contrast to vertebrates, where only some of TCF1 and TCF4 isoforms contain a C-clamp, almost all invertebrate genomes examined contain only one TCF gene with a C-clamp. The fly TCF/pan locus is subject to alternative splicing but the RNA-seq profiling indicates that the two most abundant isoforms expressed 


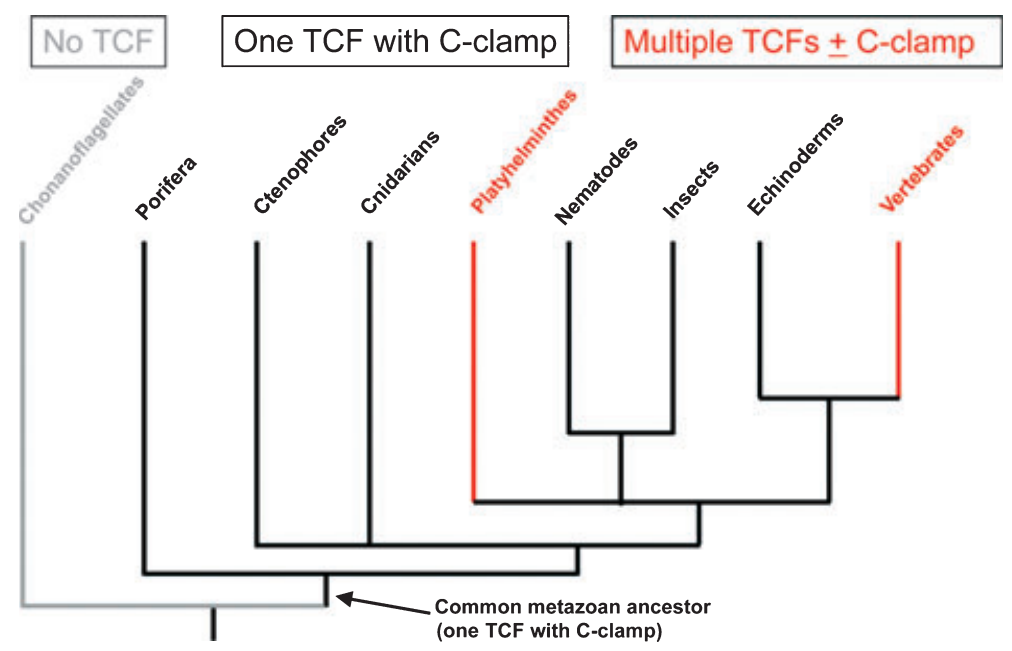

Figure 8 Phylogenetic tree showing the evolution of the TCF family. The genome sequence of Monosiga brevicollis (choanoflagellate) reveals no TCF family member, while that of Amphimedon queenslandica (porifera), Mnemiopsis leidyi (ctenophore), Nematostella vectensis (cnidarian), Caenorhabditis elegans (nematode), Drosophilia melanogaster (insect) and Strongylocentrotus purpuratus (echinoderm) have a single TCF gene encoding a protein with HMG domain, basic tail and a C-clamp. Schistosoma mansoni (Platyhelminthes) has three TCF genes; two with a C-clamp and one without. Mammals and amphibians have four TCF genes, two of which have C-clamp containing isoforms. These patterns suggest that the last common ancestor of all metazoans contained a single TCF gene with a C-clamp. In the two lineages where the TCF family increased in number, the C-clamp became dispensible in some family members. TCF, t-cell factor; HMG, high mobility group.

throughout development (van de Wetering et al. 1997), possess both a HMG and a C-clamp domain (see modencode website: http://modencode.oicr.on.ca/fgb2/ gbrowse/fly/?name=4:87956..131430). While such detailed analysis of TCF isoforms in other invertebrates has not yet been performed, it appears that the ancestral TCF gene contained both domains, and that after amplification during the vertebrate lineage, the C-clamp was lost (LEF1 and TCF3) or partially retained through alternative splicing (TCF1 and TCF4) (Fig. 8). This model makes the prediction that Helper sites will play an important part in specifying invertebrate WREs, as has been found in Drosophila (Chang et al. 2008b), while additional mechanisms exist for target location of vertebrate TCFs lacking a C-clamp. It should be pointed out that despite the high degree of similarity among C-clamps, some of the invertebrate domains have nonconservative changes at some positions. For example, the M. leidyi C-clamp has an arginine in place of the third cysteine (Fig. 2). Direct analysis of these C-clamps will be required to determine whether they enhance TCF binding, as is the case for TCF/Pan, TCF1E and TCF4E.

\section{Genome-wide analysis of TCF binding and targets}

In an attempt to define the $\mathrm{Wnt} / \beta$-catenin transcriptome, microarray based screens have been performed in a variety of cell types. The number of genes whose expression is altered in the cells varies from hundreds to thousands (van de Wetering et al. 2002, Jackson et al. 2005, Klapholz-Brown et al. 2007, Van der Flier et al. 2007). A list of these microarray studies can be found on the Wnt homepage curated by the Nusse Lab at http://www.stanford.edu/group/nusselab/cgi-bin/wnt/ and also at the Stanford Microarray Database website: http://genome-www5.stanford.edu/. One simple message from these data sets is the limited amount of overlap between Wnt targets in different cell types. It has been estimated that as few as $5 \%$ of targets are identified in all studies (Vlad et al. 2008). While variations in experimental protocols and signal detection may contribute to this low number, most of the cell-specific differences likely reflect the existence of discrete transcriptional programs. In one study, microarray analysis of PC12 and NIH3T3 cells identified 129 and 355 genes with alteration of expression in response to Wnt3a treatment respectively (Railo et al. 2009). Only two genes were commonly activated in both cell lines, one of which was axin2, often considered a universally induced feedback antagonist of $\mathrm{Wnt} / \beta$-catenin signalling (Jho et al. 2002).

While some classes of Wnt targets such as Wnt pathway components, proliferative genes or anti-apoptotic genes are found in multiple studies (Longo et al. 2002, Chen et al. 2007, Klapholz-Brown et al. 2007, Van der Flier et al. 2007, Railo et al. 2009), other classes may be more restricted in their expression domains. For instance, angiogenic (Masckauchan et al. 
2005) or osteoblastic and adipogenic targets (Jackson et al. 2005) are most likely Wnt responsive only in permissive tissue specific contexts.

One limitation of microarrays is that they do not distinguish between direct and indirect targets. ChIPbased genomic surveys offer the potential to identify regions of the genome that are enriched for a particular TCF or $\beta$-catenin. How many of these bound regions actually correspond to a functional WRE? For example, in one study of TCF4 binding sites in LS174T cells, a CRC cell line, over 6800 high quality binding peaks were identified using a ChIP-microarray approach (Hatzis et al. 2008). More than $70 \%$ of the identified peaks were over $10 \mathrm{~kb}$ from the nearest TSS, highlighting the tremendous amount of genomic real estate that must be examined when searching for WREs. In many cases, several TCF4-bound regions were found near a single gene, such as the 11 peaks surrounding the Axin 2 gene. Four of these regions had WRE activity in a reporter assay, while 10 out of 22 other TCF 4 bound regions from other locations tested positive in this assay (Hatzis et al. 2008). It remains to be seen whether the regions that tested negative in the reporter assay are simply non-functional binding sites for TCF4 or are WREs that are not active in a simple reporter assay. The relatively small degree of overlap $(12.5-20.5 \%$ depending on how the comparison is made) between whether a TCF4-bound region was found within $100 \mathrm{~kb}$ of a TSS from a gene upregulated in adenomas suggests that many of these Wnt targets may be indirectly regulated (Hatzis et al. 2008).

Another study using ChIP followed by high throughput sequencing (ChIP-seq) identified over 20000 TCF4 bound regions in the human CRC cell line HCT116 (Blahnik et al. 2010). Over 6000 of these motifs map to putative enhancer regions with $10-100 \mathrm{~kb}$ of a TSS, while over 9000 mapped within $2 \mathrm{~kb}$ of a TSS. Using the same cell line, over 2100 regions enriched for $\beta$-catenin binding were also reported (Bottomly et al. 2010). In this study, only $47 \%$ of the peaks contained at least one consensus TCF motif in the vicinity of the peak. The remaining peaks may represent TCF-independent $\beta$-catenin targets, peaks containing TCF binding motifs which diverge from the consensus, or false positives.

The above studies indicate that TCF4 can bind to regions far removed from the TSS of target genes. This suggests that the most common way of determining whether a developmental gene is directly regulated by $\mathrm{Wnt} / \beta$-catenin signalling, that is, scanning the region immediately upstream of the candidate gene's TSS for conserved TCF binding sites, followed by site-directed mutagenesis, may miss many WREs. While continued genome-wide surveys of TCF-bound chromatin in interesting developmental contexts is desirable, an alternative is to use computational approaches to detect WREs within entire genomes. For example, an algorithm called the enhancer element locator utilized binding site affinity matrixes and motif clustering conservation between two or more species to identify potential WREs (Hallikas et al. 2006). Several putative elements were tested in a transgenic mouse assay and found to be expressed in patterns that were consistent with positive regulation by $\mathrm{Wnt} / \beta$-catenin signalling, though this was not directly confirmed by site-directed mutation of the conserved TCF sites (Hallikas et al. 2006). While this method is likely to identify some WREs, the challenge of sorting through the entire genome requires stringent screening parameters which likely miss many biologically relevant elements. While one of the benefits of this algorithm is the reliance on conservation of motif clusters rather that strict sequence conservation, in some instances, enhancer elements in divergent species have been shown to retain functional conservation while losing motif clustering or locational conservation (Kalay \& Wittkopp 2010), and thus may elude this type of analysis.

Given the likelihood that many targets of the $\mathrm{Wnt} / \beta$ catenin pathway are cell specific, it seems that a combination of transcriptome analysis, physical localization assays (e.g. ChIP-seq) and further refinement of computational approaches will be needed to efficiently identify WREs in all the interesting contexts where the pathway plays important roles. The existence of WREs acting over great distances makes this undertaking even more challenging. These efforts should be aided by the realization that many Wnt targets are controlled by TCFs in combination with other transcription factors, often in direct contact with each other. Some of the literature on this topic is covered in the following section.

\section{TCF isoforms: a complicated situation gets more so}

The existence of alternative splicing and promoter selection in vertebrate TCF genes results in a highly complex and varied inventory of TCF isoforms. For example, the mouse TCF4 locus contains 17 exons, and more than a dozen TCF4 isoforms resulting from alternative splicing have been identified (Weise et al. 2010). Four isoforms (E isoforms) contained a C-clamp, though the protein sequence differed at 3 positions depending on whether exon 14 or 15 was used. Three isoforms contained a truncated C-clamp (after the third cysteine - see Fig. 2) and three others contained new protein sequence after position 20 of the motif (Weise et al. 2010). These six isoforms were collectively referred to as $\mathrm{S}$ isoforms, while isoforms completely lacking the C-clamp were labelled M isoforms (Fig. 9). Representatives from each group were compared in 


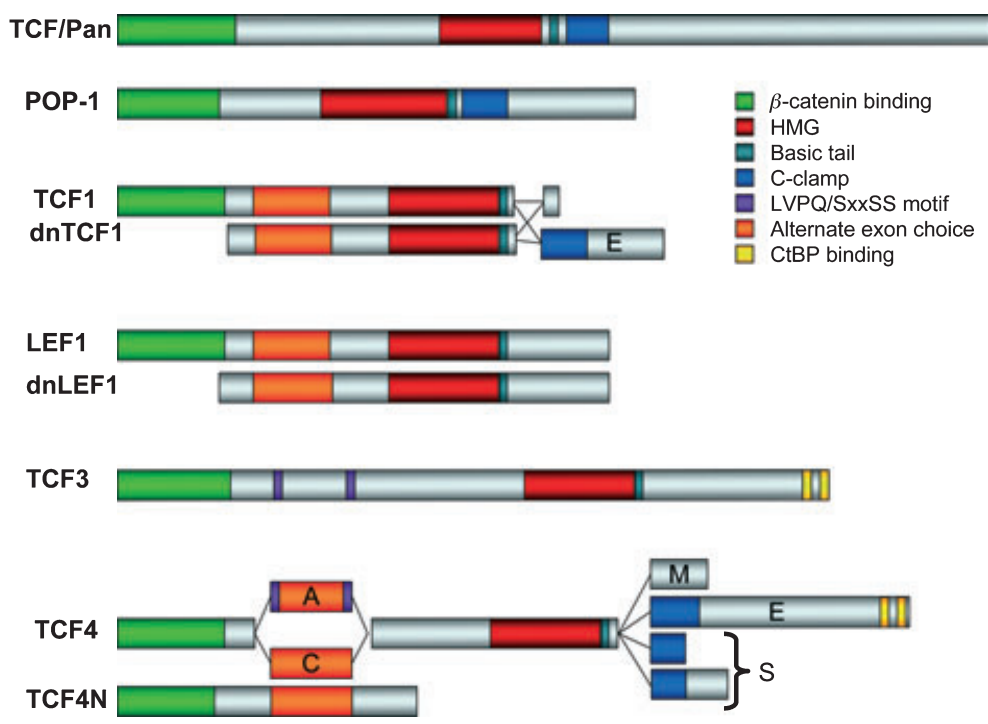

Figure 9 Diversity of TCF/LEFs. Invertebrates contain a single TCF member containing the $\beta$-catenin binding (green), HMG (red), basic tail (turquoise), and C-clamp (blue) domains. Pictured here is the most abundant isoform in Drosophila (Pan A) and the C. elegans POP-1. In vertebrates, alternate promoter usage and alternative splicing result in a myriad of TCF isoforms with diverse functional properties. Alternate usage of downstream promoters can result in isoforms which lack the $\beta$-catenin binding domain, and function as natural dominant negatives, such as dnTCF1 and dnLEF1 (Roose et al. 1999, Hovanes et al. 2001). Alternate exon usage (orange) occurs in all family members except TCF3, and the LVPQ/SXXSS motif (purple) which is invariant in TCF3 confers repressive activity on TCF4 isoforms which contain it (as in TCF4A) (Liu et al. 2005). Inclusion of the C-clamp motif is seen in E-tail containing isoforms TCF1E and TCF4E. M isoforms lack the C-clamp, while S isoforms contain truncated C-clamp domains (Weise et al. 2010). Some TCF3 and TCF4 isoforms also contain CtBP binding sites. TCF, T-cell factor; LEF, lymphoid enhancer-binding factor; HMG, high mobility group.

several assays and significant differences were found. For example a TCF4E isoform could bind to and regulate a $c d x 1$ WRE to a far greater extent than TCF4S or TCF4M isoforms (Weise et al. 2010). The biological role of the TCF4S isoforms merits further study but there is data suggesting that TCF4E isoforms are preferentially required for increased growth and proliferation in some CRC cell lines (Atcha et al. 2007) and the presence of TCF4E isoforms is correlated with increased disease progression in renal cell carcinoma (Shiina et al. 2003).

Another class of TCF isoforms lacks the $\beta$-catenin binding domain normally found at the N-terminus (Fig. 9). These isoforms are predicted to block Wnt/ $\beta$-catenin signalling, since experimentally derived TCFs lacking this domain act as potent dominant negatives (Behrens et al. 1996, Molenaar 1996, van de Wetering et al. 1997, Kratochwil et al. 2002). For example, high expression of truncated TCF1 ( $d n T C F 1)$ isoforms have been proposed to explain the tumour suppressor effect of TCF1 in mice (Roose et al. 1999). In human intestinal epithelial cells, LEF1 can be expressed from two distinct promoters. Transcription from the second promoter produces a LEF1 lacking the $\beta$-catenin binding domain (Hovanes et al. 2001). In human CRC, this truncated LEF1 is suppressed, which is predicted to contribute to higher levels of $\mathrm{Wnt} / \beta$-catenin signalling (Hovanes et al. 2001, Yokoyama et al. 2010). In T-helper cells, dnTCF1 is thought to regulate cell polarization via IL4 signalling. TCF1E activates GATA3 expression, which then suppresses dnTCF1 transcription in an IL4 dependent manner. This positive feedback loop promotes $\mathrm{T}$ helper cell polarization (Maier et al. 2011).

Other TCF isoforms influence the ability of the proteins to act in repression or activation. In Xenopus, TCF4A contains two motifs in the central portion of the protein (LVPQ and SXXSS) that are missing in TCF4C (Fig. 9). TCF4A can rescue embryos depleted of TCF3, suggesting that it can act as a repressor, while TCF4C can rescue embryos depleted of TCF1 or LEF1, suggesting a role in transcriptional activation (Liu et al. 2005). In CRC, expression of TCF4E isoforms clacking a binding site for CtBP (a transcriptional co-repressor) has been correlated with increased malignancy (Cuilliere-Dartigues et al. 2006). Furthermore, these isoforms have decreased repressive activity in cell culture reporter assays (Cuilliere-Dartigues et al. 2006, Tang et al. 2008).

Given the complexities of understanding even a single TCF isoform, comprehending how the entire TCF isoform repertoire is orchestrated to influence $\mathrm{Wnt} / \beta$ - 
catenin signalling is a long-term objective for the field. For further information on TCF isoforms, see the following review (Arce et al. 2006).

\section{Post-translational modifications of TCFs}

Post-translational modifications of TCFs are known to influence their subcellular localization, stability and their ability to bind to DNA and cofactors. These modifications can have a stimulatory or inhibitory effect, depending on the context. For example, the SUMO E3 ligase PIASy has been shown to facilitate sumoylation of LEF1, resulting in sequestration of the protein into nuclear bodies, where it cannot activate Wnt targets (Sachdev et al. 2001). Conversely, PIASy sumoylates TCF4, which increases its affinity for $\beta$-catenin, promoting target gene activation (Yamamoto et al. 2003b). The physiological role for PIASy in the $\mathrm{Wnt} / \beta$-catenin pathway is not clear, given that disruption of this gene in mice resulted in no morphological defects and only mild effects on some Wnt targets (Roth et al. 2004).

TCFs have also been shown to be acetylated by the invertebrate homologs of CBP and p300. These histone acetyltransferases are normally associated with histone acetylation and gene activation (Ogryzko et al. 1996). Indeed, $\mathrm{CBP} / \mathrm{p} 300$ is known to be recruited to WREs through binding to $\beta$-catenin/Arm and is required for activation of Wnt targets (Mosimann et al. 2009). Paradoxically, partial loss of fly CBP gene activity elevated Wg/Arm signalling (Waltzer \& Bienz 1998). This was shown to be the result of CBP acetylation of TCF/Pan on K25, a conserved lysine in the $\beta$-catenin/ Arm binding domain. This modification weakens binding of TCF/Pan to Arm (Waltzer \& Bienz 1998). An inhibitory role for $\mathrm{CBP} / \mathrm{p} 300$ has also been reported in mammalian cells, though the exact mechanism is not clear (Li et al. 2007). In C. elegans, POP-1 can be acetylated by human p300 at K185 just N-terminal of the HMG domain (Gay et al. 2003). Acetylation at this site also occurs in worms, and was required for nuclear localization and biological activity of POP-1 (Gay et al. 2003). This region of POP1 is not well conserved in other TCFs, so it is not clear whether this mechanism occurs in other organisms.

Phosphorylation has also been linked to POP-1 nuclear localization. In Wnt receiving cells, a complex of the MAP kinase LIT-1 (NLK) and WRM-1 (a worm $\beta$-catenin) binds to POP-1 and phosphorylates it (Rocheleau et al. 1999). This results in nuclear export of POP-1, which is mediated by PAR-5, a 14-3-3 protein (Lo et al. 2004). This export lowers the level of nuclear POP-1, facilitating the switch of POP-1 from a repressor to a $\beta$-catenin (SYS-1 or BAR-1) bound transcriptional activator (Phillips \& Kimble 2009).
Interestingly, a Wnt and CaMKII-dependent efflux of dnTCF1 has also been reported in human CRC cells (Najdi et al. 2009).

Is the NLK-mediated phosphorylation and nuclear export found in C. elegans operating in other organisms? In Xenopus, NLK phosphorylation of TCF4 and LEF1 promotes ubiquitylation and degradation (Yamada et al. 2006). In Drosophila, overexpression of Nemo, the fly homolog of NLK, inhibits Wg/Arm signalling and reduction of nemo activates the pathway (Zeng \& Verheyen 2004). Whether this occurs through nuclear efflux or degradation of TCF/Pan is not yet known.

Several other kinases have been shown to influence TCF activity through direct phosphorylation. CKII can promote Wnt target gene activation by phosphorylating LEF1, which reduces its affinity for TLE co-repressors (Wang \& Jones 2006, Sun \& Weis 2011). The Traf2and Nck-interacting kinase (TNIK) is required for activation of TCF4- $\beta$-catenin in mammalian cells and can form a complex with TCF4 and $\beta$-catenin (Shitashige et al. 2008, Mahmoudi et al. 2009). High levels of TNIK have also been shown to be required for maximal growth of CRC cell lines with elevated $\mathrm{Wnt} / \beta$-catenin signalling (Shitashige et al. 2010). The positive relationship between the pathway and TNIK is conserved in Xenopus, where primary axis formation and activation of Spemann organizer genes are dependent on TNIK and its kinase activity (Satow et al. 2010). This study demonstrated a $\beta$-catenin-dependent recruitment of TNIK to the siamois and other organizer WREs, consistent with a direct role in Wnt target gene activation (Satow et al. 2010).

At least one other TCF phosphorylation event occurs at Xenopus Wnt targets in early embryogenesis. In Xenopus embryos, TCF3 is phosphorylated in response to $\mathrm{Wnt} / \beta$-catenin signalling (Hikasa et al. 2010). Homeodomain interacting protein kinase 2 (HIPK2) is a major mediator of this Wnt-dependent phosphorylation and requires $\beta$-catenin for this activity. Reduction of HIPK2 reduces TCF3 phosphorylation and inhibits induction of the Spemann organizer (Hikasa et al. 2010). Importantly, expression of a TCF3 variant that cannot be modified by HIPK2 also blocks activation of Wnt targets. Interestingly, HIPK2-dependent phosphorylation of TCF3 by Wnt/ $\beta$-catenin signalling results in a reduction of TCF3 on siamois WRE chromatin (Hikasa et al. 2010). These data support a model where $\beta$-catenin promotes HIPK2 modification of TCF3, which results in removal from the WRE, alleviating the repressive influence of TCF3. HIPK2 also phosphorylates TCFs in human cells (Hikasa \& Sokol 2011), but the functional consequence of this modification awaits further study. In flies, HIPK2 promotes Wg signalling 
through stabilization of Arm (Lee et al. 2009), though modification of TCF/Pan has not been excluded.

One interesting speculation is that HIPK2 and TNIK act in concert to activate Wnt targets in the Xenopus embryo. $\beta$-catenin allows HIPK2 to phosphorylate TCF3, removing it from the WRE (Hikasa et al. 2010). At the same time, $\beta$-catenin recruits TNIK to TCF4, which somehow allows the TCF4- $\beta$-catenin complex to activate transcription (Satow et al. 2010). In this way, $\beta$-catenin could affect a swap of the TCFs that mediate repression and activation respectively. Recently, it has been shown for Vent2, a Wnt target in ventral Xenopus blastomeres, that pathway activation results in a replacement of TCF3 by TCF1 on the Vent 2 regulatory region (Hikasa \& Sokol 2011). Since TCF3 represses and TCF1 activates Vent2 expression (Hikasa \& Sokol 2011), this study provides the first direct support for a 'TCF switch' model where Wnt/ $\beta$-catenin signalling promotes a physical change of distinct TCFs (Fig. 7C). Whether other kinases such as TNIK are involved in this switch remains to be examined.

\section{Combinatorial interactions of TCFs and other transcription factors}

Given the flexibility of what constitutes a HMG binding site, it is likely that this interaction is not sufficient for TCFs to distinguish WREs from non-functional binding sites that occur throughout the genome. Indeed, this appears to be the case in Drosophila, where bipartite binding to WREs occurs through HMG domain-HMG site and C-clamp-Helper site interactions (Chang et al. 2008b). While the conservation of the C-clamp among invertebrates (Figs 2 and 8) suggests that this strategy may be prevalent in these organisms, what about the situation in vertebrates, where most vertebrate TCF isoforms do not possess a C-clamp? In this section, several transcription factors are discussed that interact with TCFs and/or $\beta$-catenin and appear to act cooperatively with TCFs to bind to regulatory elements.

One family of transcription factors that interact with TCFs on cis-regulatory elements are the Smads, which mediate many aspects of TGF- $\beta$ signalling (Moustakas $\&$ Heldin 2009). The Wnt/ $\beta$-catenin and TGF- $\beta$ pathways cross-talk at several levels (Eivers et al. 2009, Itasaki \& Hoppler 2010) and this review will limit the discussion to reports where both pathways appear to assemble Smad-TCF- $\beta$-catenin complexes on cis-acting regulatory elements. This was first shown for the regulatory region of the twin gene in Xenopus embryos (Nishita et al. 2000) and mammalian cells (Labbe et al. 2000). In both contexts, both Smad and HMG binding sites were required for maximal activation of reporter constructs by $\mathrm{Wnt} / \beta$-catenin and TGF- $\beta$ signalling. The HMG domain of LEF1 can directly interact with Smad
3 or Smad 4 (Labbe et al. 2000, Nishita et al. 2000). These results suggest a model where a combination of protein-DNA interactions and protein-protein interactions can promote the formation of a Smad-TCF- $\beta$ catenin complex in a signalling-dependent manner (Fig. 10B).

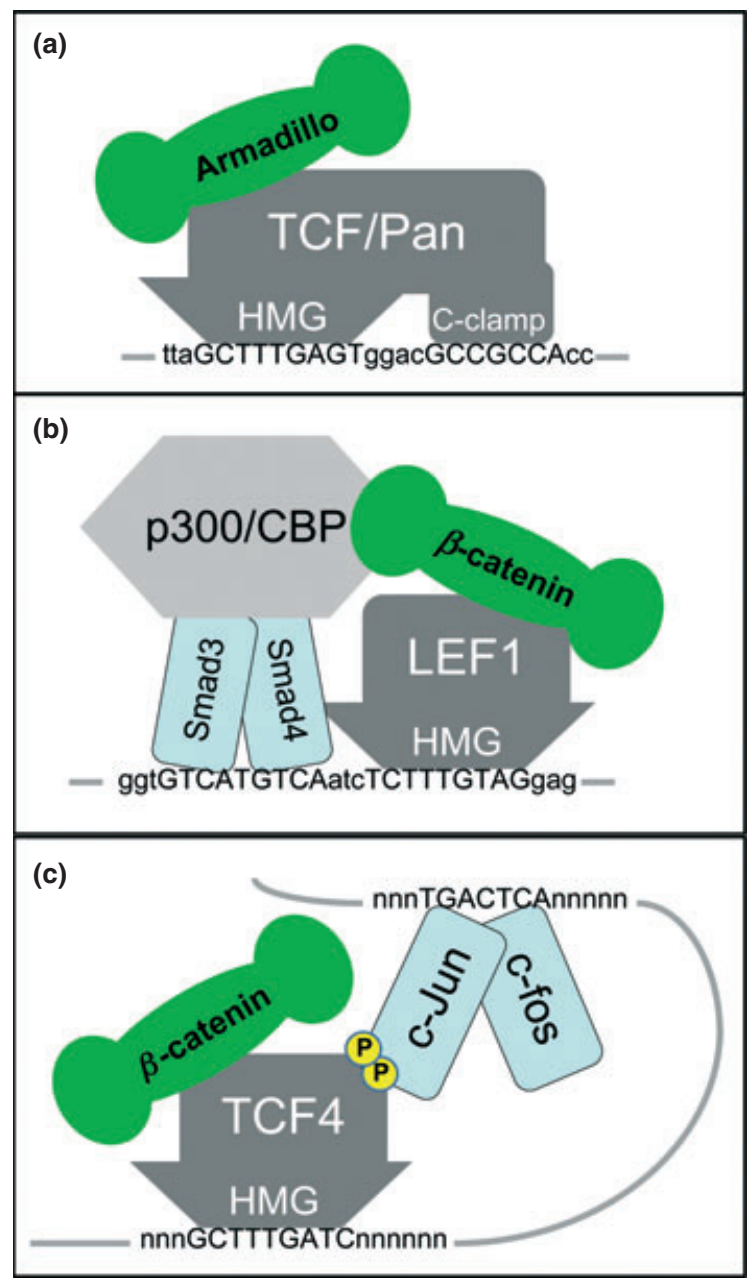

Figure 10 Three different mechanisms that contribute to TCF target selection in the nucleus. (a) Bipartite binding of TCF/Pan with HMG domain-HMG site and C-clamp-Helper site interactions at a binding site in the intronic WRE from $n k d$ (Chang et al. 2008b). This strategy increases the TCF recognition site to approx. 16 basepairs. (b) Combinatorial binding between LEF1 and a Smad heterodimer on the twin WRE in Xenopus (Labbe et al. 2000, Nishita et al. 2000). The adjacent location of the Smad and TCF binding site again increases the amount of basepairs required for binding. Smads and $\beta$-catenin are also thought to cooperate in recruiting $\mathrm{p} 300 / \mathrm{CBP}$ to TGF $\beta$ regulated WREs (Lei et al. 2004). (c) In the case of the c-jun and $c-m y c$ regulatory regions, the TCF and AP-1 sites are not near each other (Nateri et al. 2005, Yochum et al. 2008), suggesting a model where DNA looping is stabilized by interactions between c-Jun and TCF. TCF, T-cell factor; HMG, high mobility group; WRE, Wnt response elements; LEF, lymphoid enhancer-binding factor. 
Since these initial reports, other genes have been identified that are co-regulated by TCFs and Smads. Most of these studies are in the context of cell culture, with regulatory elements from the Msx2 (Hussein et al. 2003), c-myc (Hu \& Rosenblum 2005), gastrin (Lei et al. 2004, Chakladar et al. 2005), Sm22a (Shafer \& Towler 2009), TMEPA1 (Nakano et al. 2010) and several osteogenic genes (Rodriguez-Carballo et al. 2011). But the existence of functional Smad and TCF binding sites in close proximity to each other has also been found in Emx2 elements active in the developing CNS of the mouse (Theil et al. 2002, Suda et al. 2010). While these studies mostly relied on reporter constructs, there is some ChIP data to suggest that $\mathrm{Wnt} / \beta$-catenin signalling can increase Smad recruitment to regulatory chromatin (Hussein et al. 2003, Shafer \& Towler 2009). Conversely, TGF- $\beta$ signalling can recruit LEF-1 or TCF4 to chromatin as well (Hussein et al. 2003, Nakano et al. 2010). The presence of both Smad and $\beta$-catenin on the chromatin has been proposed to increase binding for the histone acetyltransferases $\mathrm{CBP} / \mathrm{p} 300$, leading to increased histone acetylation and transcription (Lei et al. 2004, Rodriguez-Carballo et al. 2011) (Fig. 10B).

Another transcription factor linked with TCF- $\beta$-catenin transcriptional activation is c-Jun, a basic leucine zipper domain protein that can bind DNA specifically as a homodimer or as a heterodimer with c-fos (constituting AP-1) (Shaulian \& Karin 2002). In CRC cells, c-Jun, TCF4 and $\beta$-catenin cooperated in activating the c-Jun expression (Nateri et al. 2005). Phosphorylated c-Jun was found to associate with TCF4 and both transcription factors occupy the c-Jun regulatory region (Nateri et al. 2005). These data complement genetic interaction studies in the mouse intestine to support a model, where Wnt/ $\beta$-catenin signalling acts with $\mathrm{c}$-Jun in a positive feedback loop to promote carcinogenesis (Nateri et al. 2005, Sancho et al. 2009). In contrast to most of the elements co-regulated by TCF and Smad, the distance of the functional TCF and AP-1 site suggests the existence of a DNA loop stabilized by protein-protein and protein-DNA interactions (Fig. 10C).

While, the Wnt/ $\beta$-catenin-c-Jun autoregulatory loop may be crucial for intestinal cancer in mice and CRC in humans, additional evidence suggests that many Wnt transcriptional targets in CRC cells are co-regulated by TCF4 and c-Jun. The c-myc WRE located downstream of the $c-m y c$ gene (Fig. 6) contains a functional AP-1 site that is required for synergistic activation between the $\mathrm{Wnt} / \beta$-catenin pathway and serum-derived mitogens (Yochum et al. 2008). A genome-wide survey of chromatin sites with $\beta$-catenin enrichment revealed that $40 \%$ of the $\beta$-catenin bound regions contain both TCF and AP-1 binding sites (Bottomly et al. 2010). More than a dozen sites were bound by TCF4, $\beta$-catenin and $c$-Jun. As previously shown for $c-m y c$, the activation of several Wnt targets were enhanced by serum in CRC cells arrested in $G_{0} / G_{1}$ (Bottomly et al. 2010). The connection between Wnt/ $\beta$-catenin signalling and cell cycle progression has also been noted further upstream in the pathway (Davidson \& Niehrs 2010).

The Wnt/ $\beta$-catenin pathway-c-Jun connection has also been observed outside the context of intestinal cells and CRC. Regulatory elements controlling either the matrilysin gene in kidney or the versican gene in melanoma require both TCF and AP-1 sites (Rivat et al. 2003, Domenzain-Reyna et al. 2009). In addition, interactions between TCF4 and c-Jun (Gan et al. 2008 ) or $\beta$-catenin and the AP-1 complex (Toualbi et al. 2007) can regulate Wnt targets independent of AP-1 binding sites, though whether this type of regulation occurs under physiological conditions is not clear.

The Smad and c-Jun/AP-1 studies described above are examples where distinct signalling pathways and Wnt/ $\beta$-catenin signalling converge on regulatory elements to activate transcription. Such combinatorial control of Wnt targets can also occur through interactions with transcription factors not directly controlled by cell-cell signalling. One candidate for such factors is the Cdx family of homeodomain proteins. As outlined in a previous section, $c d x 1$ and $c d x 4$ are known to be direct transcriptional targets of the $\mathrm{Wnt} / \beta$-catenin pathway (Lickert et al. 2000, Ikeya \& Takada 2001, Pilon et al. 2006). In addition, there is some developmental genetic data suggesting that the TCF- $\beta$-catenin complex may functionally interact with $\mathrm{Cdx}$ proteins (Young et al. 2009). Indeed, Cdx1 autoregulation has been shown to require a Cdx1-LEF1- $\beta$-catenin complex, through direct interactions between the homeodomain and HMG domains (Beland et al. 2004). More recently, a genome-wide survey of $\mathrm{Cdx} 2$ binding in intestinal cell lines revealed a significant overlap between $\mathrm{Cdx} 2$ and TCF4 chromatin bound regions (Verzi et al. 2010). TCF4 binding to chromatin was found to be partially dependent on Cdx2 at several locations (Verzi et al. 2010). Interestingly, nested TCF-Cdx binding sites have been shown to be required for an intronic raldh2 enhancer that is active in the dorsal spinal cord of the chick (Castillo et al. 2010).

There are other examples of TCFs interacting with other transcription factors to regulate gene expression. LEF1 and microphthalmia-associated transcription factor are thought to physically interact to regulate gene expression in melanocyte differentiation (Yasumoto et al. 2002). Likewise, LEF1 and the homeodomain protein Pitx2 may interact in the developing dental epithelium and other tissues (Amen et al. 2007). The short list of transcription factors that interact with TCFs discussed here is likely only the tip of the iceberg. The 
genome-wide studies of TCF4 binding patterns have found an enrichment for many other transcription factor binding sites besides AP-1, including NF1, PPAR $\gamma$, HNF4, Elk-1, GATA3, c-Ets-1, Bach-1 and FoxD-1 (Hatzis et al. 2008, Blahnik et al. 2010). TCF-protein interactions may be the normative mechanism to locate WREs in the information rich nucleus, though the binding partner is likely to be different for different targets. It should also be noted that while the mechanisms described above have been assumed to operate for TCFs lacking C-clamps, they may also function to facilitate target gene location of C-clamp containing TCFs. It seems likely that multiple mechanisms acting in concert are required for TCFs to locate WREs in the genome.

\section{TCF-independent recruitment of $\beta$-catenin to Wnt targets}

TCFs are clearly the best characterized transcription factors that mediate the regulation of gene expression via $\mathrm{Wnt} / \beta$-catenin signalling. In addition to TCFs, there are several other DNA-binding proteins that have been shown to bind to $\beta$-catenin and effect transcriptional responses. Many nuclear receptors, including the oestrogen and androgen receptors bind $\beta$-catenin and co-regulate targets of these hormones, as reviewed elsewhere (Mulholland et al. 2005, Beildeck et al. 2010). In this section, we discuss other transcription factors that serve as recruiters for nuclear $\beta$-catenin and how they may contribute to the enormous diversity of transcriptional outputs that are generated by the Wnt/ $\beta$-catenin pathway.

To conclude that a transcription factor is sufficient to recruit $\beta$-catenin to a regulatory element, the factor must bind and co-regulate targets with $\beta$-catenin. This is the case for Sox17, which regulates endodermal genes during vertebrate gastrulation. $\beta$-catenin augments Sox17's ability to activate target genes and the two proteins physically interact (Sinner et al. 2004). However, a role for TCFs in this process was not ruled out and in CRC cells, Sox17 has also been shown to interact with TCFs and promote their degradation (Sinner et al. 2007). In another case, the homeodomain protein Prop1 and $\beta$-catenin are both required for Pit1 expression in the developing mouse pituitary gland (Olson et al. 2006). These proteins directly interact and are co-localized on Pit1 regulatory chromatin. LEF1 is not required for Pit 1 expression, but other TCF family members were not examined (Olson et al. 2006). PitX2 can also bind to $\beta$-catenin and bring it to the cyclin D2 promoter in mouse myoblast cells (Kioussi et al. 2002). A synthetic enhancer containing multimerized PitX2 sites is activated in a $\beta$-catenin-dependent manner, suggesting that PitX2 is sufficient for recruiting $\beta$-catenin to DNA
(Kioussi et al. 2002). It should be pointed out that PitX2 can also bind LEF1, suggesting that it sometimes works with TCFs to regulate Wnt targets (Vadlamudi et al. 2005, Amen et al. 2007).

One approach to rule out a role for TCFs in the activation of target genes by $\beta$-catenin is the use of dominant negative constructs of TCF (dnTCF) that cannot bind $\beta$-catenin. When expressed at sufficient levels, such constructs should prevent the binding of endogenous TCFs to regulatory elements (Behrens et al. 1996, Molenaar 1996, van de Wetering et al. 1997, Kratochwil et al. 2002). In cultured myoblasts, $\beta$-catenin is required for the bHLH protein MyoD to activate muscle specific genes (Kim et al. 2008). The presence of high levels of $\beta$-catenin enhanced MyoD binding to myogenic elements, presumably through direct binding. This regulation was not affected by expression of dnTCF (Kim et al. 2008). dnTCF also did not block the ability of $\beta$-catenin to augment transcriptional activation of hypoxia inducible factor $1 \alpha$ (HIF1 $\alpha$ ) (Kaidi et al. 2007).

In CRC cells with high endogenous levels of $\beta$-catenin, hypoxia (which dramatically increases HIF1 $\alpha$ levels) results in a shift of $\beta$-catenin away from the classic Wnt target $c-m y c$ towards HIF1 $\alpha$ targets (Kaidi et al. 2007). It should be noted that this effect is cell specific, since in several stem cells, hypoxia activates Wnt $/ \beta$-catenin signalling by HIF $1 \alpha$-dependent induction of LEF1 and TCF1 transcription and $\beta$-catenin protein levels (Mazumdar et al. 2010). In these cells, sufficient $\beta$-catenin is thought to allow both types of transcription factors to activate target genes (Mazumdar et al. 2010).

Another example where a stress-induced factor can divert $\beta$-catenin away from TCFs is the FOXO family of Forkhead domain transcription factors. FOXO proteins can directly bind $\beta$-catenin and use it to activate gene expression in $C$. elegans and mammalian cells (Essers et al. 2005). Induction of FOXO protein levels during oxidative stress reduces TCF-dependent gene expression, due to competition for limiting levels of $\beta$-catenin (Almeida et al. 2007, Hoogeboom et al. 2008).

How important are non-TCFs in mediating Wnt/ $\beta$-catenin signalling during normal development? In cnidarians, the only functional data thus far on TCFs suggests that in Hydra, TCF is absolutely required for Wnt-dependent head regeneration (Duffy et al. 2010). In Drosophila, Tcf/pan mutants clearly are qualitatively similar to wg mutants (Brunner et al. 1997, van de Wetering et al. 1997, Schweizer et al. 2003), but it is not clear that it is required for all Wg signalling. In vertebrates, the role of TCFs is much more difficult to assess, given the likely redundancy between the four TCFs. While the available data suggests that vertebrates TCFs play a major role in mediating $\mathrm{Wnt} / \beta$-catenin 
signalling, the sum of all other transcription factors recruiting $\beta$-catenin to Wnt target genes may ultimately be much more significant than currently appreciated.

\section{Direct transcriptional repression by $\beta$-catenin}

This review has focused exclusively on the ability of $\beta$-catenin to activate transcription, which is reasonable considering the large pile of evidence for such a role. But it is worth noting that $\mathrm{Wnt} / \beta$-catenin signalling leads to down-regulation of gene expression about as often as activating genes (van de Wetering et al. 2002, Jung \& Kim 2005, Naishiro et al. 2005, Klapholz-Brown et al. 2007). Because of the pathway's obvious role in activation, it is usually assumed that these genes are indirectly repressed by $\mathrm{Wnt} / \beta$-catenin signalling, that is, the pathway activates a repressor that then inhibits another genes expression. While this no doubt occurs, there are a growing number of cases where $\beta$-catenin is thought to directly mediate repression through TCF family members. This is distinct from the well-known repressive role of TCFs in the absence of signalling that has been previously discussed.

What are the experimental criteria for determining that a target is directly repressed by $\mathrm{Wnt} / \beta$-catenin signalling? A straightforward approach is to monitor target gene expression when the pathway is activated in cells treated with protein synthesis inhibitors. While, this is straightforward for many pathways, for example, TGF $\beta$ (Kang et al. 2003), it is problematic for Wnt/ $\beta$-catenin signalling, given the requirement for new synthesis of $\beta$-catenin once its degradation is blocked (see Fig. 1). There are hormone-inducible versions of $\beta$-catenin, created by fusing portions of a nuclear receptor to $\beta$-catenin, and these have been used to determine activation of targets in the presence of protein synthesis inhibitors (Li et al. 2009, Elkouby et al. 2010). But these reagents can be tricky to utilize for identifying direct targets of repression (Blauwkamp et al. 2008).

In lieu of this approach, researchers have used a combination of site-directed mutagenesis of TCF binding sites in repressed cis-regulatory elements to provide support for direct regulation. In flies, such studies have shown that WREs from the stripe and $d p p$ genes contain TCF sites that are absolutely required for repression (Piepenburg et al. 2000, Theisen et al. 2007). In cell culture, a luciferase reporter has been used in a similar way to demonstrate that $\mathrm{Wnt} / \beta$-catenin signalling directly represses E-cadherin in keratinocytes (Jamora et al. 2003), and p16INK4a in melanoma (Delmas et al. 2007). In these cases, ChIP was also employed to demonstrate that TCF and $\beta$-catenin were physically present on the repressed WREs (Jamora et al. 2003, Delmas et al. 2007).
What is known about the mechanism of these examples of TCF- $\beta$-catenin repression? For the stripe WRE, the functional TCF binding site overlaps with a binding site for Cubitus Interruptis (Ci), which is crucial for activation of stripe in embryos (Piepenburg et al. 2000). This suggests that TCF/Pan-Arm may displace the $\mathrm{Ci}$ activator. In the case of $d p p$, Brinker binds to the WRE and somehow acts with TCF/Pan-Arm to mediate repression in the leg imaginal disc (Theisen et al. 2007). In keratinocytes, LEF1- $\beta$-catenin works additively with the Snail repressor to inhibit E-cadherin transcription (Jamora et al. 2003). It is not clear in these cases or that of pINK16a where the specificity lies that allows TCF$\beta$-catenin to repress, rather than activate, gene expression.

Another example of direct repression by the pathway occurs in cultured hemocytic cells in Drosophila, where Wg/Arm signalling represses expression of Ugt36Bc, an enzyme deposited in the extracellular matrix (Blauwkamp et al. 2008). TCF/Pan is enriched in the same region upstream of the $U g t 36 B c$ TSS that contains a WRE that is repressed by the pathway. This WRE was localized to a $178 \mathrm{bp}$ region that contained no classic TCF binding sites. However, footprinting revealed the existence of three TCF sites, which share a consensus of AGAWAW. These sites are functional, mediating activation of the WRE in the absence of signalling and Armdependent repression (Blauwkamp et al. 2008). Thus, $U g t 36 B c$ is regulated by a 'reverse transcriptional switch' compared with the classic switch depicted in Fig. 1.

The existence of novel TCF binding sites in the Ugt reporter suggested that the nature of the binding site contained the specificity for the transcriptional output. Support for this came from an experiment where the novel sites were converted to classic ones. Strikingly, this altered WRE was now activated in response to Wg/ Arm signalling (Blauwkamp et al. 2008). The possibility of allosteric regulation of TCFs by DNA is supported by structural analysis of the LEF1 HMG domain alone and when complexed with a high affinity binding site. When the HMG is not bound by DNA, it is partially unstructured, particularly helix 1. Upon DNA binding, the HMG domain is converted to a well-folded, highly ordered state (Love et al. 2004). It would not be surprising if different DNA-binding sites could influence the conformation of TCF, which could then influence the recruitment of co-activators or co-repressors by $\beta$-catenin/Arm.

Another clue to the mechanism of TCF/Arm direct repression was found through mutagenesis of the Arm gene. Deletion or mutation of portions of Arm known to be involved in transcriptional activation created a variant called DisArmed. Consistent with the alterations, DisArmed could not regulate several WREs that 
are activated by the pathway (Blauwkamp et al. 2008). However it could still efficiently repress Ugt36Bc expression and the $U g t$ reporter. In addition, DisArmed could repress several other downregulated Wg targets in cultured cells and fly hemocytes, suggesting that they also are directly repressed by TCF/Pan-Arm (Blauwkamp et al. 2008).

As is the case with activated Wnt targets, there are also reports of non-TCF proteins utilizing $\beta$-catenin to repress gene expression. The best studied is the homeodomain protein Prop1, discussed earlier as a transcription factor that binds $\beta$-catenin to activate transcription (Olson et al. 2006). Like TCFs, it can also do the opposite, recruiting $\beta$-catenin to a regulatory element controlling another transcription factor called Hesx1 (Olson et al. 2006). This repression requires reptin, a transcriptional co-repressor (Olson et al. 2006). The antimetastasis gene KAI1 is also repressed by a complex containing $\beta$-catenin and Reptin, but the DNA-binding transcription factor is not known (Kim et al. 2005). Interestingly, Reptin is known to bind to $\beta$-catenin/Arm in a region that is not altered in the DisArmed protein (Bauer et al. 2000), though it is not known whether fly Reptin is involved in Ugt36Bc repression by Wg/Arm signalling.

As with other variations from the classic regulatory mechanism outlined in Fig. 1, it is not yet clear how often direct repression by $\beta$-catenin occurs, either through TCFs or other transcription factors. Is it a rarity that plays only a small role in transcriptional regulation by the $\mathrm{Wnt} / \beta$-catenin pathway? Or has the focus on transcriptional activation and classic TCF binding sites obscured a currently underappreciated aspect of Wnt gene regulation? Clearly more research in this area is required to find out.

\section{Conclusions}

The first detailed characterizations of Wg/Arm signalling already revealed what is now a common assumption, that this single pathway has a remarkable number of roles during fly development (Baker 1988, Peifer et al. 1991). The appreciation of $\mathrm{Wnt} / \beta$-catenin signalling diversity has only grown in the past twenty years, and this review has only covered a small fraction of the established roles of the pathway in metazoan development. How is this diversity achieved? In vertebrates, differences among the TCF family members and the large number of other transcription factors that recruit $\beta$-catenin to WREs is likely part of the answer. But in flies, it thus far appears that a single TCF mediates most, if not all of the Wg/Arm pathway's effects (Brunner et al. 1997, van de Wetering et al. 1997, Schweizer et al. 2003). Combinatorial inputs from other signalling pathways certainly provide an answer for why some WREs are activated in a cell-specific manner, for example, eve in cardiac mesoderm (Halfon et al. 2000, Lee \& Frasch 2000, Knirr \& Frasch 2001, Han et al. 2002). Other mechanisms, for example, cellspecific chromatin accessibility, are thought to occur (Wohrle et al. 2007), but remain relatively unexplored.

Despite the challenge of understanding the complexities of Wg target gene regulation, our current knowledge is detailed enough so that it can be exploited to further understand how this pathway controls development. The realization of an ancient posterior Wnt signalling gradient throughout metazoans (Petersen \& Reddien 2009, Niehrs 2010), provides one example. For cnidarians, we think it likely that the potentially important targets (e.g. Brachyury) will be bound by TCFs by a similar bipartite mechanism as has been shown to operate in Drosophila (Chang et al. 2008b), given the presence of highly conserved HMG and C-clamp domains in cnidarians (Figs 2 and 8). Using information from other systems may allow the dissection of the genetic networks in great detail, complementing the careful analysis of regulatory factors that are expressed temporally downstream of Wnts, exemplified by the study of the amphibian NC (Li et al. 2009, Elkouby et al. 2010) (Fig. 4). Perhaps in the near future, a combination of genome-wide surveys, WRE identification through bioinformatics and informed examination of candidate target genes can identify important targets relatively quickly in many developmental systems.

This dynamic can be observed in the study of the Wnt/ $\beta$-catenin pathway in CRC. The identification of a WRE more than $335 \mathrm{~kb}$ removed from the c-myc TSS could have only been achieved with a combination of genomic approaches and a recognition of what constitutes a TCF binding site (Pomerantz et al. 2009, Tuupanen et al. 2009, Sotelo et al. 2010, Wright et al. 2010) (Fig. 6). Optimization of these approaches should facilitate the identification of relevant targets for the many other pathologies that $\mathrm{Wnt} / \beta$-catenin signalling has now been linked to.

Despite intense effort over the past 15 years, there is much to learn about how TCFs (and other transcription factors) transform elevated levels of nuclear $\beta$-catenin into the appropriate transcriptional responses in a cell, tissue and temporally specific manner. The vast size of metazoan genomes and the great distances over which WREs can operate make this task even more daunting. Given the importance of this pathway in normal development and physiology as well as numerous pathologies, it's clear that further investigation is worth the effort.

\section{Conflict of interest}

The authors declare that they have no conflict of interest. 
This work was support by grants from the NIH (RO1 GM082994) and NSF (090348) to KMC. HCA is supported by NIH training grant T32-GM07315.

\section{References}

Adamska, M., Larroux, C., Adamski, M., Green, K., Lovas, E., Koop, D., Richards, G.S., Zwafink, C. \& Degnan, B.M. 2010. Structure and expression of conserved Wnt pathway components in the demosponge Amphimedon queenslandica. Evol Dev 12, 494-518.

Afouda, B.A., Martin, J., Liu, F., Ciau-Uitz, A., Patient, R. \& Hoppler, S. 2008. GATA transcription factors integrate Wnt signalling during heart development. Development 135, 3185-3190.

Ai, D., Fu, X., Wang, J., Lu, M.F., Chen, L., Baldini, A., Klein, W.H. \& Martin, J.F. 2007. Canonical Wnt signaling functions in second heart field to promote right ventricular growth. Proc Natl Acad Sci USA 104, 9319-9324.

Alfieri, C.M., Cheek, J., Chakraborty, S. \& Yutzey, K.E. 2010. Wnt signaling in heart valve development and osteogenic gene induction. Dev Biol 338, 127-135.

Almeida, M., Han, L., Martin-Millan, M., O’Brien, C.A. \& Manolagas, S.C. 2007. Oxidative stress antagonizes Wnt signaling in osteoblast precursors by diverting beta-catenin from $\mathrm{T}$ cell factor- to forkhead box O-mediated transcription. J Biol Chem 282, 27298-27305.

Amen, M., Liu, X., Vadlamudi, U., Elizondo, G., Diamond, E., Engelhardt, J.F. \& Amendt, B.A. 2007. PITX2 and betacatenin interactions regulate Lef-1 isoform expression. $\mathrm{Mol}$ Cell Biol 27, 7560-7573.

Arce, L., Yokoyama, N.N. \& Waterman, M.L. 2006. Diversity of LEF/TCF action in development and disease. Oncogene $25,7492-7504$.

Armengol, C., Cairo, S., Fabre, M. \& Buendia, M.A. 2009. Wnt signaling and hepatocarcinogenesis: the hepatoblastoma model. Int J Biochem Cell Biol 43, 265-270.

Atcha, F.A., Munguia, J.E., Li, T.W., Hovanes, K. \& Waterman, M.L. 2003. A new beta-catenin-dependent activation domain in T cell factor. J Biol Chem 278, 16169-16175.

Atcha, F.A., Syed, A., Wu, B., Hoverter, N.P., Yokoyama, N.N., Ting, J.H., Munguia, J.E., Mangalam, H.J., Marsh, J.L. \& Waterman, M.L. 2007. A unique DNA binding domain converts T-cell factors into strong Wnt effectors. Mol Cell Biol 27, 8352-8363.

Aulehla, A., Wehrle, C., Brand-Saberi, B., Kemler, R., Gossler, A., Kanzler, B. \& Herrmann, B.G. 2003. Wnt3a plays a major role in the segmentation clock controlling somitogenesis. Dev Cell 4, 395-406.

Baker, N.E. 1988. Embryonic and imaginal requirements for wingless, a segment-polarity gene in Drosophila. Dev Biol 125, 96-108.

Baker, N.E. 2007. Patterning signals and proliferation in Drosophila imaginal discs. Curr Opin Genet Dev 17, 287-293.

Balmelle, N., Zamarreno, N., Krangel, M.S. \& HernandezMunain, C. 2004. Developmental activation of the TCR alpha enhancer requires functional collaboration among proteins bound inside and outside the core enhancer. J Immunol 173, 5054-5063.
Barembaum, M. \& Bronner-Fraser, M. 2005. Early steps in neural crest specification. Semin Cell Dev Biol 16, 642-646.

Barker, N. \& Clevers, H. 2010. Leucine-rich repeat-containing G-protein-coupled receptors as markers of adult stem cells. Gastroenterology 138, 1681-1696.

Barolo, S. 2006. Transgenic Wnt/TCF pathway reporters: all you need is Lef? Oncogene 25, 7505-7511.

Bauer, A., Chauvet, S., Huber, O., Usseglio, F., Rothbacher, U., Aragnol, D., Kemler, R. \& Pradel, J. 2000. Pontin52 and reptin52 function as antagonistic regulators of beta-catenin signalling activity. $E M B O J$ 19, 6121-6130.

van Beest, M., Dooijes, D., van De Wetering, M., Kjaerulff, S., Bonvin, A., Nielsen, O. \& Clevers, H. 2000. Sequencespecific high mobility group box factors recognize 10-12base pair minor groove motifs. J Biol Chem 275, 27266-27273.

Behrens, J., von Kries, J.P., Kuhl, M., Bruhn, L., Wedlich, D., Grosschedl, R. \& Birchmeier, W. 1996. Functional interaction of beta-catenin with the transcription factor LEF-1. Nature 382, 638-642.

Beildeck, M.E., Gelmann, E.P. \& Byers, S.W. 2010. Crossregulation of signaling pathways: an example of nuclear hormone receptors and the canonical Wnt pathway. Exp Cell Res 316, 1763-1772.

Beland, M., Pilon, N., Houle, M., Oh, K., Sylvestre, J.R., Prinos, P. \& Lohnes, D. 2004. Cdx1 autoregulation is governed by a novel Cdx1-LEF1 transcription complex. Mol Cell Biol 24, 5028-5038.

Bischoff, M. \& Schnabel, R. 2006. A posterior centre establishes and maintains polarity of the Caenorhabditis elegans embryo by a Wnt-dependent relay mechanism. PLoS Biol 4, e396.

Blahnik, K.R., Dou, L., O'Geen, H., McPhillips, T., Xu, X., Cao, A.R., Iyengar, S., Nicolet, C.M., Ludascher, B., Korf, I. \& Farnham, P.J. 2010. Sole-Search: an integrated analysis program for peak detection and functional annotation using ChIP-seq data. Nucleic Acids Res 38, e13.

Blanpain, C. \& Fuchs, E. 2009. Epidermal homeostasis: a balancing act of stem cells in the skin. Nat Rev Mol Cell Biol 10, 207-217.

Blanpain, C., Horsley, V. \& Fuchs, E. 2007. Epithelial stem cells: turning over new leaves. Cell 128, 445-458.

Blauwkamp, T.A., Chang, M.V. \& Cadigan, K.M. 2008. Novel TCF-binding sites specify transcriptional repression by Wnt signalling. EMBO J 27, 1436-1446.

Bodmer, R. \& Venkatesh, T.V. 1998. Heart development in Drosophila and vertebrates: conservation of molecular mechanisms. Dev Genet 22, 181-186.

Bottomly, D., Kyler, S.L., McWeeney, S.K. \& Yochum, G.S. 2010. Identification of \{beta\}-catenin binding regions in colon cancer cells using ChIP-Seq. Nucleic Acids Res 38, 5735-5745.

Brannon, M., Gomperts, M., Sumoy, L., Moon, R.T. \& Kimelman, D. 1997. A beta-catenin/XTcf-3 complex binds to the siamois promoter to regulate dorsal axis specification in Xenopus. Genes Dev 11, 2359-2370.

Brocardo, M. \& Henderson, B.R. 2008. APC shuttling to the membrane, nucleus and beyond. Trends Cell Biol 18, 587596. 
Broun, M., Gee, L., Reinhardt, B. \& Bode, H.R. 2005. Formation of the head organizer in hydra involves the canonical Wnt pathway. Development 132, 2907-2916.

Brunner, E., Peter, O., Schweizer, L. \& Basler, K. 1997. Pangolin encodes a Lef-1 homologue that acts downstream of Armadillo to transduce the Wingless signal in Drosophila. Nature 385, 829-833.

Cadigan, K.M. 2008. Wnt-beta-catenin signaling. Curr Biol 18, R943-R947.

Cadigan, K.M. \& Peifer, M. 2009. Wnt signaling from development to disease: insights from model systems. Cold Spring Harb Perspect Biol 1, a002881.

Cai, C.L., Liang, X., Shi, Y., Chu, P.H., Pfaff, S.L., Chen, J. \& Evans, S. 2003. Isl1 identifies a cardiac progenitor population that proliferates prior to differentiation and contributes a majority of cells to the heart. Dev Cell 5, 877-889.

Carlsson, P., Waterman, M.L. \& Jones, K.A. 1993. The hLEF/ TCF-1 alpha HMG protein contains a context-dependent transcriptional activation domain that induces the TCR alpha enhancer in T cells. Genes Dev 7, 2418-2430.

Castillo, H.A., Cravo, R.M., Azambuja, A.P., Simoes-Costa, M.S., Sura-Trueba, S., Gonzalez, J., Slonimsky, E., Almeida, K., Abreu, J.G., de Almeida, M.A. et al. 2010. Insights into the organization of dorsal spinal cord pathways from an evolutionarily conserved raldh2 intronic enhancer. Development 137, 507-518.

Cavallo, R.A., Cox, R.T., Moline, M.M., Roose, J., Polevoy, G.A., Clevers, H., Peifer, M. \& Bejsovec, A. 1998. Drosophila Tcf and Groucho interact to repress Wingless signalling activity. Nature 395, 604-608.

Cha, S.W., Tadjuidje, E., Tao, Q., Wylie, C. \& Heasman, J. 2008. Wnt5a and Wnt11 interact in a maternal Dkk1-regulated fashion to activate both canonical and non-canonical signaling in Xenopus axis formation. Development 135, 3719-3729.

Chacon, M.A., Varela-Nallar, L. \& Inestrosa, N.C. 2008. Frizzled-1 is involved in the neuroprotective effect of Wnt3a against Abeta oligomers. J Cell Physiol 217, 215-227.

Chakladar, A., Dubeykovskiy, A., Wojtukiewicz, L.J., Pratap, J., Lei, S. \& Wang, T.C. 2005. Synergistic activation of the murine gastrin promoter by oncogenic Ras and beta-catenin involves SMAD recruitment. Biochem Biophys Res Commun 336, 190-196.

Chamorro, M.N., Schwartz, D.R., Vonica, A., Brivanlou, A.H., Cho, K.R. \& Varmus, H.E. 2005. FGF-20 and DKK1 are transcriptional targets of beta-catenin and FGF-20 is implicated in cancer and development. EMBO J 24, 73-84.

Chang, J.L., Chang, M.V., Barolo, S. \& Cadigan, K.M. 2008a. Regulation of the feedback antagonist naked cuticle by Wingless signaling. Dev Biol 321, 446-454.

Chang, M.V., Chang, J.L., Gangopadhyay, A., Shearer, A. \& Cadigan, K.M. 2008b. Activation of wingless targets requires bipartite recognition of DNA by TCF. Curr Biol 18, 1877-1881.

Chen, S., McLean, S., Carter, D.E. \& Leask, A. 2007. The gene expression profile induced by Wnt $3 \mathrm{a}$ in NIH $3 \mathrm{~T} 3$ fibroblasts. J Cell Commun Signal 1, 175-183.

Chera, S., Ghila, L., Dobretz, K., Wenger, Y., Bauer, C., Buzgariu, W., Martinou, J.C. \& Galliot, B. 2009. Apoptotic cells provide an unexpected source of Wnt3 signaling to drive hydra head regeneration. Dev Cell 17, 279-289.

Clevers, H. 2006. Wnt/beta-catenin signaling in development and disease. Cell 127, 469-480.

Cohen, P. \& Goedert, M. 2004. GSK3 inhibitors: development and therapeutic potential. Nat Rev Drug Discov 3, 479-487.

Cohen, E.D., Wang, Z., Lepore, J.J., Lu, M.M., Taketo, M.M., Epstein, D.J. \& Morrisey, E.E. 2007. Wnt/beta-catenin signaling promotes expansion of Isl-1-positive cardiac progenitor cells through regulation of FGF signaling. J Clin Invest 117, 1794-1804.

Cohen, E.D., Tian, Y. \& Morrisey, E.E. 2008. Wnt signaling: an essential regulator of cardiovascular differentiation, morphogenesis and progenitor self-renewal. Development 135, 789-798.

Cole, M.F., Johnstone, S.E., Newman, J.J., Kagey, M.H. \& Young, R.A. 2008. Tcf3 is an integral component of the core regulatory circuitry of embryonic stem cells. Genes Dev 22, 746-755.

Cox, R.T., McEwen, D.G., Myster, D.L., Duronio, R.J., Loureiro, J. \& Peifer, M. 2000. A screen for mutations that suppress the phenotype of Drosophila armadillo, the betacatenin homolog. Genetics 155, 1725-1740.

Cuilliere-Dartigues, P., El-Bchiri, J., Krimi, A., Buhard, O., Fontanges, P., Flejou, J.F., Hamelin, R. \& Duval, A. 2006. TCF-4 isoforms absent in TCF-4 mutated MSI-H colorectal cancer cells colocalize with nuclear CtBP and repress TCF4-mediated transcription. Oncogene 25, 4441-4448.

DasGupta, R. \& Fuchs, E. 1999. Multiple roles for activated LEF/TCF transcription complexes during hair follicle development and differentiation. Development 126, 45574568.

DasGupta, R., Kaykas, A., Moon, R.T. \& Perrimon, N. 2005. Functional genomic analysis of the Wnt-wingless signaling pathway. Science 308, 826-833.

Davidson, G. \& Niehrs, C. 2010. Emerging links between CDK cell cycle regulators and Wnt signaling. Trends Cell Biol 20, 453-460.

Davidson, A.J. \& Zon, L.I. 2006. The caudal-related homeobox genes cdx $1 \mathrm{a}$ and $\mathrm{cdx} 4$ act redundantly to regulate hox gene expression and the formation of putative hematopoietic stem cells during zebrafish embryogenesis. Dev Biol 292, 506-518.

De Robertis, E.M. \& Kuroda, H. 2004. Dorsal-ventral patterning and neural induction in Xenopus embryos. Annu Rev Cell Dev Biol 20, 285-308.

Delmas, V., Beermann, F., Martinozzi, S., Carreira, S., Ackermann, J., Kumasaka, M., Denat, L., Goodall, J., Luciani, F., Viros, A., Demirkan, N., Bastian, B.C., Goding, C.R. \& Larue, L. 2007. Beta-catenin induces immortalization of melanocytes by suppressing p16INK4a expression and cooperates with N-Ras in melanoma development. Genes Dev 21, 2923-2935.

Domenzain-Reyna, C., Hernandez, D., Miquel-Serra, L., Docampo, M.J., Badenas, C., Fabra, A. \& Bassols, A. 2009. Structure and regulation of the versican promoter: the versican promoter is regulated by AP-1 and TCF transcription factors in invasive human melanoma cells. J Biol Chem 284, 12306-12317. 
Dorsky, R.I., Sheldahl, L.C. \& Moon, R.T. 2002. A transgenic Lef1/beta-catenin-dependent reporter is expressed in spatially restricted domains throughout zebrafish development. Dev Biol 241, 229-237.

Dorsky, R.I., Itoh, M., Moon, R.T. \& Chitnis, A. 2003. Two tcf3 genes cooperate to pattern the zebrafish brain. Development 130, 1937-1947.

Duffy, D.J., Plickert, G., Kuenzel, T., Tilmann, W. \& Frank, U. 2010. Wnt signaling promotes oral but suppresses aboral structures in Hydractinia metamorphosis and regeneration. Development 137, 3057-3066.

Duman-Scheel, M., Johnston, L.A. \& Du, W. 2004. Repression of dMyc expression by Wingless promotes Rbf-induced G1 arrest in the presumptive Drosophila wing margin. Proc Natl Acad Sci USA 101, 3857-3862.

Dunty, W.C. Jr, Biris, K.K., Chalamalasetty, R.B., Taketo, M.M., Lewandoski, M. \& Yamaguchi, T.P. 2008. Wnt3a/ beta-catenin signaling controls posterior body development by coordinating mesoderm formation and segmentation. Development 135, 85-94.

Dyer, L.A. \& Kirby, M.L. 2009. The role of secondary heart field in cardiac development. Dev Biol 336, 137-144.

Eilers, M. \& Eisenman, R.N. 2008. Myc's broad reach. Genes Dev 22, 2755-2766.

Eivers, E., Demagny, H. \& De Robertis, E.M. 2009. Integration of BMP and Wnt signaling via vertebrate Smad1/5/8 and Drosophila Mad. Cytokine Growth Factor Rev 20, 357365.

El Wakil, A. \& Lalli, E. 2011. The Wnt/beta-catenin pathway in adrenocortical development and cancer. Mol Cell Endocrinol 332, 32-37.

Elkouby, Y.M., Elias, S., Casey, E.S., Blythe, S.A., Tsabar, N., Klein, P.S., Root, H., Liu, K.J. \& Frank, D. 2010. Mesodermal Wnt signaling organizes the neural plate via Meis3. Development 137, 1531-1541.

Engleka, M.J. \& Kessler, D.S. 2001. Siamois cooperates with TGFbeta signals to induce the complete function of the Spemann-Mangold organizer. Int J Dev Biol 45, 241-250.

Essers, M.A., de Vries-Smits, L.M., Barker, N., Polderman, P.E., Burgering, B.M. \& Korswagen, H.C. 2005. Functional interaction between beta-catenin and FOXO in oxidative stress signaling. Science 308, 1181-1184.

Evans, S.M. 1999. Vertebrate tinman homologues and cardiac differentiation. Semin Cell Dev Biol 10, 73-83.

Faas, L. \& Isaacs, H.V. 2009. Overlapping functions of Cdx1, $\mathrm{Cdx} 2$, and $\mathrm{Cdx} 4$ in the development of the amphibian Xenopus tropicalis. Dev Dyn 238, 835-852.

Fan, Y. \& Bergmann, A. 2008. Apoptosis-induced compensatory proliferation. The Cell is dead. Long live the Cell! Trends Cell Biol 18, 467-473.

Fan, M.J., Gruning, W., Walz, G. \& Sokol, S.Y. 1998. Wnt signaling and transcriptional control of Siamois in Xenopus embryos. Proc Natl Acad Sci USA 95, 5626-5631.

Fang, M., Li, J., Blauwkamp, T., Bhambhani, C., Campbell, N. \& Cadigan, K.M. 2006. C-terminal-binding protein directly activates and represses Wnt transcriptional targets in Drosophila. EMBO J 25, 2735-2745.

van der Flier, L.G., van Gijn, M.E., Hatzis, P., Kujala, P., Haegebarth, A., Stange, D.E., Begthel, H., van den Born, M.,
Guryev, V., Oving, I., van Es, J.H., Barker, N., Peters, P.J., van de Wetering, M. \& Clevers, H. 2009. Transcription factor achaete scute-like 2 controls intestinal stem cell fate. Cell 136, 903-912.

Foley, A.C. \& Mercola, M. 2005. Heart induction by Wnt antagonists depends on the homeodomain transcription factor Hex. Genes Dev 19, 387-396.

Fujino, T., Asaba, H., Kang, M.J., Ikeda, Y., Sone, H., Takada, S., Kim, D.H., Ioka, R.X., Ono, M., Tomoyori, H. et al. 2003. Low-density lipoprotein receptor-related protein 5 (LRP5) is essential for normal cholesterol metabolism and glucose-induced insulin secretion. Proc Natl Acad Sci USA 100, 229-234.

Galceran, J., Farinas, I., Depew, M.J., Clevers, H. \& Grosschedl, R. 1999. Wnt3a-/--like phenotype and limb deficiency in Lef1(-/-)Tcf1(-/-) mice. Genes Dev 13, 709-717.

Galliot, B. \& Chera, S. 2010. The Hydra model: disclosing an apoptosis-driven generator of Wnt-based regeneration. Trends Cell Biol 20, 514-523.

Gan, X.Q., Wang, J.Y., Xi, Y., Wu, Z.L., Li, Y.P. \& Li, L. 2008. Nuclear Dvl, c-Jun, beta-catenin, and TCF form a complex leading to stabilization of beta-catenin-TCF interaction. J Cell Biol 180, 1087-1100.

Gaunt, S.J., Drage, D. \& Cockley, A. 2003. Vertebrate caudal gene expression gradients investigated by use of chick cdx-A/ lacZ and mouse $c d x-1 /$ lac $Z$ reporters in transgenic mouse embryos: evidence for an intron enhancer. Mech Dev 120, 573-586.

Gay, F., Calvo, D., Lo, M.C., Ceron, J., Maduro, M., Lin, R. \& Shi, Y. 2003. Acetylation regulates subcellular localization of the Wnt signaling nuclear effector POP-1. Genes Dev 17, 717-722.

Ge, X. \& Wang, X. 2010. Role of Wnt canonical pathway in hematological malignancies. J Hematol Oncol 3, 33.

Gee, L., Hartig, J., Law, L., Wittlieb, J., Khalturin, K., Bosch, T.C. \& Bode, H.R. 2010. Beta-catenin plays a central role in setting up the head organizer in hydra. Dev Biol 340, 116124.

van Genderen, C., Okamura, R.M., Farinas, I., Quo, R.G., Parslow, T.G., Bruhn, L. \& Grosschedl, R. 1994. Development of several organs that require inductive epithelialmesenchymal interactions is impaired in LEF-1-deficient mice. Genes Dev 8, 2691-2703.

Gessert, S. \& Kuhl, M. 2010. The multiple phases and faces of wnt signaling during cardiac differentiation and development. Circ Res 107, 186-199.

Giese, K. \& Grosschedl, R. 1993. LEF-1 contains an activation domain that stimulates transcription only in a specific context of factor-binding sites. EMBO J 12, 4667-4676.

Giese, K., Amsterdam, A. \& Grosschedl, R. 1991. DNAbinding properties of the HMG domain of the lymphoidspecific transcriptional regulator LEF-1. Genes Dev 5, 25672578.

Giese, K., Cox, J. \& Grosschedl, R. 1992. The HMG domain of lymphoid enhancer factor 1 bends DNA and facilitates assembly of functional nucleoprotein structures. Cell 69, 185-195.

Giese, K., Kingsley, C., Kirshner, J.R. \& Grosschedl, R. 1995. Assembly and function of a TCR alpha enhancer complex is 
dependent on LEF-1-induced DNA bending and multiple protein-protein interactions. Genes Dev 9, 995-1008.

Giraldez, A.J. \& Cohen, S.M. 2003. Wingless and Notch signaling provide cell survival cues and control cell proliferation during wing development. Development 130, 65336543.

Gitler, A.D., Lu, M.M., Jiang, Y.Q., Epstein, J.A. \& Gruber, P.J. 2003. Molecular markers of cardiac endocardial cushion development. Dev Dyn 228, 643-650.

Grigoryan, T., Wend, P., Klaus, A. \& Birchmeier, W. 2008. Deciphering the function of canonical Wnt signals in development and disease: conditional loss- and gain-of-function mutations of beta-catenin in mice. Genes Dev 22, 2308 2341.

Guder, C., Philipp, I., Lengfeld, T., Watanabe, H., Hobmayer, B. \& Holstein, T.W. 2006. The Wnt code: cnidarians signal the way. Oncogene $25,7450-7460$.

Gurley, K.A., Rink, J.C. \& Sanchez Alvarado, A. 2008. Betacatenin defines head versus tail identity during planarian regeneration and homeostasis. Science 319, 323-327.

Haegebarth, A. \& Clevers, H. 2009. Wnt signaling, lgr5, and stem cells in the intestine and skin. Am J Pathol 174, 715-721.

Halfon, M.S., Carmena, A., Gisselbrecht, S., Sackerson, C.M., Jimenez, F., Baylies, M.K. \& Michelson, A.M. 2000. Ras pathway specificity is determined by the integration of multiple signal-activated and tissue-restricted transcription factors. Cell 103, 63-74.

Hallikas, O., Palin, K., Sinjushina, N., Rautiainen, R., Partanen, J., Ukkonen, E. \& Taipale, J. 2006. Genome-wide prediction of mammalian enhancers based on analysis of transcription-factor binding affinity. Cell 124, 47-59.

Hamblet, N.S., Lijam, N., Ruiz-Lozano, P., Wang, J., Yang, Y., Luo, Z., Mei, L., Chien, K.R., Sussman, D.J. \& Wynshaw-Boris, A. 2002. Dishevelled 2 is essential for cardiac outflow tract development, somite segmentation and neural tube closure. Development 129, 5827-5838.

Han, Z., Fujioka, M., Su, M., Liu, M., Jaynes, J.B. \& Bodmer, R. 2002. Transcriptional integration of competence modulated by mutual repression generates cell-type specificity within the cardiogenic mesoderm. Dev Biol 252, 225-240.

Hatzis, P., van der Flier, L.G., van Driel, M.A., Guryev, V., Nielsen, F., Denissov, S., Nijman, I.J., Koster, J., Santo, E.E., Welboren, W., Versteeg, R., Cuppen, E., van de Wetering, M., Clevers, H. \& Stunnenberg, H.G. 2008. Genome-wide pattern of TCF7L2/TCF4 chromatin occupancy in colorectal cancer cells. Mol Cell Biol 28, 2732-2744.

He, T.C., Sparks, A.B., Rago, C., Hermeking, H., Zawel, L., da Costa, L.T., Morin, P.J., Vogelstein, B. \& Kinzler, K.W. 1998. Identification of c-MYC as a target of the APC pathway. Science 281, 1509-1512.

Heasman, J., Crawford, A., Goldstone, K., Garner-Hamrick, P., Gumbiner, B., McCrea, P., Kintner, C., Noro, C.Y. \& Wylie, C. 1994. Overexpression of cadherins and underexpression of beta-catenin inhibit dorsal mesoderm induction in early Xenopus embryos. Cell 79, 791-803.

Hecht, A. \& Stemmler, M.P. 2003. Identification of a promoter-specific transcriptional activation domain at the $\mathrm{C}$ terminus of the Wnt effector protein T-cell factor 4. J Biol Chem 278, 3776-3785.
Heemskerk, J., DiNardo, S., Kostriken, R. \& O'Farrell, P.H. 1991. Multiple modes of engrailed regulation in the progression towards cell fate determination. Nature 352, 404410.

Herman, M. 2001. C. elegans POP-1/TCF functions in a canonical Wnt pathway that controls cell migration and in a noncanonical Wnt pathway that controls cell polarity. Development 128, 581-590.

Herranz, H. \& Milan, M. 2008. Signalling molecules, growth regulators and cell cycle control in Drosophila. Cell Cycle 7, 3335-3337.

Hikasa, H. \& Sokol, S.Y. 2011. Phosphorylation of TCF proteins by homeodomain-interacting protein kinase 2 . J Biol Chem 286, 12093-12100.

Hikasa, H., Ezan, J., Itoh, K., Li, X., Klymkowsky, M.W. \& Sokol, S.Y. 2010. Regulation of TCF3 by Wnt-dependent phosphorylation during vertebrate axis specification. Dev Cell 19, 521-532.

Hobmayer, B., Rentzsch, F., Kuhn, K., Happel, C.M., von Laue, C.C., Snyder, P., Rothbacher, U. \& Holstein, T.W. 2000. WNT signalling molecules act in axis formation in the diploblastic metazoan Hydra. Nature 407, 186-189.

Hoogeboom, D., Essers, M.A., Polderman, P.E., Voets, E., Smits, L.M. \& Burgering, B.M. 2008. Interaction of FOXO with beta-catenin inhibits beta-catenin/T cell factor activity. J Biol Chem 283, 9224-9230.

Houston, D.W., Kofron, M., Resnik, E., Langland, R., Destree, O., Wylie, C. \& Heasman, J. 2002. Repression of organizer genes in dorsal and ventral Xenopus cells mediated by maternal XTcf3. Development 129, 4015-4025.

Hovanes, K., Li, T.W., Munguia, J.E., Truong, T., Milovanovic, T., Lawrence Marsh, J., Holcombe, R.F. \& Waterman, M.L. 2001. Beta-catenin-sensitive isoforms of lymphoid enhancer factor-1 are selectively expressed in colon cancer. Nat Genet 28, 53-57.

Hu, M.C. \& Rosenblum, N.D. 2005. Smad1, beta-catenin and Tcf4 associate in a molecular complex with the Myc promoter in dysplastic renal tissue and cooperate to control Myc transcription. Development 132, 215-225.

Huber, O., Korn, R., McLaughlin, J., Ohsugi, M., Herrmann, B.G. \& Kemler, R. 1996. Nuclear localization of beta-catenin by interaction with transcription factor LEF-1. Mech Dev 59, 3-10.

Huelsken, J., Vogel, R., Brinkmann, V., Erdmann, B., Birchmeier, C. \& Birchmeier, W. 2000. Requirement for betacatenin in anterior-posterior axis formation in mice. $J$ Cell Biol 148, 567-578.

Hurlstone, A.F., Haramis, A.P., Wienholds, E., Begthel, H., Korving, J., Van Eeden, F., Cuppen, E., Zivkovic, D., Plasterk, R.H. \& Clevers, H. 2003. The Wnt/beta-catenin pathway regulates cardiac valve formation. Nature 425, 633-637.

Hussein, S.M., Duff, E.K. \& Sirard, C. 2003. Smad4 and betacatenin co-activators functionally interact with lymphoidenhancing factor to regulate graded expression of Msx2. J Biol Chem 278, 48805-48814.

Hwang, I., Seo, E.Y. \& Ha, H. 2009. Wnt/beta-catenin signaling: a novel target for therapeutic intervention of fibrotic kidney disease. Arch Pharm Res 32, 1653-1662. 
Iglesias, M., Gomez-Skarmeta, J.L., Salo, E. \& Adell, T. 2008. Silencing of Smed-betacatenin1 generates radial-like hypercephalized planarians. Development 135, 1215-1221.

Ikeya, M. \& Takada, S. 2001. Wnt-3a is required for somite specification along the anteroposterior axis of the mouse embryo and for regulation of cdx-1 expression. Mech Dev $103,27-33$.

Inestrosa, N.C. \& Toledo, E.M. 2008. The role of Wnt signaling in neuronal dysfunction in Alzheimer's disease. Mol Neurodegener 3, 9.

Ishibashi, H., Matsumura, N., Hanafusa, H., Matsumoto, K., De Robertis, E.M. \& Kuroda, H. 2008. Expression of Siamois and Twin in the blastula Chordin/Noggin signaling center is required for brain formation in Xenopus laevis embryos. Mech Dev 125, 58-66.

Itasaki, N. \& Hoppler, S. 2010. Crosstalk between Wnt and bone morphogenic protein signaling: a turbulent relationship. Dev Dyn 239, 16-33.

Jackson, A., Vayssiere, B., Garcia, T., Newell, W., Baron, R., Roman-Roman, S. \& Rawadi, G. 2005. Gene array analysis of Wnt-regulated genes in C3H10T1/2 cells. Bone 36, 585598.

Jamora, C., DasGupta, R., Kocieniewski, P. \& Fuchs, E. 2003. Links between signal transduction, transcription and adhesion in epithelial bud development. Nature 422, 317322.

Jeong, Y., El-Jaick, K., Roessler, E., Muenke, M. \& Epstein, D.J. 2006. A functional screen for sonic hedgehog regulatory elements across a $1 \mathrm{Mb}$ interval identifies long-range ventral forebrain enhancers. Development 133, 761-772.

Jho, E.H., Zhang, T., Domon, C., Joo, C.K., Freund, J.N. \& Costantini, F. 2002. Wnt/beta-catenin/Tcf signaling induces the transcription of Axin2, a negative regulator of the signaling pathway. Mol Cell Biol 22, 1172-1183.

Jin, T. 2008. The WNT signalling pathway and diabetes mellitus. Diabetologia 51, 1771-1780.

Jung, H.C. \& Kim, K. 2005. Identification of MYCBP as a beta-catenin/LEF-1 target using DNA microarray analysis. Life Sci 77, 1249-1262.

Kaidi, A., Williams, A.C. \& Paraskeva, C. 2007. Interaction between beta-catenin and HIF-1 promotes cellular adaptation to hypoxia. Nat Cell Biol 9, 210-217.

Kalay, G. \& Wittkopp, P.J. 2010. Nomadic enhancers: tissuespecific cis-regulatory elements of yellow have divergent genomic positions among Drosophila species. PLoS Genet 6, e1001222.

Kang, Y., Chen, C.R. \& Massague, J. 2003. A self-enabling TGFbeta response coupled to stress signaling: smad engages stress response factor ATF3 for Id1 repression in epithelial cells. Mol Cell 11, 915-926.

Kelly, O.G., Pinson, K.I. \& Skarnes, W.C. 2004. The Wnt co-receptors Lrp5 and Lrp6 are essential for gastrulation in mice. Development 131, 2803-2815.

Kennell, J. \& Cadigan, K.M. 2009. APC and beta-catenin degradation. Adv Exp Med Biol 656, 1-12.

Kim, C.H., Oda, T., Itoh, M., Jiang, D., Artinger, K.B., Chandrasekharappa, S.C., Driever, W. \& Chitnis, A.B. 2000. Repressor activity of Headless/Tcf3 is essential for vertebrate head formation. Nature 407, 913-916.
Kim, J.H., Kim, B., Cai, L., Choi, H.J., Ohgi, K.A., Tran, C., Chen, C., Chung, C.H., Huber, O., Rose, D.W., Sawyers, C.L., Rosenfeld, M.G. \& Baek, S.H. 2005. Transcriptional regulation of a metastasis suppressor gene by Tip60 and beta-catenin complexes. Nature 434, 921-926.

Kim, C.H., Neiswender, H., Baik, E.J., Xiong, W.C. \& Mei, L. 2008. Beta-catenin interacts with MyoD and regulates its transcription activity. Mol Cell Biol 28, 2941-2951.

King, N., Westbrook, M.J., Young, S.L., Kuo, A., Abedin, M., Chapman, J., Fairclough, S., Hellsten, U., Isogai, Y., Letunic, I. et al. 2008. The genome of the choanoflagellate Monosiga brevicollis and the origin of metazoans. Nature 451, 783-788.

Kioussi, C., Briata, P., Baek, S.H., Rose, D.W., Hamblet, N.S., Herman, T., Ohgi, K.A., Lin, C., Gleiberman, A., Wang, J. et al. 2002. Identification of a Wnt/Dvl/beta-Catenin $\rightarrow$ Pitx2 pathway mediating cell-type-specific proliferation during development. Cell 111, 673-685.

Klapholz-Brown, Z., Walmsley, G.G., Nusse, Y.M., Nusse, R. \& Brown, P.O. 2007. Transcriptional program induced by Wnt protein in human fibroblasts suggests mechanisms for cell cooperativity in defining tissue microenvironments. PLOS ONE 2, e945.

Klaus, A., Saga, Y., Taketo, M.M., Tzahor, E. \& Birchmeier, W. 2007. Distinct roles of Wnt/beta-catenin and Bmp signaling during early cardiogenesis. Proc Natl Acad Sci USA 104, 18531-18536.

Knirr, S. \& Frasch, M. 2001. Molecular integration of inductive and mesoderm-intrinsic inputs governs even-skipped enhancer activity in a subset of pericardial and dorsal muscle progenitors. Dev Biol 238, 13-26.

Korinek, V., Barker, N., Morin, P.J., van Wichen, D., de Weger, R., Kinzler, K.W., Vogelstein, B. \& Clevers, H. 1997. Constitutive transcriptional activation by a betacatenin-Tcf complex in APC-/- colon carcinoma. Science 275, 1784-1787.

Korinek, V., Barker, N., Moerer, P., van Donselaar, E., Huls, G., Peters, P.J. \& Clevers, H. 1998. Depletion of epithelial stem-cell compartments in the small intestine of mice lacking Tcf-4. Nat Genet 19, 379-383.

Kratochwil, K., Galceran, J., Tontsch, S., Roth, W. \& Grosschedl, R. 2002. FGF4, a direct target of LEF1 and Wnt signaling, can rescue the arrest of tooth organogenesis in Lef1(-/-) mice. Genes Dev 16, 3173-3185.

Krishnan, V., Bryant, H.U. \& Macdougald, O.A. 2006. Regulation of bone mass by Wnt signaling. J Clin Invest 116, 1202-1209.

Kusserow, A., Pang, K., Sturm, C., Hrouda, M., Lentfer, J., Schmidt, H.A., Technau, U., von Haeseler, A., Hobmayer, B., Martindale, M.Q. \& Holstein, T.W. 2005. Unexpected complexity of the Wnt gene family in a sea anemone. Nature 433, 156-160.

Kwon, C., Arnold, J., Hsiao, E.C., Taketo, M.M., Conklin, B.R. \& Srivastava, D. 2007. Canonical Wnt signaling is a positive regulator of mammalian cardiac progenitors. Proc Natl Acad Sci USA 104, 10894-10899.

Kwon, C., Cordes, K.R. \& Srivastava, D. 2008. Wnt/betacatenin signaling acts at multiple developmental stages to promote mammalian cardiogenesis. Cell Cycle 7, 38153818. 
Kwon, C., Qian, L., Cheng, P., Nigam, V., Arnold, J. \& Srivastava, D. 2009. A regulatory pathway involving Notch1/ beta-catenin/Isl1 determines cardiac progenitor cell fate. Nat Cell Biol 11, 951-957.

Labbe, E., Letamendia, A. \& Attisano, L. 2000. Association of Smads with lymphoid enhancer binding factor $1 / \mathrm{T}$ cell-specific factor mediates cooperative signaling by the transforming growth factor-beta and wnt pathways. Proc Natl Acad Sci USA 97, 8358-8363.

Lam, N., Chesney, M.A. \& Kimble, J. 2006. Wnt signaling and CEH-22/tinman/Nkx2.5 specify a stem cell niche in C. elegans. Curr Biol 16, 287-295.

Lancaster, M.A. \& Gleeson, J.G. 2010. Cystic kidney disease: the role of Wnt signaling. Trends Mol Med 16, 349-360.

Lapebie, P., Gazave, E., Ereskovsky, A., Derelle, R., Bezac, C., Renard, E., Houliston, E. \& Borchiellini, C. 2009. WNT/ beta-catenin signalling and epithelial patterning in the homoscleromorph sponge Oscarella. PLOS ONE 4, e5823.

Laudet, V., Stehelin, D. \& Clevers, H. 1993. Ancestry and diversity of the HMG box superfamily. Nucleic Acids Res 21, 2493-2501.

Laurent, M.N., Blitz, I.L., Hashimoto, C., Rothbacher, U. \& Cho, K.W. 1997. The Xenopus homeobox gene twin mediates Wnt induction of goosecoid in establishment of Spemann's organizer. Development 124, 4905-4916.

Laurent-Puig, P. \& Zucman-Rossi, J. 2006. Genetics of hepatocellular tumors. Oncogene 25, 3778-3786.

Lavenu, A., Pournin, S., Babinet, C. \& Morello, D. 1994. The cis-acting elements known to regulate c-myc expression ex vivo are not sufficient for correct transcription in vivo. Oncogene 9, 527-536.

Lee, H.H. \& Frasch, M. 2000. Wingless effects mesoderm patterning and ectoderm segmentation events via induction of its downstream target sloppy paired. Development 127, 5497-5508.

Lee, W., Swarup, S., Chen, J., Ishitani, T. \& Verheyen, E.M. 2009. Homeodomain-interacting protein kinases (Hipks) promote Wnt/Wg signaling through stabilization of betacatenin/Arm and stimulation of target gene expression. Development 136, 241-251.

Lei, S., Dubeykovskiy, A., Chakladar, A., Wojtukiewicz, L. \& Wang, T.C. 2004. The murine gastrin promoter is synergistically activated by transforming growth factor-beta/Smad and Wnt signaling pathways. J Biol Chem 279, 42492-42502.

Lengfeld, T., Watanabe, H., Simakov, O., Lindgens, D., Gee, L., Law, L., Schmidt, H.A., Ozbek, S., Bode, H. \& Holstein, T.W. 2009. Multiple Wnts are involved in Hydra organizer formation and regeneration. Dev Biol 330, 186-199.

Li, J., Sutter, C., Parker, D.S., Blauwkamp, T., Fang, M. \& Cadigan, K.M. 2007. CBP/p300 are bimodal regulators of Wnt signaling. EMBO J 26, 2284-2294.

Li, B., Kuriyama, S., Moreno, M. \& Mayor, R. 2009. The posteriorizing gene Gbx2 is a direct target of Wnt signalling and the earliest factor in neural crest induction. Development 136, 3267-3278.

Lickert, H., Domon, C., Huls, G., Wehrle, C., Duluc, I., Clevers, H., Meyer, B.I., Freund, J.N. \& Kemler, R. 2000. Wnt/ (beta)-catenin signaling regulates the expression of the homeobox gene Cdx1 in embryonic intestine. Development 127, 3805-3813.

Lickert, H., Kutsch, S., Kanzler, B., Tamai, Y., Taketo, M.M. $\&$ Kemler, R. 2002. Formation of multiple hearts in mice following deletion of beta-catenin in the embryonic endoderm. Dev Cell 3, 171-181.

Liebner, S., Cattelino, A., Gallini, R., Rudini, N., Iurlaro, M., Piccolo, S. \& Dejana, E. 2004. Beta-catenin is required for endothelial-mesenchymal transformation during heart cushion development in the mouse. J Cell Biol 166, 359-367.

Lin, H.V., Rogulja, A. \& Cadigan, K.M. 2004. Wingless eliminates ommatidia from the edge of the developing eye through activation of apoptosis. Development 131, 24092418.

Lin, L., Cui, L., Zhou, W., Dufort, D., Zhang, X., Cai, C.L., Bu, L., Yang, L., Martin, J., Kemler, R., Rosenfeld, M.G., Chen, J. \& Evans, S.M. 2007. Beta-catenin directly regulates Islet1 expression in cardiovascular progenitors and is required for multiple aspects of cardiogenesis. Proc Natl Acad Sci USA 104, 9313-9318.

Lin, G., Xu, N. \& Xi, R. 2008. Paracrine Wingless signalling controls self-renewal of Drosophila intestinal stem cells. Nature 455, 1119-1123.

Liu, Z. \& Habener, J.F. 2008. Glucagon-like peptide-1 activation of TCF7L2-dependent Wnt signaling enhances pancreatic beta cell proliferation. J Biol Chem 283, 8723-8735.

Liu, P., Wakamiya, M., Shea, M.J., Albrecht, U., Behringer, R.R. \& Bradley, A. 1999. Requirement for Wnt3 in vertebrate axis formation. Nat Genet 22, 361-365.

Liu, F., van den Broek, O., Destree, O. \& Hoppler, S. 2005. Distinct roles for Xenopus Tcf/Lef genes in mediating specific responses to $\mathrm{Wnt} /$ beta-catenin signalling in mesoderm development. Development 132, 5375-5385.

Liu, Y., Asakura, M., Inoue, H., Nakamura, T., Sano, M., Niu, Z., Chen, M., Schwartz, R.J. \& Schneider, M.D. 2007. Sox17 is essential for the specification of cardiac mesoderm in embryonic stem cells. Proc Natl Acad Sci USA 104, 38593864.

Lo, M.C., Gay, F., Odom, R., Shi, Y. \& Lin, R. 2004. Phosphorylation by the beta-catenin/MAPK complex promotes 14-3-3-mediated nuclear export of TCF/POP-1 in signalresponsive cells in C. elegans. Cell 117, 95-106.

Logan, C.Y. \& Nusse, R. 2004. The Wnt signaling pathway in development and disease. Annu Rev Cell Dev Biol 20, 781810.

Longo, K.A., Kennell, J.A., Ochocinska, M.J., Ross, S.E., Wright, W.S. \& MacDougald, O.A. 2002. Wnt signaling protects 3T3-L1 preadipocytes from apoptosis through induction of insulin-like growth factors. J Biol Chem 277, 38239-38244.

Love, J.J., Li, X., Case, D.A., Giese, K., Grosschedl, R. \& Wright, P.E. 1995. Structural basis for DNA bending by the architectural transcription factor LEF-1. Nature 376, 791795.

Love, J.J., Li, X., Chung, J., Dyson, H.J. \& Wright, P.E. 2004. The LEF-1 high-mobility group domain undergoes a disorder-to-order transition upon formation of a complex with cognate DNA. Biochemistry 43, 8725-8734. 
Lucero, O.M., Dawson, D.W., Moon, R.T. \& Chien, A.J. 2010. A re-evaluation of the "oncogenic" nature of Wnt/ beta-catenin signaling in melanoma and other cancers. Curr Oncol Rep 12, 314-318.

Lum, L., Yao, S., Mozer, B., Rovescalli, A., Von Kessler, D., Nirenberg, M. \& Beachy, P.A. 2003. Identification of Hedgehog pathway components by RNAi in Drosophila cultured cells. Science 299, 2039-2045.

MacDonald, B.T., Tamai, K. \& He, X. 2009. Wnt/beta-catenin signaling: components, mechanisms, and diseases. Dev Cell 17, 9-26.

Mahmoudi, T., Li, V.S., Ng, S.S., Taouatas, N., Vries, R.G., Mohammed, S., Heck, A.J. \& Clevers, H. 2009. The kinase TNIK is an essential activator of Wnt target genes. EMBO J 28, 3329-3340.

Maier, E., Hebenstreit, D., Posselt, G., Hammerl, P., Duschl, A. \& Horejs-Hoeck, J. 2011. Inhibition of suppressive T cell factor 1 (TCF-1) isoforms in naive CD4+ T cells is mediated by IL-4/STAT6 signaling. J Biol Chem 286, 919-928.

Manolagas, S.C. \& Almeida, M. 2007. Gone with the Wnts: beta-catenin, $\mathrm{T}$-cell factor, forkhead box $\mathrm{O}$, and oxidative stress in age-dependent diseases of bone, lipid, and glucose metabolism. Mol Endocrinol 21, 2605-2614.

Maretto, S., Cordenonsi, M., Dupont, S., Braghetta, P., Broccoli, V., Hassan, A.B., Volpin, D., Bressan, G.M. \& Piccolo, S. 2003. Mapping Wnt/beta-catenin signaling during mouse development and in colorectal tumors. Proc Natl Acad Sci USA 100, 3299-3304.

Martin, B.L. \& Kimelman, D. 2008. Regulation of canonical Wnt signaling by Brachyury is essential for posterior mesoderm formation. Dev Cell 15, 121-133.

Martin, F.A., Perez-Garijo, A. \& Morata, G. 2009. Apoptosis in Drosophila: compensatory proliferation and undead cells. Int J Dev Biol 53, 1341-1347.

Marvin, M.J., Di Rocco, G., Gardiner, A., Bush, S.M. \& Lassar, A.B. 2001. Inhibition of Wnt activity induces heart formation from posterior mesoderm. Genes Dev 15, 316327.

Masckauchan, T.N., Shawber, C.J., Funahashi, Y., Li, C.M. \& Kitajewski, J. 2005. Wnt/beta-catenin signaling induces proliferation, survival and interleukin- 8 in human endothelial cells. Angiogenesis 8, 43-51.

Mazumdar, J., O’Brien, W.T., Johnson, R.S., LaManna, J.C., Chavez, J.C., Klein, P.S. \& Simon, M.C. 2010. $\mathrm{O}_{2}$ regulates stem cells through Wnt/beta-catenin signalling. Nat Cell Biol 12, 1007-1013.

McGrew, L.L., Hoppler, S. \& Moon, R.T. 1997. Wnt and FGF pathways cooperatively pattern anteroposterior neural ectoderm in Xenopus. Mech Dev 69, 105-114.

McMahon, A.P. \& Moon, R.T. 1989. Ectopic expression of the proto-oncogene int- 1 in Xenopus embryos leads to duplication of the embryonic axis. Cell 58, 1075-1084.

Meinhardt, H. 2002. The radial-symmetric hydra and the evolution of the bilateral body plan: an old body became a young brain. Bioessays 24, 185-191.

Merrill, B.J., Pasolli, H.A., Polak, L., Rendl, M., Garcia-Garcia, M.J., Anderson, K.V. \& Fuchs, E. 2004. Tcf3: a transcriptional regulator of axis induction in the early embryo. Development 131, 263-274.
Mizumoto, K. \& Sawa, H. 2007. Two betas or not two betas: regulation of asymmetric division by beta-catenin. Trends Cell Biol 17, 465-473.

Molenaar, M. 1996. XTcf-3 transcription factor mediates [beta]-catenin-induced axis formation in Xenopus embryos. Cell 86, 391-399.

Morris, J.Pt., Wang, S.C. \& Hebrok, M. 2010. KRAS, Hedgehog, Wnt and the twisted developmental biology of pancreatic ductal adenocarcinoma. Nat Rev Cancer 10, 683695.

Mosimann, C., Hausmann, G. \& Basler, K. 2009. Beta-catenin hits chromatin: regulation of Wnt target gene activation. Nat Rev Mol Cell Biol 10, 276-286.

Moustakas, A. \& Heldin, C.H. 2009. The regulation of TGFbeta signal transduction. Development 136, 36993714.

Mukhopadhyay, M., Shtrom, S., Rodriguez-Esteban, C., Chen, L., Tsukui, T., Gomer, L., Dorward, D.W., Glinka, A., Grinberg, A., Huang, S.P., Niehrs, C., Izpisua Belmonte, J.C. \& Westphal, H. 2001. Dickkopf1 is required for embryonic head induction and limb morphogenesis in the mouse. Dev Cell 1, 423-434.

Mulholland, D.J., Dedhar, S., Coetzee, G.A. \& Nelson, C.C. 2005. Interaction of nuclear receptors with the Wnt/betacatenin/Tcf signaling axis: Wnt you like to know? Endocr Rev 26, 898-915.

Muller, W., Frank, U., Teo, R., Mokady, O., Guette, C. \& Plickert, G. 2007. Wnt signaling in hydroid development: ectopic heads and giant buds induced by GSK-3beta inhibitors. Int J Dev Biol 51, 211-220.

Muncan, V., Sansom, O.J., Tertoolen, L., Phesse, T.J., Begthel, H., Sancho, E., Cole, A.M., Gregorieff, A., de Alboran, I.M., Clevers, H. \& Clarke, A.R. 2006. Rapid loss of intestinal crypts upon conditional deletion of the Wnt/Tcf-4 target gene c-Myc. Mol Cell Biol 26, 8418-8426.

Naishiro, Y., Yamada, T., Idogawa, M., Honda, K., Takada, M., Kondo, T., Imai, K. \& Hirohashi, S. 2005. Morphological and transcriptional responses of untransformed intestinal epithelial cells to an oncogenic beta-catenin protein. Oncogene 24, 3141-3153.

Najdi, R., Syed, A., Arce, L., Theisen, H., Ting, J.H., Atcha, F., Nguyen, A.V., Martinez, M., Holcombe, R.F., Edwards, R.A., Marsh, J.L. \& Waterman, M.L. 2009. A Wnt kinase network alters nuclear localization of TCF-1 in colon cancer. Oncogene 28, 4133-4146.

Nakano, N., Itoh, S., Watanabe, Y., Maeyama, K., Itoh, F. \& Kato, M. 2010. Requirement of TCF7L2 for TGF-\{beta\}dependent transcriptional activation of the TMEPAI gene. J Biol Chem 285, 38023-38033.

Nakaya, M.A., Biris, K., Tsukiyama, T., Jaime, S., Rawls, J.A. \& Yamaguchi, T.P. 2005. Wnt3a links left-right determination with segmentation and anteroposterior axis elongation. Development 132, 5425-5436.

Nateri, A.S., Spencer-Dene, B. \& Behrens, A. 2005. Interaction of phosphorylated c-Jun with TCF4 regulates intestinal cancer development. Nature 437, 281-285.

Neumann, C.J. \& Cohen, S.M. 1997. Long-range action of Wingless organizes the dorsal-ventral axis of the Drosophila wing. Development 124, 871-880. 
Nguyen, H., Merrill, B.J., Polak, L., Nikolova, M., Rendl, M., Shaver, T.M., Pasolli, H.A. \& Fuchs, E. 2009. Tcf3 and Tcf4 are essential for long-term homeostasis of skin epithelia. Nat Genet 41, 1068-1075.

Niehrs, C. 2006. Function and biological roles of the Dickkopf family of Wnt modulators. Oncogene 25, 7469-7481.

Niehrs, C. 2010. On growth and form: a Cartesian coordinate system of Wnt and BMP signaling specifies bilaterian body axes. Development 137, 845-857.

Nishita, M., Hashimoto, M.K., Ogata, S., Laurent, M.N., Ueno, N., Shibuya, H. \& Cho, K.W. 2000. Interaction between Wnt and TGF-beta signalling pathways during formation of Spemann's organizer. Nature 403, 781-785.

Noordermeer, J., Klingensmith, J., Perrimon, N. \& Nusse, R. 1994. Dishevelled and armadillo act in the wingless signalling pathway in Drosophila. Nature 367, 80-83.

Nusse, R., Fuerer, C., Ching, W., Harnish, K., Logan, C., Zeng, A., ten Berge, D. \& Kalani, Y. 2008. Wnt signaling and stem cell control. Cold Spring Harb Symp Quant Biol 73, 59-66.

Ogryzko, V.V., Schiltz, R.L., Russanova, V., Howard, B.H. \& Nakatani, Y. 1996. The transcriptional coactivators p300 and CBP are histone acetyltransferases. Cell 87, 953-959.

Olson, L.E., Tollkuhn, J., Scafoglio, C., Krones, A., Zhang, J., Ohgi, K.A., Wu, W., Taketo, M.M., Kemler, R., Grosschedl, R., Rose, D., Li, X. \& Rosenfeld, M.G. 2006. Homeodomain-mediated beta-catenin-dependent switching events dictate cell-lineage determination. Cell 125, 593-605.

Oosterwegel, M., van de Wetering, M., Dooijes, D., Klomp, L., Winoto, A., Georgopoulos, K., Meijlink, F. \& Clevers, H. 1991. Cloning of murine TCF-1, a T cell-specific transcription factor interacting with functional motifs in the CD3epsilon and T cell receptor alpha enhancers. J Exp Med 173, 1133-1142.

Pang, K., Ryan, J.F., Mullikin, J.C., Baxevanis, A.D. \& Martindale, M.Q. 1999. Genomic insights into Wnt signaling in an early diverging metazoan, the ctenophore Mnemiopsis leidyi. EvoDevo 1, 10.

Park, M., Wu, X., Golden, K., Axelrod, J.D. \& Bodmer, R. 1996. The wingless signaling pathway is directly involved in Drosophila heart development. Dev Biol 177, 104-116.

Peifer, M., Rauskolb, C., Williams, M., Riggleman, B. \& Wieschaus, E. 1991. The segment polarity gene armadillo interacts with the wingless signaling pathway in both embryonic and adult pattern formation. Development 111, 1029-1043.

Perez-Garijo, A., Shlevkov, E. \& Morata, G. 2009. The role of Dpp and Wg in compensatory proliferation and in the formation of hyperplastic overgrowths caused by apoptotic cells in the Drosophila wing disc. Development 136, 1169_ 1177.

Petersen, C.P. \& Reddien, P.W. 2008. Smed-betacatenin-1 is required for anteroposterior blastema polarity in planarian regeneration. Science 319, 327-330.

Petersen, C.P. \& Reddien, P.W. 2009. Wnt signaling and the polarity of the primary body axis. Cell 139, 1056-1068.

Phillips, B.T. \& Kimble, J. 2009. A new look at TCF and betacatenin through the lens of a divergent C. elegans Wnt pathway. Dev Cell 17, 27-34.
Piepenburg, O., Vorbruggen, G. \& Jackle, H. 2000. Drosophila segment borders result from unilateral repression of hedgehog activity by wingless signaling. Mol Cell 6, 203-209.

Pilon, N., Oh, K., Sylvestre, J.R., Bouchard, N., Savory, J. \& Lohnes, D. 2006. Cdx4 is a direct target of the canonical Wnt pathway. Dev Biol 289, 55-63.

Pinto, D. \& Clevers, H. 2005. Wnt control of stem cells and differentiation in the intestinal epithelium. Exp Cell Res 306, 357-363.

Plickert, G., Jacoby, V., Frank, U., Muller, W.A. \& Mokady, O. 2006. Wnt signaling in hydroid development: formation of the primary body axis in embryogenesis and its subsequent patterning. Dev Biol 298, 368-378.

Polakis, P. 2000. Wnt signaling and cancer. Genes Dev 14, 1837-1851.

Polakis, P. 2007. The many ways of Wnt in cancer. Curr Opin Genet Dev 17, 45-51.

Pomerantz, M.M., Ahmadiyeh, N., Jia, L., Herman, P., Verzi, M.P., Doddapaneni, H., Beckwith, C.A., Chan, J.A., Hills, A., Davis, M. et al. 2009. The $8 \mathrm{q} 24$ cancer risk variant rs6983267 shows long-range interaction with MYC in colorectal cancer. Nat Genet 41, 882-884.

Porcher, A. \& Dostatni, N. 2010. The bicoid morphogen system. Curr Biol 20, R249-R254.

Pulkkinen, K., Murugan, S. \& Vainio, S. 2008. Wnt signaling in kidney development and disease. Organogenesis 4, 55-59.

Railo, A., Pajunen, A., Itaranta, P., Naillat, F., Vuoristo, J., Kilpelainen, P. \& Vainio, S. 2009. Genomic response to Wnt signalling is highly context-dependent - evidence from DNA microarray and chromatin immunoprecipitation screens of Wnt/TCF targets. Exp Cell Res 315, 2690-2704.

Reya, T., O’Riordan, M., Okamura, R., Devaney, E., Willert, K., Nusse, R. \& Grosschedl, R. 2000. Wnt signaling regulates B lymphocyte proliferation through a LEF-1 dependent mechanism. Immunity 13, 15-24.

Riechmann, V. \& Ephrussi, A. 2001. Axis formation during Drosophila oogenesis. Curr Opin Genet Dev 11, 374-383.

Riggleman, B., Wieschaus, E. \& Schedl, P. 1989. Molecular analysis of the armadillo locus: uniformly distributed transcripts and a protein with novel internal repeats are associated with a Drosophila segment polarity gene. Genes Dev 3, 96-113.

Rivat, C., Le Floch, N., Sabbah, M., Teyrol, I., Redeuilh, G., Bruyneel, E., Mareel, M., Matrisian, L.M., Crawford, H.C., Gespach, C. \& Attoub, S. 2003. Synergistic cooperation between the AP-1 and LEF-1 transcription factors in activation of the matrilysin promoter by the src oncogene: implications in cellular invasion. FASEB J 17, 1721-1723.

Rocheleau, C.E., Downs, W.D., Lin, R., Wittmann, C., Bei, Y., Cha, Y.H., Ali, M., Priess, J.R. \& Mello, C.C. 1997. Wnt signaling and an APC-related gene specify endoderm in early C. elegans embryos. Cell 90, 707-716.

Rocheleau, C.E., Yasuda, J., Shin, T.H., Lin, R., Sawa, H., Okano, H., Priess, J.R., Davis, R.J. \& Mello, C.C. 1999. WRM-1 activates the LIT-1 protein kinase to transduce anterior/posterior polarity signals in C. elegans. Cell 97, 717-726.

Rodriguez-Carballo, E., Ulsamer, A., Susperregui, A.R., Manzanares-Cespedes, C., Sanchez-Garcia, E., Bartrons, R., 
Rosa, J.L. \& Ventura, F. 2011. Conserved regulatory motifs in osteogenic gene promoters integrate cooperative effects of canonical Wnt and BMP pathways. J Bone Miner Res 26, 718-729.

Roose, J., Molenaar, M., Peterson, J., Hurenkamp, J., Brantjes, H., Moerer, P., van de Wetering, M., Destree, O. \& Clevers, H. 1998. The Xenopus Wnt effector XTcf-3 interacts with Groucho-related transcriptional repressors. Nature 395, 608-612.

Roose, J., Huls, G., van Beest, M., Moerer, P., van der Horn, K., Goldschmeding, R., Logtenberg, T. \& Clevers, H. 1999. Synergy between tumor suppressor APC and the beta-catenin-Tcf4 target Tcf1. Science 285, 1923-1926.

Roth, W., Sustmann, C., Kieslinger, M., Gilmozzi, A., Irmer, D., Kremmer, E., Turck, C. \& Grosschedl, R. 2004. PIASydeficient mice display modest defects in IFN and Wnt signaling. I Immunol 173, 6189-6199.

Rulifson, I.C., Karnik, S.K., Heiser, P.W., ten Berge, D., Chen, H., Gu, X., Taketo, M.M., Nusse, R., Hebrok, M. \& Kim, S.K. 2007. Wnt signaling regulates pancreatic beta cell proliferation. Proc Natl Acad Sci USA 104, 6247-6252.

Sachdev, S., Bruhn, L., Sieber, H., Pichler, A., Melchior, F. \& Grosschedl, R. 2001. PIASy, a nuclear matrix-associated SUMO E3 ligase, represses LEF1 activity by sequestration into nuclear bodies. Genes Dev 15, 3088-3103.

Sancho, R., Nateri, A.S., de Vinuesa, A.G., Aguilera, C., Nye, E., Spencer-Dene, B. \& Behrens, A. 2009. JNK signalling modulates intestinal homeostasis and tumourigenesis in mice. EMBO J 28, 1843-1854.

Sansom, O.J., Reed, K.R., Hayes, A.J., Ireland, H., Brinkmann, H., Newton, I.P., Batlle, E., Simon-Assmann, P., Clevers, H., Nathke, I.S., Clarke, A.R. \& Winton, D.J. 2004. Loss of Apc in vivo immediately perturbs Wnt signaling, differentiation, and migration. Genes Dev 18, 1385-1390.

Sansom, O.J., Meniel, V.S., Muncan, V., Phesse, T.J., Wilkins, J.A., Reed, K.R., Vass, J.K., Athineos, D., Clevers, H. \& Clarke, A.R. 2007. Myc deletion rescues Apc deficiency in the small intestine. Nature 446, 676-679.

Sanson, B. 2001. Generating patterns from fields of cells. Examples from Drosophila segmentation. EMBO Rep 2, 1083-1088.

Saraswati, S., Alfaro, M.P., Thorne, C.A., Atkinson, J., Lee, E. \& Young, P.P. 2010. Pyrvinium, a potent small molecule Wnt inhibitor, promotes wound repair and post-MI cardiac remodeling. PLOS ONE 5, e15521.

Satow, R., Shitashige, M., Jigami, T., Honda, K., Ono, M., Hirohashi, S. \& Yamada, T. 2010. Traf2- and Nck-interacting kinase is essential for canonical Wnt signaling in Xenopus axis formation. J Biol Chem 285, 26289-26294.

Sauka-Spengler, T. \& Bronner-Fraser, M. 2006. Development and evolution of the migratory neural crest: a gene regulatory perspective. Curr Opin Genet Dev 16, 360-366.

Schinner, S., Ulgen, F., Papewalis, C., Schott, M., Woelk, A., Vidal-Puig, A. \& Scherbaum, W.A. 2008. Regulation of insulin secretion, glucokinase gene transcription and beta cell proliferation by adipocyte-derived Wnt signalling molecules. Diabetologia 51, 147-154.

Schinner, S., Willenberg, H.S., Schott, M. \& Scherbaum, W.A. 2009. Pathophysiological aspects of Wnt-signaling in endocrine disease. Eur J Endocrinol 160, 731-737.
Schneider, V.A. \& Mercola, M. 2001. Wnt antagonism initiates cardiogenesis in Xenopus laevis. Genes Dev 15, 304-315.

Schweizer, L., Nellen, D. \& Basler, K. 2003. Requirement for Pangolin/dTCF in Drosophila Wingless signaling. Proc Natl Acad Sci USA 100, 5846-5851.

Shafer, S.L. \& Towler, D.A. 2009. Transcriptional regulation of SM22alpha by Wnt3a: convergence with TGFbeta(1)/ Smad signaling at a novel regulatory element. J Mol Cell Cardiol 46, 621-635.

Shaulian, E. \& Karin, M. 2002. AP-1 as a regulator of cell life and death. Nat Cell Biol 4, E131-E136.

Shetty, P., Lo, M.C., Robertson, S.M. \& Lin, R. 2005. C. elegans TCF protein, POP-1, converts from repressor to activator as a result of Wnt-induced lowering of nuclear levels. Dev Biol 285, 584-592.

Shiina, H., Igawa, M., Breault, J., Ribeiro-Filho, L., Pookot, D., Urakami, S., Terashima, M., Deguchi, M., Yamanaka, M., Shirai, M., Kaneuchi, M., Kane, C.J. \& Dahiya, R. 2003. The human T-cell factor-4 gene splicing isoforms, Wnt signal pathway, and apoptosis in renal cell carcinoma. Clin Cancer Res 9, 2121-2132.

Shimizu, T., Bae, Y.K., Muraoka, O. \& Hibi, M. 2005. Interaction of Wnt and caudal-related genes in zebrafish posterior body formation. Dev Biol 279, 125-141.

Shitashige, M., Satow, R., Honda, K., Ono, M., Hirohashi, S. \& Yamada, T. 2008. Regulation of Wnt signaling by the nuclear pore complex. Gastroenterology 134, 1961-1971.

Shitashige, M., Satow, R., Jigami, T., Aoki, K., Honda, K., Shibata, T., Ono, M., Hirohashi, S. \& Yamada, T. 2010. Traf2- and Nck-interacting kinase is essential for Wnt signaling and colorectal cancer growth. Cancer Res 70, 50245033.

Shu, L., Sauter, N.S., Schulthess, F.T., Matveyenko, A.V., Oberholzer, J. \& Maedler, K. 2008. Transcription factor 7-like 2 regulates beta-cell survival and function in human pancreatic islets. Diabetes 57, 645-653.

Siegfried, E., Wilder, E.L. \& Perrimon, N. 1994. Components of wingless signalling in Drosophila. Nature 367, 76-80.

Sierra, J., Yoshida, T., Joazeiro, C.A. \& Jones, K.A. 2006. The APC tumor suppressor counteracts beta-catenin activation and H3K4 methylation at Wnt target genes. Genes Dev 20, 586-600.

Sinenko, S.A., Mandal, L., Martinez-Agosto, J.A. \& Banerjee, U. 2009. Dual role of wingless signaling in stem-like hematopoietic precursor maintenance in Drosophila. Dev Cell 16, 756-763.

Sinner, D., Rankin, S., Lee, M. \& Zorn, A.M. 2004. Sox17 and beta-catenin cooperate to regulate the transcription of endodermal genes. Development 131, 3069-3080.

Sinner, D., Kordich, J.J., Spence, J.R., Opoka, R., Rankin, S., Lin, S.C., Jonatan, D., Zorn, A.M. \& Wells, J.M. 2007. Sox17 and Sox 4 differentially regulate beta-catenin/T-cell factor activity and proliferation of colon carcinoma cells. Mol Cell Biol 27, 7802-7815.

Smith, W.C. \& Harland, R.M. 1991. Injected Xwnt-8 RNA acts early in Xenopus embryos to promote formation of a vegetal dorsalizing center. Cell 67, 753-765.

Smith-Bolton, R.K., Worley, M.I., Kanda, H. \& Hariharan, I.K. 2009. Regenerative growth in Drosophila imaginal discs is regulated by Wingless and Myc. Dev Cell 16, 797-809. 
Snippert, H.J., Haegebarth, A., Kasper, M., Jaks, V., van Es, J.H., Barker, N., van de Wetering, M., van den Born, M., Begthel, H., Vries, R.G., Stange, D.E., Toftgard, R. \& Clevers, H. 2010. Lgr6 marks stem cells in the hair follicle that generate all cell lineages of the skin. Science 327, 1385 1389.

Sokol, S., Christian, J.L., Moon, R.T. \& Melton, D.A. 1991. Injected Wnt RNA induces a complete body axis in Xenopus embryos. Cell 67, 741-752.

Sosinsky, A., Bonin, C.P., Mann, R.S. \& Honig, B. 2003. Target Explorer: an automated tool for the identification of new target genes for a specified set of transcription factors. Nucleic Acids Res 31, 3589-3592.

Sotelo, J., Esposito, D., Duhagon, M.A., Banfield, K., Mehalko, J., Liao, H., Stephens, R.M., Harris, T.J., Munroe, D.J. \& Wu, X. 2010. Long-range enhancers on 8q24 regulate c-Myc. Proc Natl Acad Sci USA 107, 3001-3005.

Soucek, L. \& Evan, G.I. 2010. The ups and downs of Myc biology. Curr Opin Genet Dev 20, 91-95.

Standley, H.J., Destree, O., Kofron, M., Wylie, C. \& Heasman, J. 2006. Maternal XTcf1 and XTcf4 have distinct roles in regulating Wnt target genes. Dev Biol 289, 318-328.

Stepniak, E., Radice, G.L. \& Vasioukhin, V. 2009. Adhesive and signaling functions of cadherins and catenins in vertebrate development. Cold Spring Harb Perspect Biol 1, a002949.

Stern, C.D. 2005. Neural induction: old problem, new findings, yet more questions. Development 132, 2007-2021.

Stoick-Cooper, C.L., Weidinger, G., Riehle, K.J., Hubbert, C., Major, M.B., Fausto, N. \& Moon, R.T. 2007. Distinct Wnt signaling pathways have opposing roles in appendage regeneration. Development 134, 479-489.

Suda, Y., Kokura, K., Kimura, J., Kajikawa, E., Inoue, F. \& Aizawa, S. 2010. The same enhancer regulates the earliest Emx2 expression in caudal forebrain primordium, subsequent expression in dorsal telencephalon and later expression in the cortical ventricular zone. Development 137, 2939-2949.

Sun, J. \& Weis, W.I. 2011. Biochemical and structural characterization of beta-catenin interactions with nonphosphorylated and CK2-phosphorylated Lef-1. J Mol Biol 405, 519-530.

Takashima, S., Mkrtchyan, M., Younossi-Hartenstein, A., Merriam, J.R. \& Hartenstein, V. 2008. The behaviour of Drosophila adult hindgut stem cells is controlled by Wnt and Hh signalling. Nature 454, 651-655.

Tang, W., Dodge, M., Gundapaneni, D., Michnoff, C., Roth, M. \& Lum, L. 2008. A genome-wide RNAi screen for Wnt/ beta-catenin pathway components identifies unexpected roles for TCF transcription factors in cancer. Proc Natl Acad Sci USA 105, 9697-9702.

Tao, Q., Yokota, C., Puck, H., Kofron, M., Birsoy, B., Yan, D., Asashima, M., Wylie, C.C., Lin, X. \& Heasman, J. 2005. Maternal wnt11 activates the canonical wnt signaling pathway required for axis formation in Xenopus embryos. Cell 120, 857-871.

Theil, T., Aydin, S., Koch, S., Grotewold, L. \& Ruther, U. 2002. Wnt and Bmp signalling cooperatively regulate graded Emx2 expression in the dorsal telencephalon. Development 129, 3045-3054.
Theisen, H., Syed, A., Nguyen, B.T., Lukacsovich, T., Purcell, J., Srivastava, G.P., Iron, D., Gaudenz, K., Nie, Q., Wan, F.Y., Waterman, M.L. \& Marsh, J.L. 2007. Wingless directly represses DPP morphogen expression via an armadillo/TCF/Brinker complex. PLoS ONE 2, e142.

Thorpe, C.J., Schlesinger, A., Carter, J.C. \& Bowerman, B. 1997. Wnt signaling polarizes an early C. elegans blastomere to distinguish endoderm from mesoderm. Cell 90, 695-705.

Tian, Y., Yuan, L., Goss, A.M., Wang, T., Yang, J., Lepore, J.J., Zhou, D., Schwartz, R.J., Patel, V., Cohen, E.D. \& Morrisey, E.E. 2010. Characterization and in vivo pharmacological rescue of a Wnt2-Gata6 pathway required for cardiac inflow tract development. Dev Cell 18, 275-287.

Tomlinson, I., Webb, E., Carvajal-Carmona, L., Broderick, P., Kemp, Z., Spain, S., Penegar, S., Chandler, I., Gorman, M., Wood, W. et al. 2007. A genome-wide association scan of tag SNPs identifies a susceptibility variant for colorectal cancer at 8q24.21. Nat Genet 39, 984-988.

Toualbi, K., Guller, M.C., Mauriz, J.L., Labalette, C., Buendia, M.A., Mauviel, A. \& Bernuau, D. 2007. Physical and functional cooperation between AP-1 and beta-catenin for the regulation of TCF-dependent genes. Oncogene 26, 34923502.

Travis, A., Amsterdam, A., Belanger, C. \& Grosschedl, R. 1991. LEF-1, a gene encoding a lymphoid-specific protein with an HMG domain, regulates T-cell receptor alpha enhancer function [corrected]. Genes Dev 5, 880-894.

Tuupanen, S., Turunen, M., Lehtonen, R., Hallikas, O., Vanharanta, S., Kivioja, T., Bjorklund, M., Wei, G., Yan, J., Niittymaki, I. et al. 2009. The common colorectal cancer predisposition SNP rs6983267 at chromosome 8q24 confers potential to enhanced Wnt signaling. Nat Genet 41, 885890.

Tycko, B., Li, C.M. \& Buttyan, R. 2007. The Wnt/beta-catenin pathway in Wilms tumors and prostate cancers. Curr Mol Med 7, 479-489.

Ueno, S., Weidinger, G., Osugi, T., Kohn, A.D., Golob, J.L., Pabon, L., Reinecke, H., Moon, R.T. \& Murry, C.E. 2007. Biphasic role for Wnt/beta-catenin signaling in cardiac specification in zebrafish and embryonic stem cells. Proc Natl Acad Sci USA 104, 9685-9690.

Vadlamudi, U., Espinoza, H.M., Ganga, M., Martin, D.M., Liu, X., Engelhardt, J.F. \& Amendt, B.A. 2005. PITX2, betacatenin and LEF-1 interact to synergistically regulate the LEF-1 promoter. J Cell Sci 118, 1129-1137.

Vallin, J., Thuret, R., Giacomello, E., Faraldo, M.M., Thiery, J.P. \& Broders, F. 2001. Cloning and characterization of three Xenopus slug promoters reveal direct regulation by Lef/beta-catenin signaling. J Biol Chem 276, 30350-30358. Van der Flier, L.G., Sabates-Bellver, J., Oving, I., Haegebarth, A., De Palo, M., Anti, M., Van Gijn, M.E., Suijkerbuijk, S., Van de Wetering, M., Marra, G. \& Clevers, H. 2007. The intestinal Wnt/TCF signature. Gastroenterology 132, 628632.

Verzi, M.P., Hatzis, P., Sulahian, R., Philips, J., Schuijers, J., Shin, H., Freed, E., Lynch, J.P., Dang, D.T., Brown, M., Clevers, H., Liu, X.S. \& Shivdasani, R.A. 2010. TCF4 and CDX2, major transcription factors for intestinal function, 
converge on the same cis-regulatory regions. Proc Natl Acad Sci USA 107, 15157-15162.

Visel, A., Blow, M.J., Li, Z., Zhang, T., Akiyama, J.A., Holt, A., Plajzer-Frick, I., Shoukry, M., Wright, C., Chen, F., Afzal, V., Ren, B., Rubin, E.M. \& Pennacchio, L.A. 2009. ChIP-seq accurately predicts tissue-specific activity of enhancers. Nature 457, 854-858.

Vlad, A., Rohrs, S., Klein-Hitpass, L. \& Muller, O. 2008. The first five years of the Wnt targetome. Cell Signal 20, 795802.

Vonica, A. \& Gumbiner, B.M. 2007. The Xenopus Nieuwkoop center and Spemann-Mangold organizer share molecular components and a requirement for maternal Wnt activity. Dev Biol 312, 90-102.

Waltzer, L. \& Bienz, M. 1998. Drosophila CBP represses the transcription factor TCF to antagonize Wingless signalling. Nature 395, 521-525.

Wang, S. \& Jones, K.A. 2006. CK2 controls the recruitment of Wnt regulators to target genes in vivo. Curr Biol 16, 22392244.

Waterman, M.L. \& Jones, K.A. 1990. Purification of TCF-1 alpha, a T-cell-specific transcription factor that activates the $\mathrm{T}$-cell receptor $\mathrm{C}$ alpha gene enhancer in a context-dependent manner. New Biol 2, 621-636.

Waterman, M.L., Fischer, W.H. \& Jones, K.A. 1991. A thymus-specific member of the HMG protein family regulates the human $\mathrm{T}$ cell receptor $\mathrm{C}$ alpha enhancer. Genes Dev 5 , 656-669.

Weise, A., Bruser, K., Elfert, S., Wallmen, B., Wittel, Y., Wohrle, S. \& Hecht, A. 2010. Alternative splicing of Tcf712 transcripts generates protein variants with differential promoter-binding and transcriptional activation properties at Wnt/beta-catenin targets. Nucleic Acids Res 38, 1964-1981.

Wend, P., Holland, J.D., Ziebold, U. \& Birchmeier, W. 2010. Wnt signaling in stem and cancer stem cells. Semin Cell Dev Biol 21, 855-863.

van de Wetering, M., Oosterwegel, M., Dooijes, D. \& Clevers, H. 1991. Identification and cloning of TCF-1, a T lymphocyte-specific transcription factor containing a sequence-specific HMG box. EMBO J 10, 123-132.

van de Wetering, M., Cavallo, R., Dooijes, D., van Beest, M., van Es, J., Loureiro, J., Ypma, A., Hursh, D., Jones, T., Bejsovec, A., Peifer, M., Mortin, M. \& Clevers, H. 1997. Armadillo coactivates transcription driven by the product of the Drosophila segment polarity gene dTCF. Cell 88, 789799.

van de Wetering, M., Sancho, E., Verweij, C., de Lau, W., Oving, I., Hurlstone, A., van der Horn, K., Batlle, E., Coudreuse, D., Haramis, A.P. et al. 2002. The beta-catenin/ TCF-4 complex imposes a crypt progenitor phenotype on colorectal cancer cells. Cell 111, 241-250.

White, J.A. \& Heasman, J. 2008. Maternal control of pattern formation in Xenopus laevis. J Exp Zool B Mol Dev Evol 310, 73-84.

Willert, K. \& Jones, K.A. 2006. Wnt signaling: is the party in the nucleus? Genes Dev 20, 1394-1404.

Wills, A.A., Kidd, A.R. III, Lepilina, A. \& Poss, K.D. 2008. Fgfs control homeostatic regeneration in adult zebrafish fins. Development 135, 3063-3070.
Windsor, P.J. \& Leys, S.P. 2010. Wnt signaling and induction in the sponge aquiferous system: evidence for an ancient origin of the organizer. Evol Dev 12, 484-493.

Wohrle, S., Wallmen, B. \& Hecht, A. 2007. Differential control of Wnt target genes involves epigenetic mechanisms and selective promoter occupancy by T-cell factors. Mol Cell Biol 27, 8164-8177.

Wright, J.B., Brown, S.J. \& Cole, M.D. 2010. Upregulation of c-MYC in cis through a large chromatin loop linked to a cancer risk-associated single-nucleotide polymorphism in colorectal cancer cells. Mol Cell Biol 30, 1411-1420.

Wu, X., Golden, K. \& Bodmer, R. 1995. Heart development in Drosophila requires the segment polarity gene wingless. Dev Biol 169, 619-628.

Yamada, M., Ohnishi, J., Ohkawara, B., Iemura, S., Satoh, K., Hyodo-Miura, J., Kawachi, K., Natsume, T. \& Shibuya, H. 2006. NARF, an nemo-like kinase (NLK)-associated ring finger protein regulates the ubiquitylation and degradation of T cell factor/lymphoid enhancer factor (TCF/LEF). J Biol Chem 281, 20749-20760.

Yamaguchi, T.P., Takada, S., Yoshikawa, Y., Wu, N. \& McMahon, A.P. 1999. T (Brachyury) is a direct target of Wnt3a during paraxial mesoderm specification. Genes Dev 13, 3185-3190.

Yamamoto, S., Hikasa, H., Ono, H. \& Taira, M. 2003 a. Molecular link in the sequential induction of the Spemann organizer: direct activation of the cerberus gene by Xlim-1, Xotx2, Mix.1, and Siamois immediately downstream from Nodal and Wnt signaling. Dev Biol 257, 190-204.

Yamamoto, H., Ihara, M., Matsuura, Y. \& Kikuchi, A. 2003b. Sumoylation is involved in beta-catenin-dependent activation of Tcf-4. EMBO J 22, 2047-2059.

Yang, X., van Beest, M., Clevers, H., Jones, T., Hursh, D.A. \& Mortin, M.A. 2000. Decapentaplegic is a direct target of dTcf repression in the Drosophila visceral mesoderm. Development 127, 3695-3702.

Yasumoto, K., Takeda, K., Saito, H., Watanabe, K., Takahashi, K. \& Shibahara, S. 2002. Microphthalmia-associated transcription factor interacts with LEF-1, a mediator of Wnt signaling. EMBO J 21, 2703-2714.

Yochum, G.S., Cleland, R. \& Goodman, R.H. 2008. A genome-wide screen for beta-catenin binding sites identifies a downstream enhancer element that controls c-Myc gene expression. Mol Cell Biol 28, 7368-7379.

Yochum, G.S., Sherrick, C.M., Macpartlin, M. \& Goodman, R.H. 2010. A beta-catenin/TCF-coordinated chromatin loop at MYC integrates $5^{\prime}$ and $3^{\prime}$ Wnt responsive enhancers. Proc Natl Acad Sci USA 107, 145-150.

Yokoyama, H., Ogino, H., Stoick-Cooper, C.L., Grainger, R.M. \& Moon, R.T. 2007. Wnt/beta-catenin signaling has an essential role in the initiation of limb regeneration. Dev Biol 306, 170-178.

Yokoyama, N.N., Pate, K.T., Sprowl, S. \& Waterman, M.L. 2010. A role for YY1 in repression of dominant negative LEF-1 expression in colon cancer. Nucleic Acids Res 38, 6375-6388.

Young, T., Rowland, J.E., van de Ven, C., Bialecka, M., Novoa, A., Carapuco, M., van Nes, J., de Graaff, W., Duluc, I., Freund, J.N., Beck, F., Mallo, M. \& Deschamps, J. 2009. 
$\mathrm{Cdx}$ and Hox genes differentially regulate posterior axial growth in mammalian embryos. Dev Cell 17, 516-526.

Zamora, M., Manner, J. \& Ruiz-Lozano, P. 2007. Epicardiumderived progenitor cells require beta-catenin for coronary artery formation. Proc Natl Acad Sci USA 104, 18109-18114.

Zanke, B.W., Greenwood, C.M., Rangrej, J., Kustra, R., Tenesa, A., Farrington, S.M., Prendergast, J., Olschwang, S., Chiang, T., Crowdy, E. et al. 2007. Genome-wide association scan identifies a colorectal cancer susceptibility locus on chromosome 8q24. Nat Genet 39, 989-994.
Zardawi, S.J., O’Toole, S.A., Sutherland, R.L. \& Musgrove, E.A. 2009. Dysregulation of Hedgehog, Wnt and Notch signalling pathways in breast cancer. Histol Histopathol 24, 385-398.

Zecca, M., Basler, K. \& Struhl, G. 1996. Direct and longrange action of a wingless morphogen gradient. Cell 87, 833-844.

Zeng, Y.A. \& Verheyen, E.M. 2004. Nemo is an inducible antagonist of Wingless signaling during Drosophila wing development. Development 131, 2911-2920. 